\title{
Use of Dual Frequency Identification Sonar to Determine Adult Chinook Salmon (Oncorhynchus tshawytscha) Escapement in the Secesh River, Idaho
}

\author{
Annual Report
}

January 2008 - December 2008

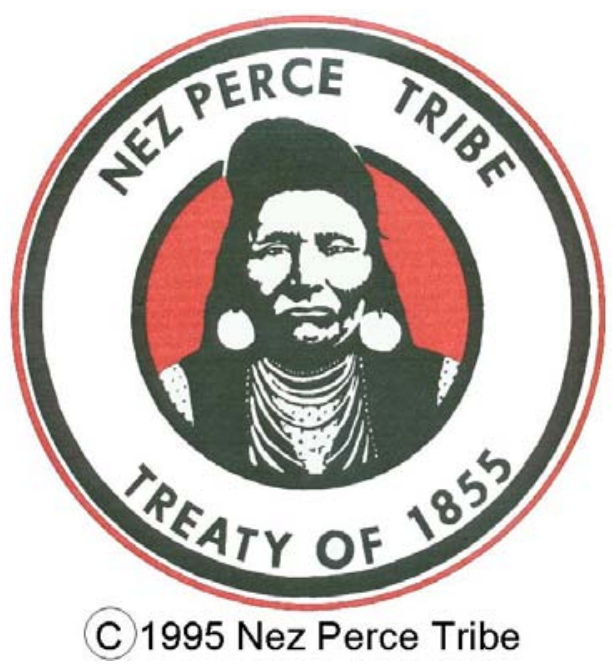

Prepared by:

Paul A. Kucera

Nez Perce Tribe

Department of Fisheries Resources Management

Lapwai, ID 83540

Prepared for:

U.S. Department of Energy

Bonneville Power Administration

Environment, Fish and Wildlife

P.O. Box 3621

Portland, OR 97208-3621

Project Number 199703000

Contract Number 00035429

June 2009 
Use of Dual Frequency Identification Sonar to Determine Adult Chinook Salmon (Oncorhynchus tshawytscha)

Escapement in the Secesh River, Idaho

\author{
Annual Report \\ January 2008 - December 2008 \\ Prepared by: \\ Paul A. Kucera \\ Nez Perce Tribe \\ Department of Fisheries Resources Management \\ Lapwai, ID 83540 \\ Prepared for: \\ U.S. Department of Energy \\ Bonneville Power Administration \\ Environment, Fish and Wildlife \\ P.O. Box 3621 \\ Portland, OR 97208-3621
}

Project Number 199703000

Contract Number 00035429

June 2009 


\begin{abstract}
Chinook salmon in the Snake River basin were listed as threatened under the Endangered Species Act in 1992 (NMFS 1992). The Secesh River represents the only stream in the Snake River basin where natural origin (wild) salmon escapement monitoring occurs at the population level, absent a supplementation program. As such the Secesh River has been identified as a long term salmon escapement and productivity monitoring site by the Nez Perce Tribe Department of Fisheries Resources Management. Salmon managers will use this data for effective population management and evaluation of the effect of conservation actions on a natural origin salmon population. The Secesh River also acts as a reference stream for supplementation program comparison.
\end{abstract}

Dual frequency identification sonar (DIDSON) was used to determine adult spring and summer Chinook salmon escapement in the Secesh River in 2008. DIDSON technology was selected because it provided a non-invasive method for escapement monitoring that avoided listed species trapping and handling incidental mortality, and fish impedance related concerns.

The DIDSON monitoring site was operated continuously from June 13 to September 14 . The first salmon passage was observed on July 3. DIDSON site total estimated salmon escapement, natural and hatchery fish, was 888 fish \pm 65 fish (95\% confidence interval). Coefficient of variation associated with the escapement estimate was 3.7\%. The DIDSON unit was operational $98.1 \%$ of the salmon migration period.

Adult salmon migration timing in the Secesh River occurred over 74 days from July 3 to September 14, with 5,262 total fish passages observed. The spawning migration had 10\%, median, and $90 \%$ passage dates of July 8 , July 16, and August 12 , respectively. The maximum number of net upstream migrating salmon was above the DIDSON monitoring site on August 27.

Validation monitoring of DIDSON target counts with underwater optical cameras occurred for species identification. A total of 860 optical camera identified salmon passage observations were identical to DIDSON target counts. However, optical cameras identified eight jack salmon (3 upstream, 5 downstream) less than $55 \mathrm{~cm}$ in length that DIDSON did not count as salmon because of the length criteria employed $(\geq 55 \mathrm{~cm})$.

Precision of the DIDSON technology was evaluated by comparing estimated net upstream salmon escapement and associated 95\% confidence intervals between two DIDSON sonar units operated over a five day period. The DIDSON 1 salmon escapement was 145.7 fish $( \pm 2.3)$, and the DIDSON 2 escapement estimate was 150.5 fish $( \pm 5)$. The overlap in the $95 \%$ confidence intervals suggested that the two escapement estimates were not significantly different from each other.

Known length salmon carcass trials were conducted in 2008 to examine the accuracy of manually measured lengths, obtained using DIDSON software, on high frequency files at a $5 \mathrm{~m}$ window length. Linear regression demonstrated a highly significant relationship between known 
lengths and manually measured salmon carcass lengths $(\mathrm{p}<0.0001)$. A negative bias in manual length measurement existed among the two observers in the analysis.

Total Secesh River salmon escapement (natural origin and hatchery) in 2008 was 912 fish. Natural origin salmon escapement in the entire Secesh River drainage was 847 fish. The estimated natural origin spawner abundance was 836 fish. Salmon spawner abundance in 2008 increased by three fold compared to 2007 abundance levels. The 10 year geometric mean natural origin spawner abundance was 538 salmon and was below the recommended viable population threshold level established by the ICTRT (2007).

One additional Snake River basin salmon population was assessed for comparison of natural origin salmon spawner abundance. The Johnson Creek/EFSF Salmon River population had a 10 year geometric mean natural origin spawner abundance of 254 salmon. Salmon spawner abundance levels in both streams were below viable population thresholds.

DIDSON technology has been used in the Secesh River to determine salmon escapement over the past five years. The results suggest that DIDSON technology is reliable and can be used to generate accurate and precise estimates of salmon escapement if appropriate methods are used. 


\section{TABLE OF CONTENTS}

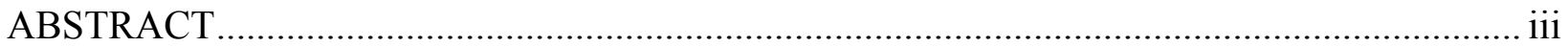

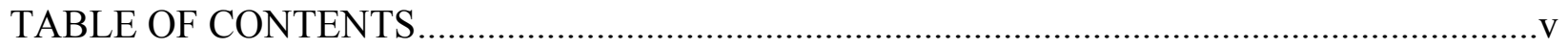

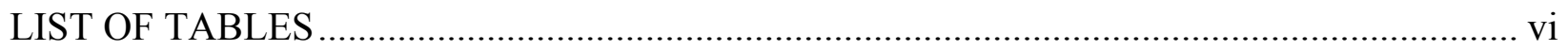

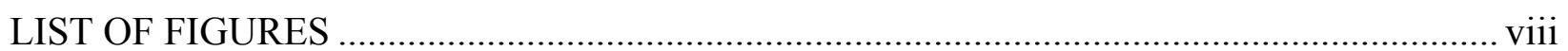

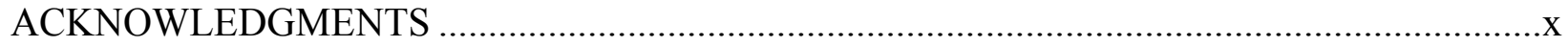

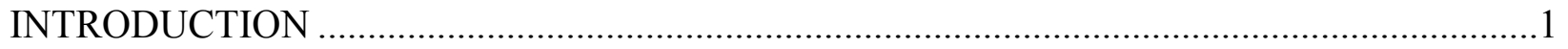

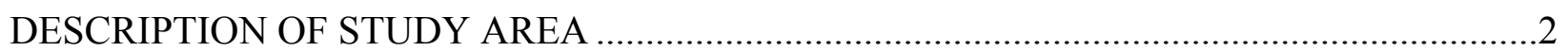

METHODS (...

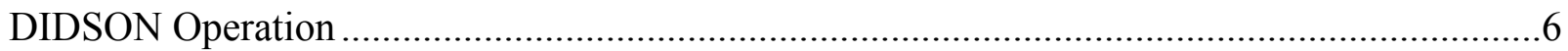

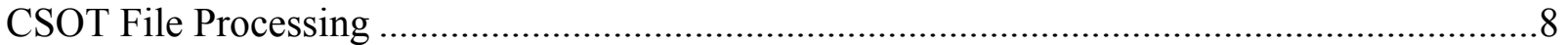

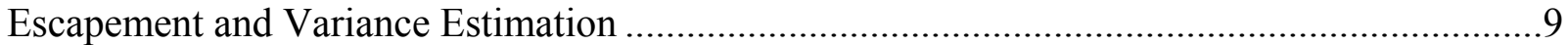

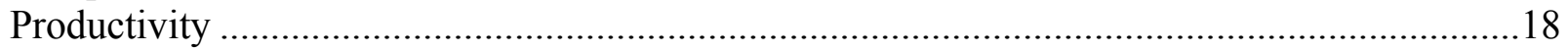

Seasonal Migration and Diel Movement Patterns ………....................................................19

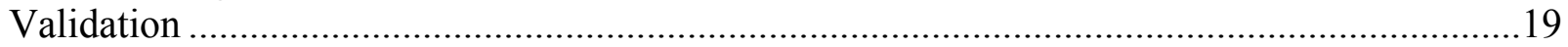

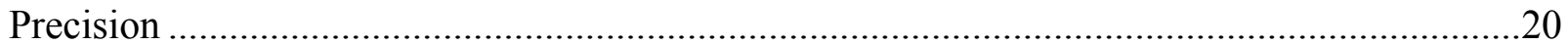

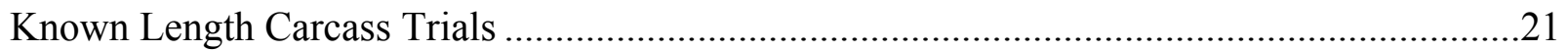

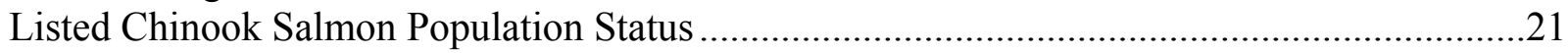

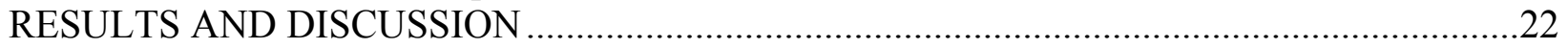

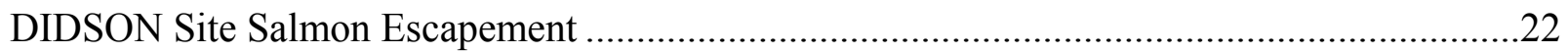

Potential Sources of Error in DIDSON Escapement Estimates ...........................................26

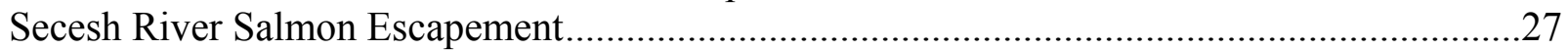

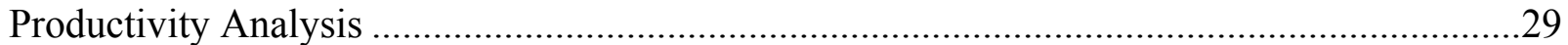

Migration Timing and Diel Movement Patterns ..................................................................29

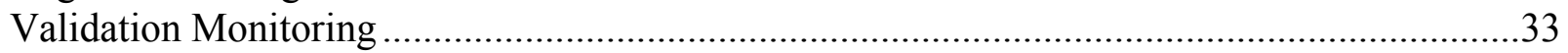

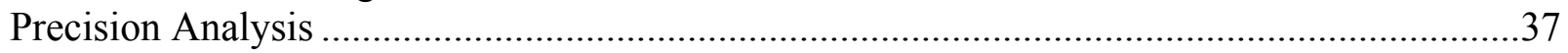

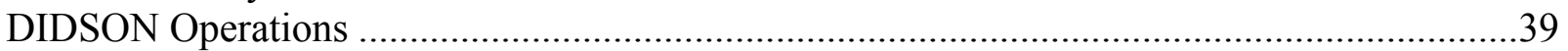

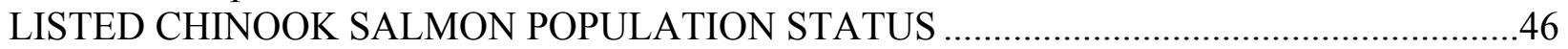

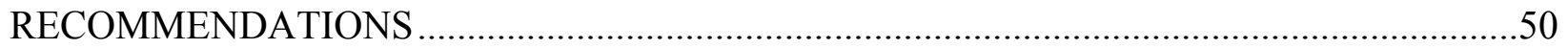

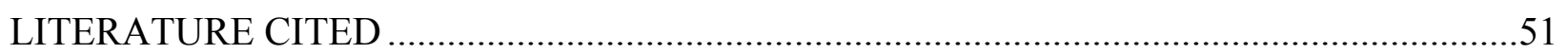

APPENDIX 


\section{LIST OF TABLES}

Table 1. Chinook salmon, rainbow trout, and other fish species sensitivity to sound (after Gregory et al. 2001).

Table 2. Secesh River adult salmon escapement estimate at the DIDSON monitoring site ( $\pm 95 \%$ confidence intervals), coefficient of variation, adjustments to the estimated escapement due to equipment down time and DIDSON file reader and CSOT processing error, estimated number of salmon remaining upstream of the monitoring site at the end of the migration season, and percent of total Secesh River redds located upstream of the monitoring site from 2004 to 2008.

Table 3. Potential sources of error in DIDSON salmon escapement estimation in the

Secesh River in 2008.

Table 4. Validation zone comparison, by direction of fish passage, between DIDSON target counts and optical camera identified salmon passages from 12 stratified random sample days in the Secesh River in 2008.

Table 5. DIDSON salmon escapement estimate compared to the relative number of bull trout and bull trout $\geq 55 \mathrm{~cm}$ in length observed at the Lake Creek underwater video count station from 2004 to 2008 .

Table 6. Comparison of total viewer salmon passage observations, estimated net upstream salmon passages ( $\pm 95 \%$ confidence interval), and actual net upstream salmon passages used in DIDSON precision analysis in 2005, 2006, 2007, and 2008

Table 7. DIDSON transect location, frame rate data was recorded at, percent of time unit was operational, whether validation and precision occurred, and sonar unit used in the Secesh River 2004 to 2008.

Table 8. Total estimated adult salmon escapement (wild and hatchery), natural origin escapement, natural origin spawner abundance, and average hatchery fraction in the Secesh River from 1998 to 2008

Appendix Table 1. Two sample $\mathrm{Z}$ test comparing within observer file reader error of fish original DIDSON 1 file manual counts, and comparison of original DIDSON file to fish motion-only file counts on subsampled days, by direction of fish movement, of adult salmon in the Secesh River in 2008. Ho: P1 = P2, Ha: P1 $\neq$ $\mathrm{P} 2$. Significant difference at $\mathrm{p}<0.05$ level highlighted in bold. Period 1 (early season) was from July 3 to July 22, and period 2 (late season) was from July 23 to September 14.

Appendix Table 2. Two sample $\mathrm{Z}$ test comparing within observer file reader error of CSOT processed files by direction of movement and migration period in the Secesh River in 2008. Ho: $\mathrm{P} 1=\mathrm{P} 2, \mathrm{Ha}: \mathrm{P} 1 \neq \mathrm{P} 2$. Significant difference at $\mathrm{p}<$ 0.05 level highlighted in bold. Migration period 1 (early season) was fom July 3 to July 22, and period 2 (late season) was from July 23 to September 14. 
Appendix Table 3. Estimated observer error of missed salmon passages by direction for the entire season of original DIDSON files and CSOT processed files in the Secesh River in 2008. The number of observed passages and the number of passages possible are also shown. Two sample $Z$ test compares error by direction

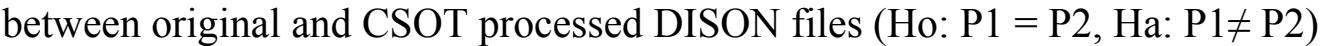

Appendix Table 4. Equipment downtime at the DIDSON monitoring site in 2008.

Appendix Table 5. Percent of the salmon migration observed at the Secesh River DIDSON monitoring site, by date, from 2004 to 2008 (adjusted data).

Appendix Table 6. Extensive area Chinook salmon redd count data from the Secesh River and tributaries from 1998 to 2008.

Appendix Table 7. Dates of observed total and net upstream migration, net adjustments due to reader and motion detection error, net adjustments due to downtime, adjusted daily net upstream passages, and adjusted cumulative net upstream passages of adult spring and summer Chinook salmon at the DIDSON monitoring site in the Secesh River in 2008. 


\section{LIST OF FIGURES}

Figure 1. Location of the DIDSON monitoring site in the Secesh River. 3

Figure 2. Control panel display of a high frequency DIDSON image of a $103.5 \mathrm{~cm}$ adult chinook salmon in the Secesh River. 5

Figure 3. Photograph of the engineered DIDSON salmon escapement monitoring site in the Secesh River during high water (upper photo) and low summer stream flow conditions (lower photo).

Figure 4. Topside box with laptop computer that collects DIDSON files on an external hard drive, and quadplexes optical camera data with the DIDSON signal on a VHS tape for validation studies.

Figure 5. Multiplexed DIDSON image (upper photo) and validation video recording (lower photo) of a $91.8 \mathrm{~cm}$ adult Chinook salmon collected during validation studies in the Secesh River

Figure 6. Multiplexed DIDSON image (upper photo) and validation video recording (lower photo) of a $52.7 \mathrm{~cm}$ bull trout collected during validation studies in the Secesh River.

Figure 7. Multiplexed DIDSON image (upper photo) and validation video recording (lower photo) of a $42 \mathrm{~cm}$ rainbow trout collected during validation studies in the Secesh River.

Figure 8. Distribution of the 15 days reviewed for assessment of motion error and reader specific error compared to total salmon passages in the Secesh River in 2008. August 15, the peak observed salmon passage date, was reviewed for error determination

Figure 9. Cross-section view of the validation zone indicating where optical cameras were used as the independent method to validate DIDSON target counts in the Secesh River in 2008.

Figure 10. Estimated wild and hatchery adult salmon escapement ( $\pm 95 \%$ confidence intervals) at the DIDSON monitoring site in the Secesh River from 2004 to 2008.

Figure 11. Comparison of DIDSON adult salmon escapement estimates adjusted for observor error ( $\pm 95 \%$ confidence intervals) and unadjusted for observor error, in the Secesh River from 2004 to 2008.

Figure 12. Population scale salmon escapement in the Secesh River (natural origin and hatchery) from 1998 to 2008 ...... 28

Figure 13. Linear regression between natural origin salmon escapement and spawner abundance in the Secesh River from 2004 to 2008.

Figure 14. Staff gage versus net upstream salmon migration in the Secesh River in 2008 (unadjusted data).

Figure 15. Average, minimum, and maximum daily water temperature versus cumulative net upstream salmon migration in the Secesh River in 2008 (unadjusted data).

Figure 16. Net upstream and total passages of adult salmon migrating past the DIDSON monitoring site in the Secesh River in 2008 (unadjusted data). 
Figure 17. Percent of total observed salmon passages by hour for the early season (July 3 to July 22) and late season (July 23 to September 14) salmon migration in the Secesh River in 2008

Figure 18. Daily net upstream salmon passages (all vertical bars) and underwater optical camera validation period for species identification (dark black vertical bars) at the DIDSON monitoring site in the Secesh River in 2008 .

Figure 19. Linear regression between known carcass length and measured carcass length of observer 1 (upper graph) and observer 2 (lower graph) of 21 salmon carcasses in the Secesh River in 2008

Figure 20. Estimated natural origin salmon spawner abundance (wild fish) in the Secesh River from 1998 to 2008 compared to quasi-extinction threshold, population viability (delisting) threshold (ICTRT 2005), and management goals

Figure 21. Estimated natural origin salmon spawner abundance and 10 year geometric mean spawner abundance in the Secesh River (upper graph) and Johnson Creek/EFSF Salmon River (lower graph) populations from 1998 to 2008. Spawner abundance is compared to ICTRT (2005) recommended viability and quasi-extinction thresholds

Appendix Figure 1. Linear regression between DIDSON determined salmon escapement and muntiple pass extensive area redd counts located upstream of the DIDSON site in the Secesh River from 2004 to 2008. Redd count data courtesy of Jerry Lockhart. 


\section{ACKNOWLEDGMENTS}

The Nez Perce Tribe provided the administrative framework for successful operation of this project. We acknowledge our cooperating agency, the Bonneville Power Administration, for

providing funding for this research project. We acknowledge the contribution of Bob Johnson of the Pacific Northwest National Laboratory (PNNL), whose idea it was to utilize DIDSON technology as an adult salmon escapement monitoring technique. We especially thank Nez Perce Tribe Department of Fisheries Resources Management project personnel Mike Busby, Dan Felt, and Robyn Armstrong for assistance in the field and sonar and validation video file reading. We acknowledge the Nez Perce Tribe Idaho Salmon Supplementation (BPA Project No. 198909802) study personnel Jerry Lockhart, Ryan Kinzer, Wes Kellar, Travis Covel, Neal Meshell, and Jade Helmich for providing salmon redd count and carcass data, and for assistance in the field. Chris Beasley, Jody White, and Rishi Sharma provided statistical consulting to standardize salmon escapement estimation methods and variance estimators. Jay Hesse and Jason Vogel provided useful comments on an earlier version of this report. We also thank Ed Belcher and Bill Hanot of Sound Metrics for assistance with DIDSON operations and computer software. 


\section{INTRODUCTION}

Determination of adult spawner abundance is a critical aspect of a viable population management strategy (Foose et al. 1995, Botkin et al. 2000) which is recognized within the scientific community, in listed species recovery planning (NMFS 2000, NMFS 2002, McElhaney et al. 2000), and for effective resource management. This project emphasizes collection of adult Chinook salmon (Oncorhynchus tshawytscha) escapement and productivity information for long term monitoring of the natural origin (wild) salmon population in the Secesh River. Spring and summer Chinook salmon in the Snake River basin were listed as threatened under the Endangered Species Act in 1992 (NMFS 1992). The Secesh River salmon population is recognized by the Nez Perce Tribe and Interior Columbia Basin Technical Recovery Team (ICTRT 2005) for recovery planning purposes. The Secesh River also represents a control stream under the Idaho Salmon Supplementation studies (Bowles and Leitzinger 1991), and a reference stream for the Johnson Creek and Northeast Oregon Hatchery supplementation programs (Vogel et al. 2005, Hesse et al. 2006).

Biological Opinion related documents (NMFS 2000, NOAA 2004, U.S. Army Corps of Engineers et al. 2004, 2005) acknowledge the need for assessment of biological performance of wild salmon and steelhead populations in tributary streams, and for measurement of recovery status of listed species. The Northwest Power and Conservation Council's Fish and Wildlife program (NPCC 2000, NPPC 2005) lists biological objectives which contains abundance as one of the primary biological performance measures. The Salmon Subbasin Management Plan (Ecovista 2004) specifically identifies the need for tributary specific wild stock abundance and productivity data for population level monitoring, and assessment of delisting criteria to achieve aquatic biological objectives of the plan. McElhaney et al. (2000) call for performance standards at the population level to be evaluated in terms of abundance, population growth rate, spatial distribution, and genetic diversity. The ICTRT (2005) recommended a minimum adult salmon spawner abundance (viability) threshold of 3,500 fish for the South Fork Salmon River major population group (MPG). This included designation of the Secesh River as an intermediate population size category, with a viability level of 750 fish. The ICTRT further recommended that MPG viability guidelines require that two of the populations in the South Fork Salmon River should exceed VSP guidelines. Population monitoring plays an important role by providing the information necessary to determine status at the population level. Currently, there is limited quantitative information available to directly measure salmon escapement and spawner abundance in Snake River basin streams with known acuracy and precision.

The research division of the Nez Perce Tribe Department of Fisheries Resources Management has been investigating new and innovative methods to determine adult salmon escapement (abundance) in Snake River basin streams. Underwater video has proven to be an effective method for quantifying adult salmon escapement in smaller headwater stream environments. However, underwater video and temporary weir structures have not proven effective in larger salmon producing streams (Faurot et al. 2000, Faurot and Kucera 2001a, and Faurot and Kucera $2001 \mathrm{~b}$ ). Dual frequency identification sonar (DIDSON) was identified as a potential technology for salmon escapement monitoring that does not require permanent structures and can operate during high spring flows and turbid stream conditions. DIDSON is a new method in fisheries 
science that has been used to document fish passage at hydroelectric projects (Moursund et al. 2002, Mueller et al. 2003), to determine adult salmon passage rates and escapement in remote stream environments (Maxwell and Gove 2004, Kucera and Faurot 2005), and to document deep water fall Chinook redds (Tiffan et al. 2004). However, DIDSON has not been thoroughly tested and validated in streams to estimate adult salmon escapement.

Testing of the DIDSON technology to enumerate salmon escapement in the Secesh River was initiated in 2003, in collaboration with the Pacific Northwest National Laboratory (Johnson et al. 2004) and the Applied Physics Laboratory from the University of Washington. The positive results from the initial tests led to full scale experimental testing of the DIDSON technology from 2004 to 2008 to attempt to determine adult salmon escapement in the Secesh River. This is the first project in the Snake River basin that has attempted to use DIDSON technology to enumerate adult salmon escapement in a stream. It is the only project in the Snake River basin that provides population level wild salmon escapement information from a non-supplemented control or reference stream.

The goal of this project is two fold in nature. First, the project is evaluating DIDSON technology as an adult salmon escapement monitoring tool. Second, the major project goal is to provide a long term wild salmon escapement and productivity data set (with known accuracy and precision) for examination of trends at the population level and for recovery metric monitoring. Project information is expected to determine salmon population staus and provide information for the assessment of performance measures (primary and derived) and standards. Fisheries managers will use the information from this project for population management and in recovery metric status monitoring. Information from this project, and other projects that collect actual escapement data, will provide the abundance data sets necessary to provide a scientifically sound basis for salmon conservation and allow evaluation of viability thresholds (NMFS 2000, NMFS 2002, ICTRT 2005).

\section{DESCRIPTION OF STUDY AREA}

The Secesh River is located in west central Idaho (Figure 1) and has a watershed that encompasses 688 square kilometers. The DIDSON monitoring site was located in the Secesh River at rkm 30 at the United States (U.S.) Forest Service Chinook Campground. Salmon escapement monitoring occurred at this site because it is located downstream of the vast majority of salmon spawning habitat in the Secesh River, and in upstream headwater tributaries

of Lake Creek and Summit Creek. Some salmon spawning does occur downstream of this site in marginal habitat in the mainstem Secesh River, and in Lick Creek. 


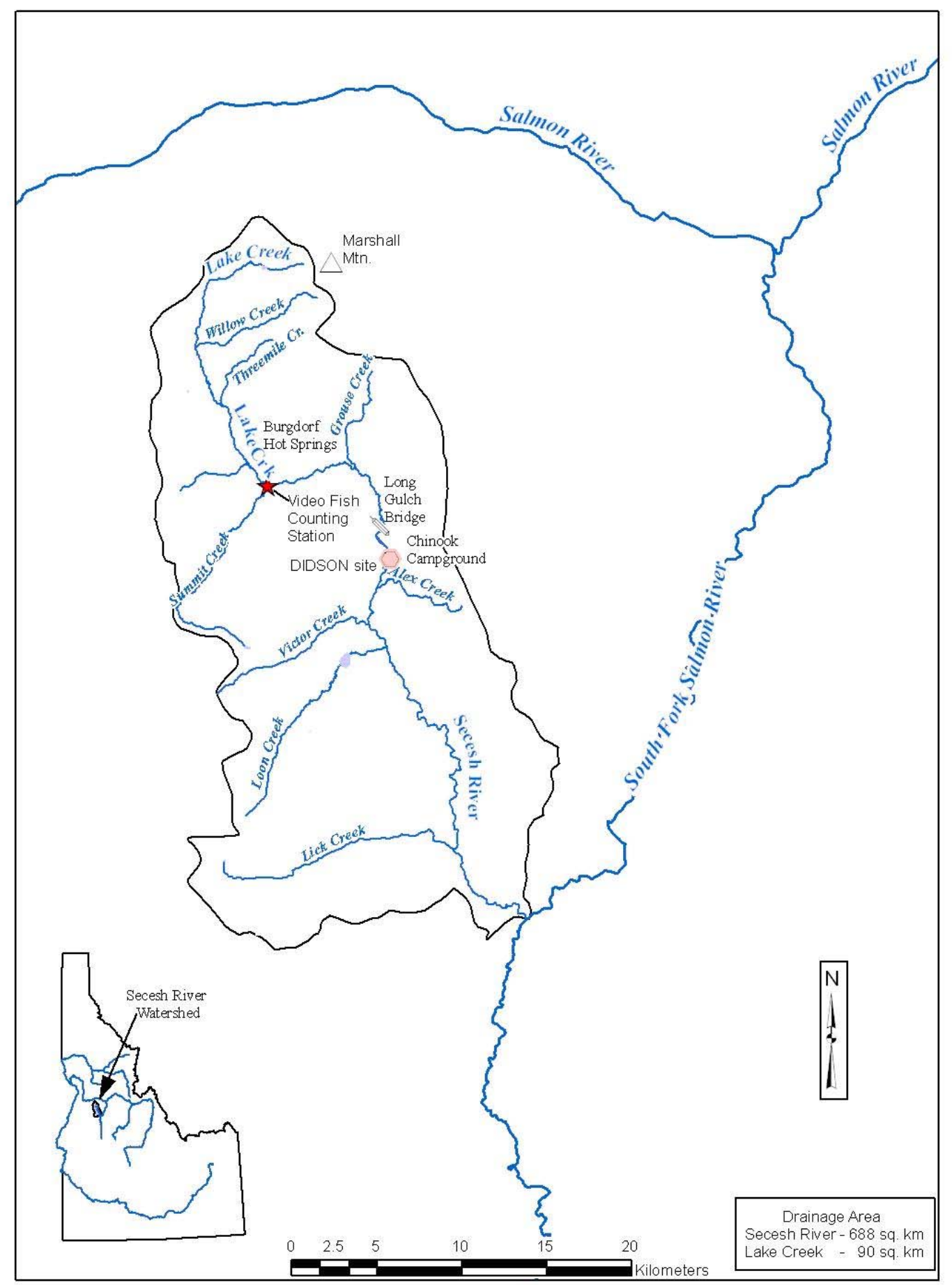

Figure 1. Location of the DIDSON monitoring site in the Secesh River. 


\section{METHODS}

DIDSON is a new class of identification sonar that allows near video quality images for identification of objects under water (Figure 2). The acoustic imaging camera operates at ultra high frequencies, at $1.8 \mathrm{MHz}$ and $1.1 \mathrm{MHz}$, and uses acoustic lens' which allow high quality images up to $60 \mathrm{~m}$. It was developed by the Applied Physics Laboratory at the University of Washington for the Space and Naval Warfare Systems Center harbor surveillance program (Belcher et al.2001). The literature was examined to determine the potential for salmon and steelhead avoidance to these frequencies. Gregory et al. (2001) summarized the relevant published literature on fish sensitivity to sound (Table 1.) Chinook salmon, rainbow trout $(O$. mykiss), and atlantic salmon (Salmon salar) have demonstrated avoidance behavior to sound at 10 Hertz (Hz) (Knudsen et al. 1997, Knudsen et al. 1994, Enger et al. 1992, Knudsen et al. 1992) which is at a very low frequency. Atlantic salmon have detected sound frequencies below 380 $\mathrm{Hz}$ (Hawkins and Johnstone 1978). Some of the Alosidae family, alewife (Alosa pseudoharengus), American shad (A. sapidissima), blueback herring (A. aestivalis), and twaite shad (A. fallax fallax), demonstrate avoidance responses up to $162,000 \mathrm{~Hz}$. The frequencies the DIDSON unit operates at $(1.8 \mathrm{MHz})$ is ultra high frequency sound and appears to be well above the audible range of Chinook salmon. By using up to 96 different sonar beams, high frequency sound waves are sent through water to register vibrations reflected from an object. DIDSON collects sufficient information to show the size, shape, and direction of movement (upstream or downstream) of an object. The observer views a two dimensional silhouette of a fish swimming (Figure 2), not a sonar blip that requires positive identification in the laboratory. The advantages of the acoustic imaging camera are: 1) it uses a higher frequency resulting in better target resolution, 2) provides a more understandable target image, 3 ) it has a larger signal beam of $12^{\circ} \times 29^{\circ}$, instead of $6^{\circ} \times 6^{\circ}$, that allows the target to be tracked over a greater distance, 4) it does not require extensive aiming and testing, 5) records at frame rates of 4 to 21 frames per second, 6) the ease of operation, 7) does not require permanent structures, 8) does not require NEPA and an EIS, 9) can be relocated easily, and 10) operates equally well in high turbid water conditions, low stream flow conditions, and at night. The cost of each acoustic camera $(\$ 75,000)$ appears relatively high, but when compared to other alternatives (Johnson et al. 2004) is not that expensive. 


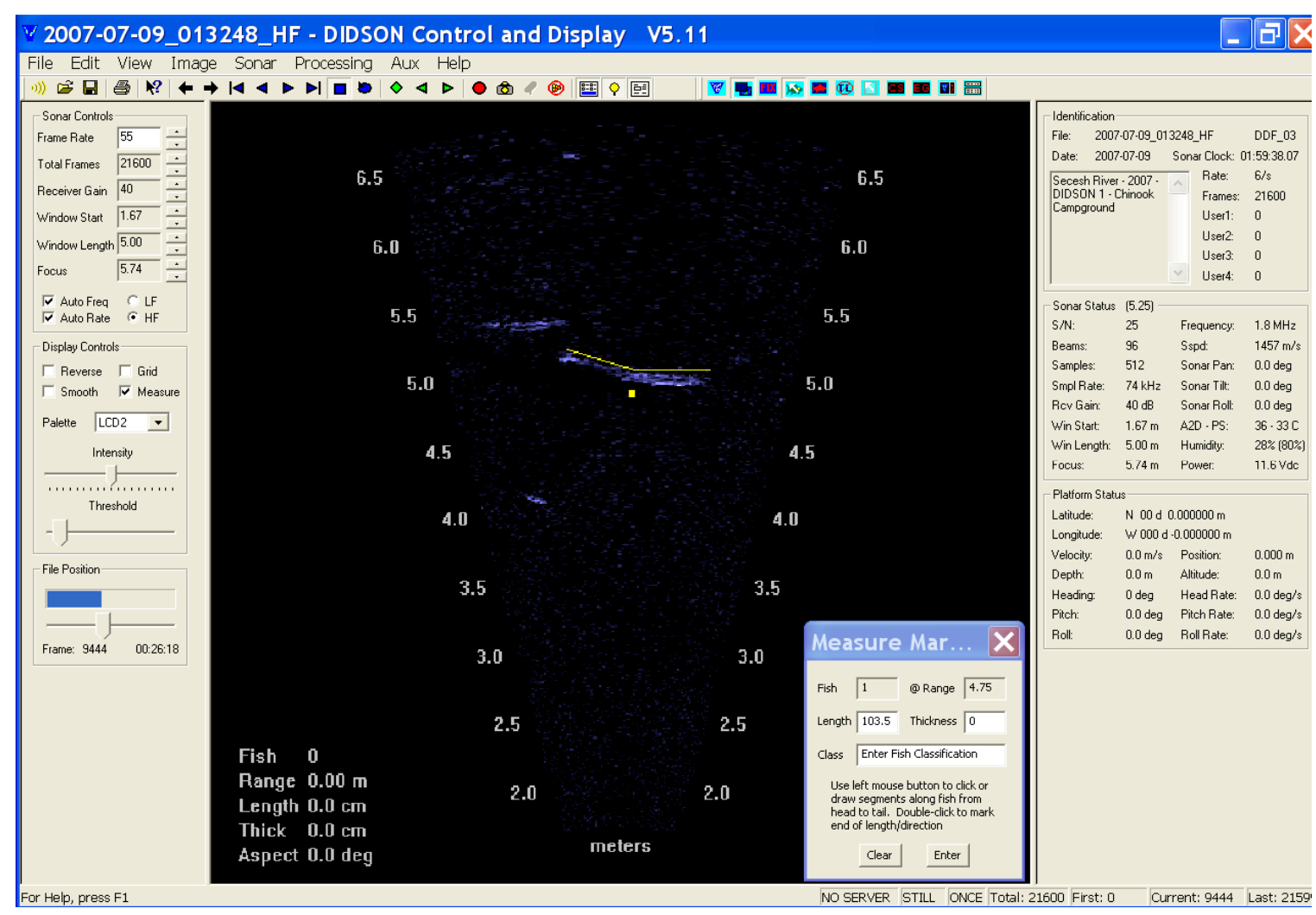

Figure 2. Control panel display of a high frequency DIDSON image of a $103.5 \mathrm{~cm}$ adult Chinook salmon in the Secesh River.

Table 1. Chinook salmon, rainbow trout, and other fish species sensitivity to sound (after Gregory et al. 2001).

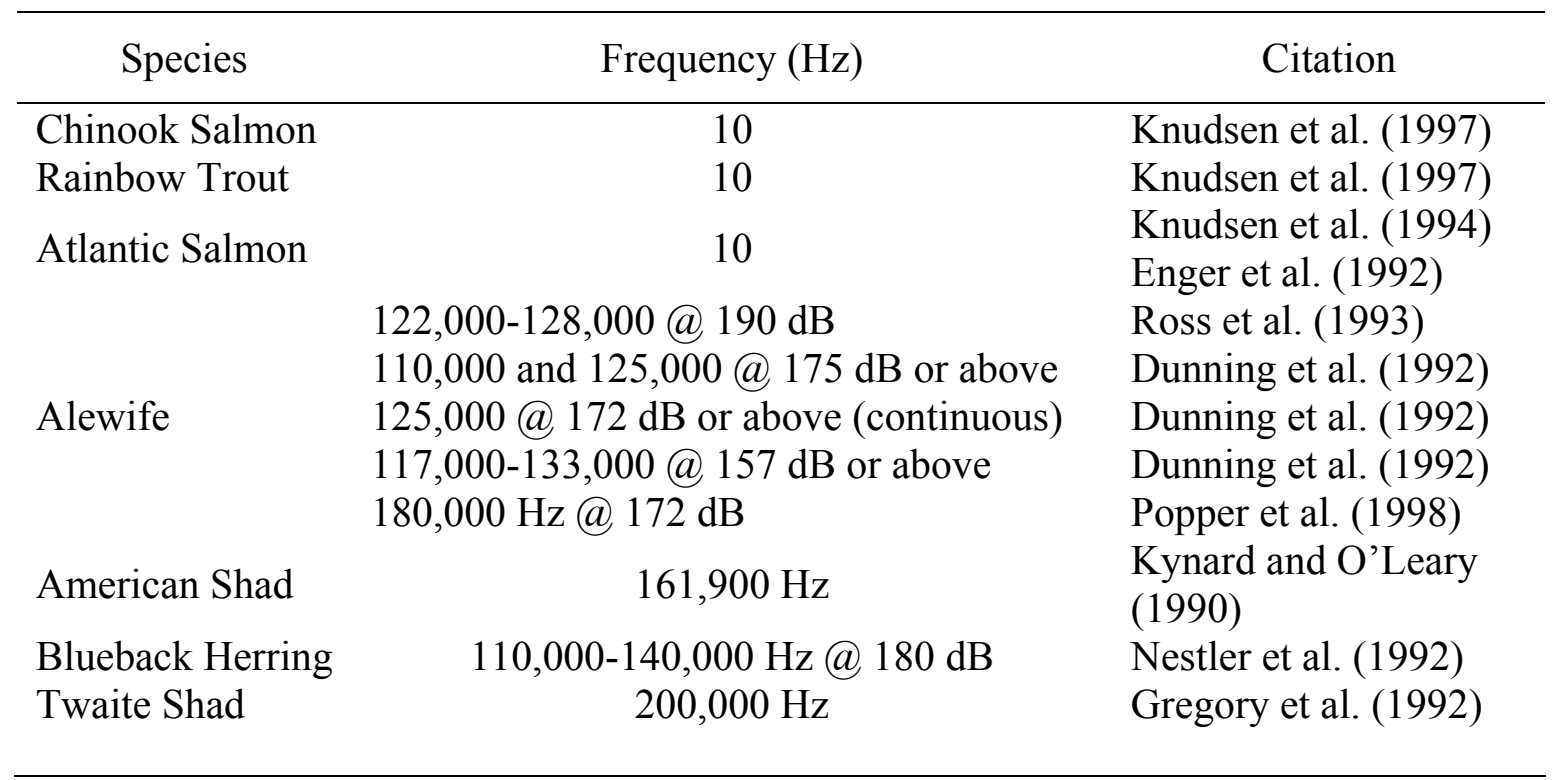




\section{DIDSON Operation}

Two DIDSON sonar units were installed and operated in the Secesh River in 2008. The purpose of the upstream DIDSON unit was to estimate adult salmon escapement similar to 2007 operations. The upstream DIDSON unit was installed and operated continuously from June 10 through September 19, except for periods of downtime. The second DIDSON unit was installed approximately $12 \mathrm{~m}$ downstream of the first DIDSON site on June 7 and operated continuously through September 19 when it was removed from the monitoring site. The purpose of the second DIDSON unit was to provide a measure of the precision of DIDSON technology. Operationally, stream width at the DIDSON site was approximately $26 \mathrm{~m}$ and maximum stream depth was 2.1 $\mathrm{m}$. Both units were operated identically and sampled the entire water column.

Through consultation with the Pacific Northwest National Laboratory, who have extensive hydroacoustic expertise, it was decided to install a crump style artificial substrate on the stream bottom and a bank standoff structure on the far bank (Figure 3). This was implemented to force adult salmon off of the stream bottom and away from undercut banks to ensure that clear sonar recordings of migrating adult salmon would be collected. Temporary fence structures were installed approximately one meter downstream of each sonar unit that extended from the near shore to 1-2 meters beyond the sonar units. The fence structure was installed to keep salmon within the ensonified water column, and to preclude upstream migrating fish from getting too close to the sonar unit and casting a sonar shadow.

As water levels dropped during the course of the summer it was necessary to periodically move the sonar units into deeper water and extend the temporary fence structures out into the stream channel. Anytime the DIDSON units were deployed or moved, a calibration target was placed instream from the DIDSON unit surface to the bottom and from the far shore surface to bottom to verify that the entire water column was ensonified. If the calibration target was not successfully acquired the DIDSON unit was re-aimed until it was.

The DIDSON unit and optical cameras were connected into a topside box which contained the DIDSON laptop computer, external hard drive, time lapse VCR, and multiplexer (Figure 4). High frequency DIDSON files were recorded at both DIDSON monitoring sites at six frames per second, 24 hours per day, and seven days per week. DIDSON file size was approximately 25 gigabytes of data per day per sonar unit. Collected DIDSON files from both sonar units were backed up daily to an additional external hard drive. The topside box, DIDSON unit, optical camera LED arrays, and optical cameras were powered by four sets of six volt batteries connected in series to provide 12 volts, and charged daily with a generator. 

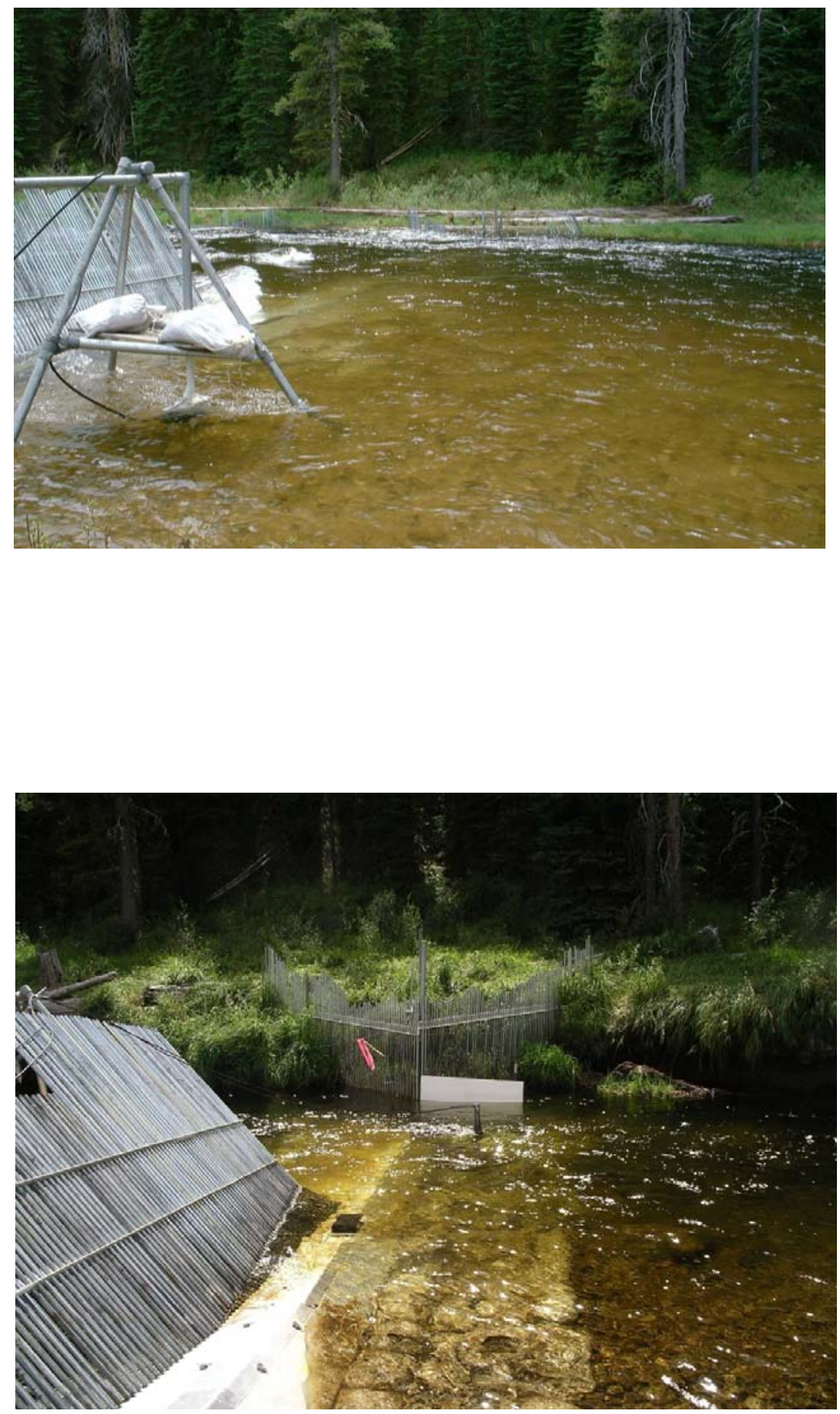

Figure 3. Photograph of the engineered DIDSON salmon escapement monitoring site in the Secesh River during high water (upper photo) and low summer stream flow conditions (lower photo). 


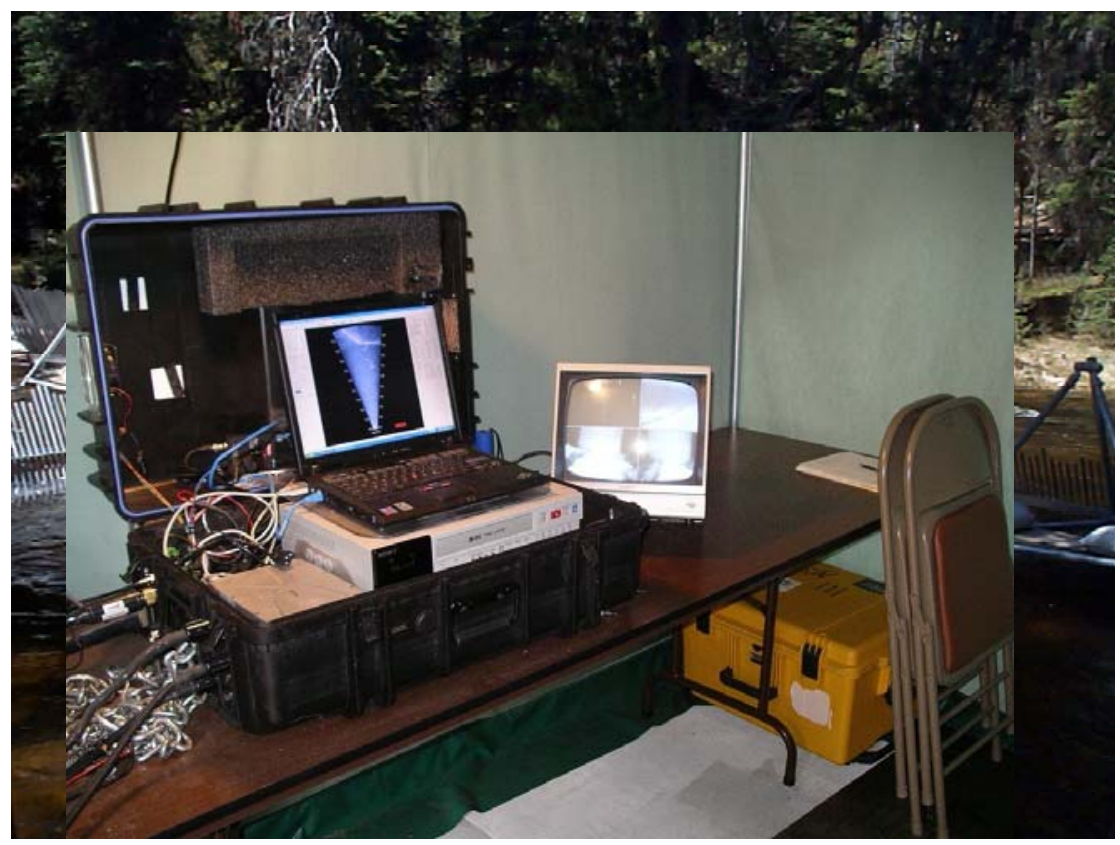

Figure 4. Topside box with laptop computer that collects DIDSON files on an external hard drive, and quadplexes optical camera data with the DIDSON signal on a VHS tape for validation studies.

Maintenance of the monitoring site occurred daily and consisted of exchanging external hard drives, exchanging validation videotapes, removing debris from picket weirs, cleaning DIDSON sonar lenses (when necessary), and fueling the generator. During the early summer, pollen and/or fine sediments tended to collect on the acoustic len's and automatic focusing pins of the DIDSON units which caused distorted and out of focus images. Cleaning of the acoustic len's and the automatic focusing pin every three to five days remedied this problem. In addition, the staff gage level was recorded daily and water temperature was monitored with a hobo data logger which recorded hourly stream temperature.

\section{CSOT File Processing}

In 2008, the Convoluted Samples Over Threshold (CSOT) feature of the DIDSON software was used to process high frequency DIDSON files to fish motion-only periods from July 3 through September 14. The CSOT is a motion detection algorithm that allows for the capture and recording of frames that contain motion relative to background structure. The software feature presents a methodology that saves both disk space and observation time. The algorithm is based on three user specified parameters, a background subtraction parameter " $\mathrm{A}$ ", the number of samples, and a threshold value in decibels $(\mathrm{dB})$.

The viewable DIDSON image consists of 49,152 individual pixels ( 512 x 96 beams), also called samples. The color intensity for each sample displayed on the screen is relative to the target strength return (measured in $\mathrm{dB}$ ) within that specific sample. The number of samples a target 
occupies within the sonar beam is relative to its length and width as well as the distance from the sonar unit. Longer length targets cover more individual sonar beams while wider targets occupy more samples within a single beam. Because of the spread of the sonar beam, an object farther away from the sonar will occupy fewer samples than the same object close to the sonar. In addition, the target strength of an object also varies with its aspect to the sonar unit.

For the CSOT feature, the user specifies the number of samples (non-contiguous) greater than a $\mathrm{dB}$ threshold value that is of interest, and only frames that contain a greater number of samples with targets strengths above the specified threshold are recorded. The back ground subtraction value "A" (range $>0<1$ ) sets the rate at which stationary objects are removed from the image.

The CSOT processing parameters for 2008 were selected based on the experience gained from processing files from 2005 through 2007 (Kucera and Orme 2006, Kucera and Orme 2007) and trials conducted in 2008. In 2008, nine days of original DIDSON files were viewed, one file every seven days throughout the season, starting on July 3, and all salmon passages recorded. DIDSON files were then processed with the CSOT feature using a background subtraction value of 0.98 , a threshold value of $6 \mathrm{~dB}$, and with the number of samples parameter set at 25, 40, 75, and 125. Processed files from each day and from each number of sample values were once again viewed and salmon passages compared to passages observed during that days original DIDSON file review. The largest number of the samples parameter that successfully captured and recorded clear and distinct passages of all known salmon was used to process the following six days of DIDSON files.

\section{Escapement and Variance Estimation}

Adult salmon escapement in the Secesh River was determined by calculating the maximum net upstream number of salmon targets that migrated past the DIDSON monitoring site once spawning had commenced. Therefore, the escapement estimate represents the largest number of spawning adults that was available to contribute to salmon reproductive success. In addition, an end of the season escapement estimate was generated to estimate the number of adult salmon leaving the spawning area, and to allow the efficiency of carcass recoveries to be calculated.

Determination of net upstream movement was simply a matter of cumulative addition for upstream movement, or subtraction when a salmon target moved downstream. Salmon escapement was determined by viewing CSOT processed DIDSON files of fish motion-only periods, and manually counting fish targets (Figure 2) that were $\geq 55 \mathrm{~cm}$ in length. The DIDSON software's measuring tool allowed total length measurement of individual fish targets. This size-based approach allowed enumeration of adult salmon-sized targets separate from other fish species moving through the DIDSON monitoring site. Adult steelhead overlap in size with and could potentially be counted as adult salmon. However, the steelhead spawning migration timing was believed to be temporally discrete from the salmon migration timing in 2008. Bull trout was the only other fish species large enough to overlap in size with jack salmon $(55 \mathrm{~cm}$ or greater). Large non-fish targets such as ducks, otters, and debris were identifiable using the lengths and widths (overall shape) and swimming motion of the targets. Identification of nonfish targets improved with observer experience. A representative high frequency DIDSON file 
of adult salmon (Figure 5), bull trout (Figure 6), and rainbow trout (Figure 7) was selected to demonstrate the relative difference in target size between the three species. Confidence in fish species identification was gained when viewing and comparing the relative size of hundreds of salmon with non-salmon species and comparing it with optical camera validation information (Figures 5, 6, and 7).

In 2008 salmon escapement was determined by two observers independently viewing CSOT processed DIDSON files of the salmon migration. Data recorded included date, time of passage, the direction of passage (upstream or downstream), total length of the target, and distance from the sonar unit. After the first salmon passage of the season was identified, DIDSON files were read before this date to ensure seven days of no salmon passages prior to the first observed fish. This approach was assumed to account for the first salmon passage of the season. All observers noted targets that were questionable in terms of length, passage direction, or non-fish targets. After all files were viewed, all questionable targets and all targets between $52 \mathrm{~cm}$ and $60 \mathrm{~cm}$ were reviewed by the observers for concensus. The data was stratified by time period (early and late season passages), by observer, and by direction of passage. The early season salmon migration was defined as July 3 through July 22, and the late season migration was defined as July 23 through September 14.

Three known sources of error were addressed to adjust the estimated adult salmon escapement. The sources of error are CSOT processing error, observer error, and equipment downtime error. A systematic subsample of 15 days of original DIDSON files, not CSOT processed files, was reviewed independently by three reviewers. The systematic sample included files from every fourth consecutive day being read from July 5 through August 30. Date, time, direction, length, and location of salmon targets were recorded. This provided the basis to estimate the proportion of missed passages (error) by direction of passage for each observer, by time period, and for CSOT processed files. All passage discrepancies both within and between the 15 subsample day original files, and the same 15 day CSOT processed files were reviewed to verify missed passages. It was assumed that the maximum number of passages observed by the three independent reviewers, within the subsampled days, represented the true number of passages and that no salmon passages went undetected by all three reviewers. Error was calculated using a single fish passage as the sample unit. The 15 day systematic sample (Figure 8) represented $22.8 \%$ of the total number of CSOT processed salmon targets observed. 
4.5

4.0

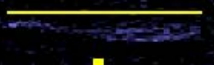

3.5

3.0

2.5

Fish 0

Range $0.00 \mathrm{~m}$

Length $0.0 \mathrm{~cm}$

Thick $0.0 \mathrm{~cm}$

Aspect 0.0 deg
3.0

2.5

Class Enter Fish Classification

Use left mouse button to click or draw segments along fish from head to tail. Double-click to mark

$0.5 \quad 0.5$ meters

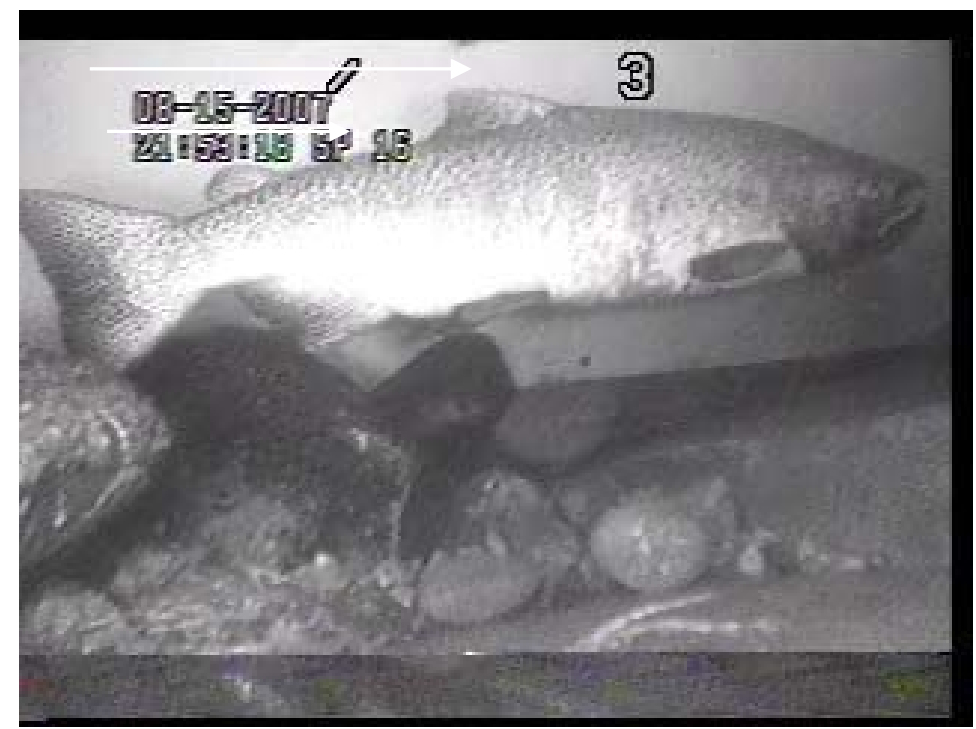

Figure 5. Multiplexed DIDSON image (upper photo) and validation video recording (lower photo) of a $91.8 \mathrm{~cm}$ adult Chinook salmon collected during validation studies in the Secesh River. 
4.5
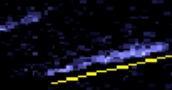

4.0
Fish 0

Range $0.00 \mathrm{~m}$ Length $0.0 \mathrm{~cm}$ Thick $0.0 \mathrm{~cm}$ Aspect 0.0 deg

Use left mouse button to click or draw segments along fish from head to tail. Double-click to mark end of length/direction
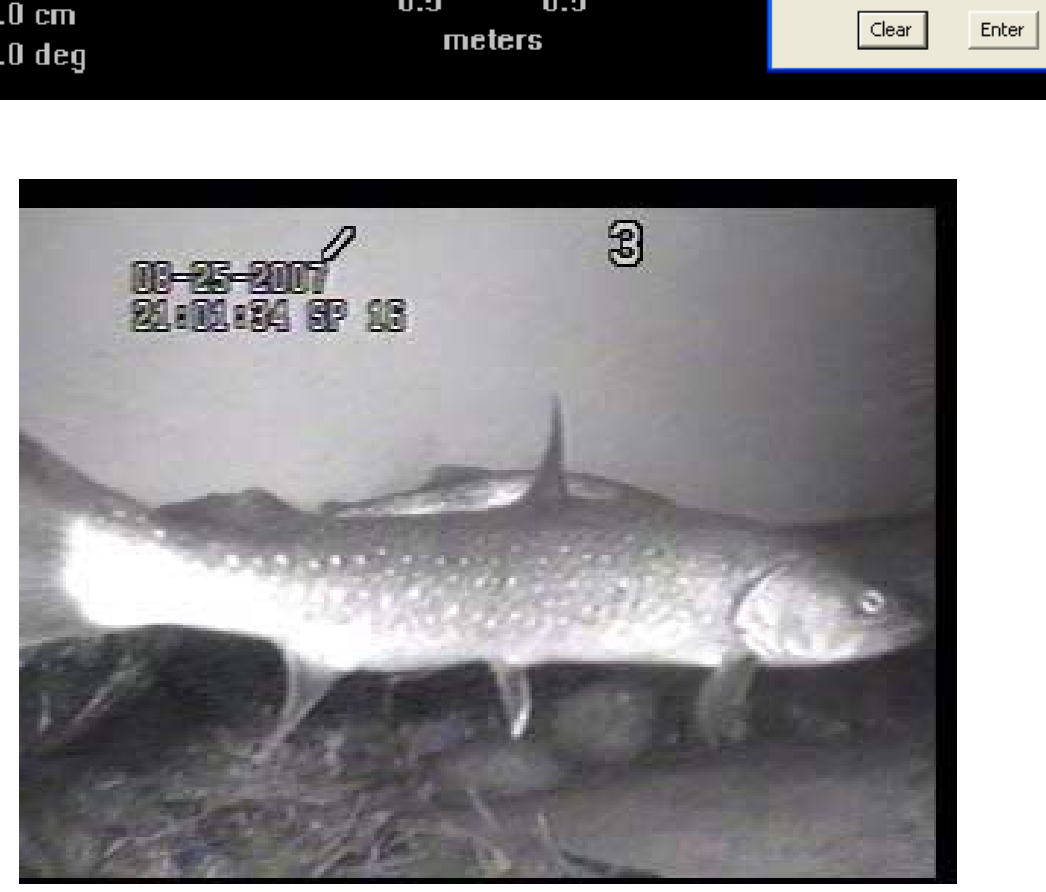

Figure 6. Multiplexed DIDSON image (upper photo) and validation video recording (lower photo) of a $52.7 \mathrm{~cm}$ bull trout collected during validation studies in the Secesh River. 


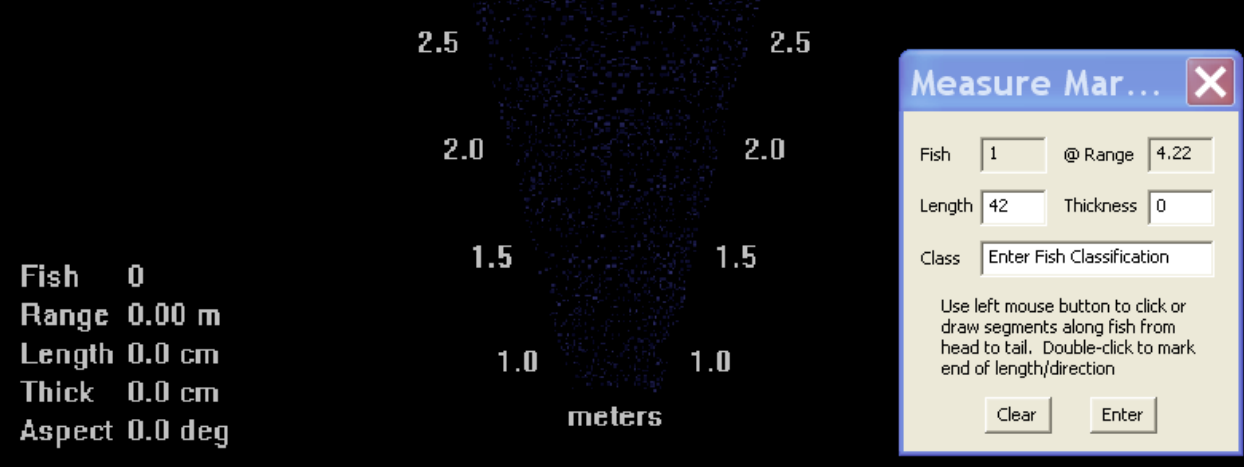

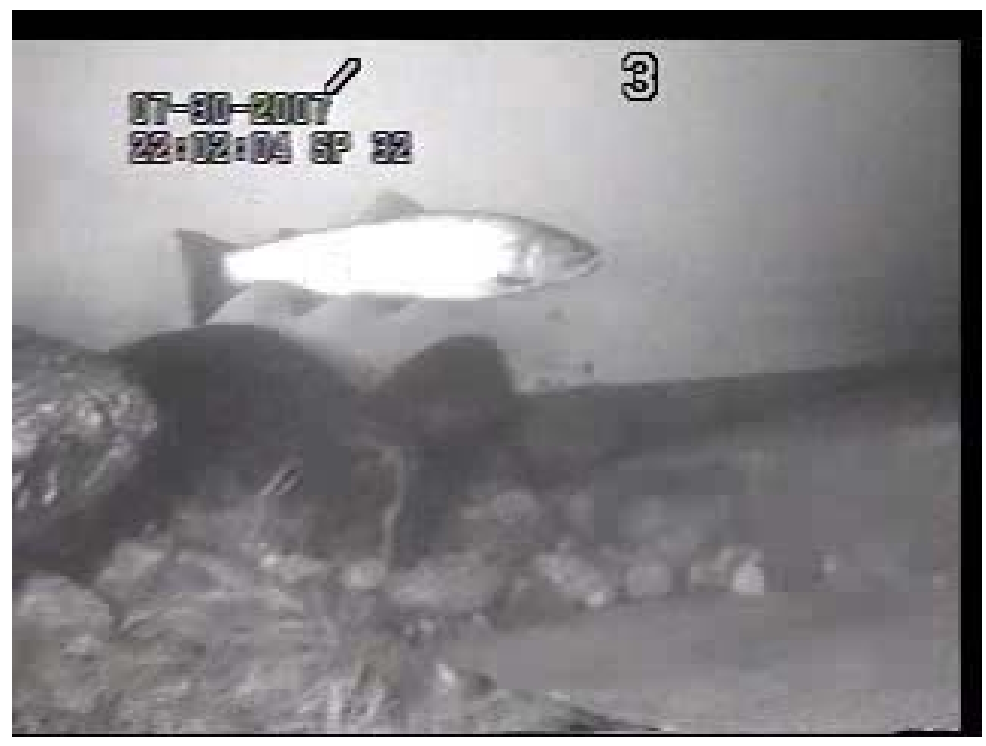

Figure 7. Multiplexed DIDSON image (upper photo) and validation video recording (lower photo) of a $42 \mathrm{~cm}$ rainbow trout collected during validation studies in the Secesh River. 
First, CSOT processing error was determined by comparing original DIDSON files with CSOT processed files to ensure that CSOT processed files accurately captured all salmon passages. CSOT error was estimated using the same 15 day systematic sample reviewed for observer error. All passage discrepancies between the 15 days of original files and CSOT processed files were reviewed. Passages that were not present or passages that were represented by a single frame on CSOT processed files were categorized as a CSOT error. CSOT error was calculated as the number of passages missed by CSOT processing divided by the number of passages present on original files. Differences in CSOT error, by direction, were evaluated with a z-test.

Secondly, since CSOT processed files and original DIDSON files were both read manually, observer error (viewer efficiency) was assessed. Individual observer error by direction of passage and time period was determined from the 15 day systematic sample. Each individual's observer error was calculated as the number of passages (by direction) missed divided by the total number of passages (by direction) possible. The individual's observer error was applied by direction to correct each individual's daily observed salmon passages for the entire season. In addition, observer error was estimated for each observer by direction for the six to eight days of CSOT files and for the 15 days of original files. Observation error may be different between CSOT files and original files due to: 1) discontinuity of time and image frames in CSOT files resulting in choppy and erratic image flow making viewing difficult; 2) CSOT processing sometimes resulted in only a few frames of a salmon passage being recorded, making detection of a passage more difficult; and 3) observers may unknowingly be more attentive of fish passages during review when aware that the files are also being reviewed by others. Differences in observation error between observers, by direction, and between file types were evaluated with a z-test.

The third source of error are salmon passages that potentially could go undetected during periods of DIDSON equipment downtime. Power failures or random computer glitches were generally the cause of longer periods of downtime. Downtime was calculated from time gaps recorded by observers during file review and from time gaps between files. A daily mean upstream passage was used to estimate passages that may have occurred during equipment downtime. Downtime corrections were made to each day that experienced downtime greater than 30 minutes. Corrections consisted of that day's observations added to the mean daily net upstream passage multiplied by the proportion of the day not sampled. 


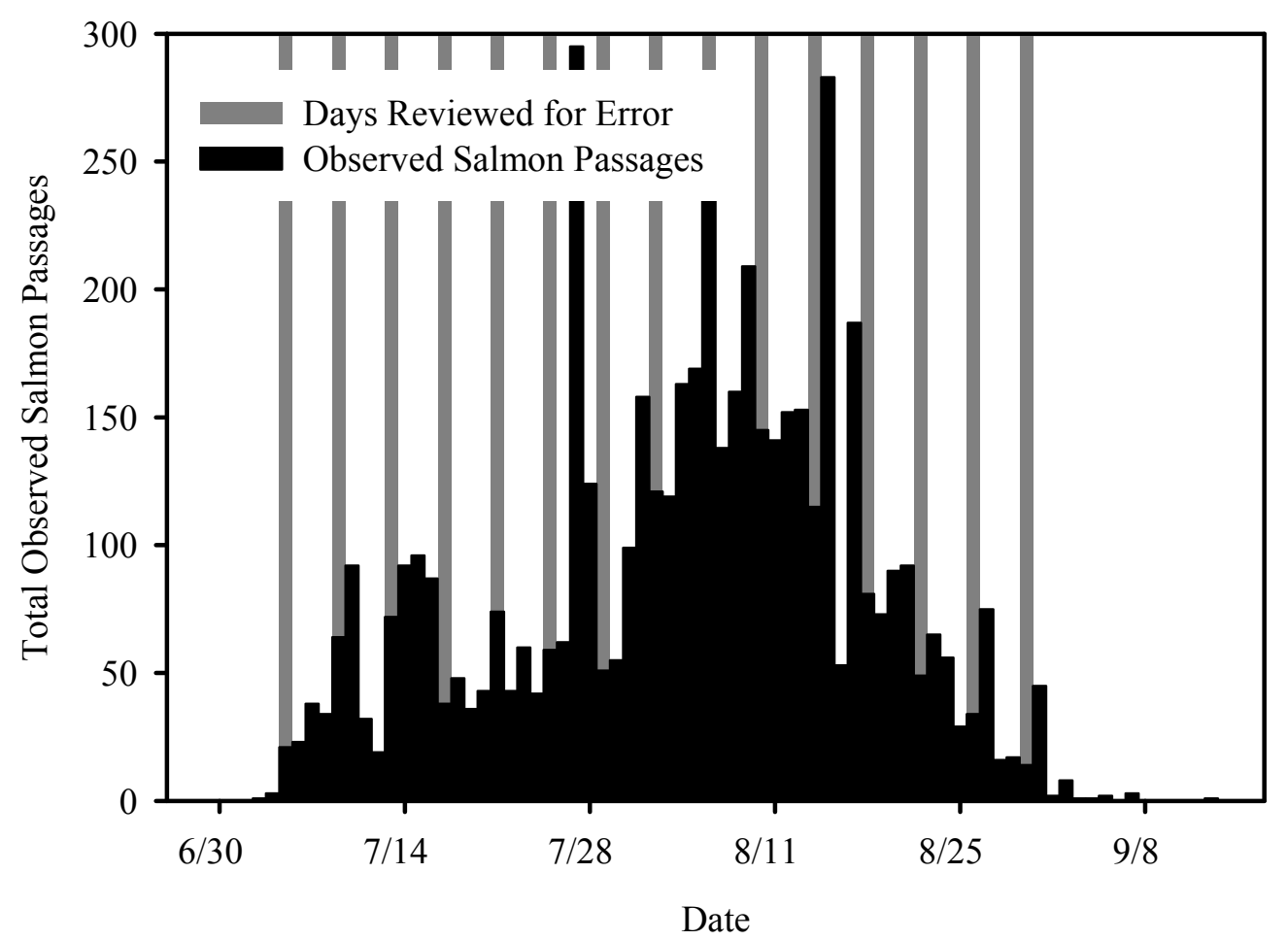

Figure 8. Distribution of the 15 days reviewed for assessment of motion error and reader specific error compared to total salmon passages in the Secesh River in 2008.

The total net upstream escapement (Total_Net_Up) was calculated by summing the estimated net escapement within stratified time periods (TPeriod_Net_Up) as

$$
\text { Total_Net_Up }=\sum_{t}^{n} \text { TPeriod_Net_Up }{ }_{-}
$$

Where $t$ is an individual time period and $n$ is the number of stratified time periods within the season. Net escapement within each individual time period (TPeriod_Net_Up) was the sum of the estimated net upstream passages that may have occurred during equipment downtime (DN_Time_Net_Up) and the total adjusted net upstream passages (Adj_Net_Up), adjusted for both observer and CSOT error as

$$
\text { TPeriod_Net_Up }=\left(D N \_T i m e \_N e t \_U p_{t}\right)+\left(\text { Adj_Net_Up } p_{t}\right) .
$$

Adjustments for the net upstream passages that may have occurred during equipment downtime (DN_Time_Net_Up) was estimated by multiplying the mean daily total adjusted net upstream passages ( $\overline{\text { Adj_Net_Up }}$ ) by the sum of days not sampled (Days_Not_Sampled) within each stratified time period as per the below equation. For downtime periods greater than one day, an 
average daily passage from the seven days prior to and following the period of extended downtime was used (Chris Beasley and Rishi Sharma, Quantitative Consultants - personal communication).

$$
D N \_T i m e \_N e t \_U p_{t}=\overline{A d j \_N e t \_U p_{t}} \cdot \sum(\text { Days_Not_Sampled })_{t} \text {. }
$$

Days that had downtime adjustments were excluded from the mean. The number of days not sampled could be a whole number or a fraction of a day. The total adjusted net upstream passages (Adj_Net_Up) that occurred within a time period was calculated as the sum of the adjusted viewer observation (Adj_Reviewer_Obs) by direction (d) of passage (upstream and downstream) divided by 1 minus the CSOT error (CSOT_Error) by direction (d) within each time period $(\mathrm{t})$ as

$$
\text { Adj_Net_Up } p_{t}=\sum\left[\text { Adj_Reviewer_Obs } s_{t, d} /\left(1-C S O T_{-} \text {Error }_{t, d}\right)\right] \text {. }
$$

The adjusted reviewer observation (Ajd_Reviewer_Obs) by direction (d) within each time period (t) was calculated as sum of each individual (i) reviewers observation (Reviewer_Obs) divided by 1 minus that individuals (i) observation error (Reviewer_Error) by direction $(\overline{\mathrm{d}})$ within each time period $(\mathrm{t})$ as

$$
\text { Adj_Reviewer_Obs }{ }_{d, t}=\sum\left[\text { Reviewer_Obs }_{t, d, i} /\left(1-\text { Reviewer_Error }_{t, d, i}\right)\right] \text {. }
$$

The CSOT error (CSOT_Error) was estimated as the number of observations missed during CSOT processing (CSOT_Obs_Missed) divided by the number of observations possible on original files (CSOT_Obs_Possible) by direction of passage $(d)$ within each time period $(\mathrm{t})$ as

$$
\mathrm{CSOT}_{-} \text {Error }_{t, d}=\mathrm{CSOT}_{-} \mathrm{Obs} \text { Missed }_{t, d} / \mathrm{CSOT}_{-} \mathrm{Obs} \_ \text {Possible }_{t, d} .
$$

Individual (i) observation error (Reviewer_Error) was estimated as the number of observations missed (Reviewer_Obs_Missed) divided by the number of observations possible (Viewer_Obs_Possible) by direction of passage (d) within each time period (t) as

$$
\text { Reviewer_Error }{ }_{t, d, i}=\text { Reviewer_Obs_Missed }{ }_{t, d, i} / \text { Viewer_Obs_Possible }_{t, d, i \operatorname{Rev}} \text {. }
$$




\section{Variance of Net Upstream Escapement}

The confidence interval of the escapement estimate was based on the variance associated with observer error and the variance associated with passages estimated to have occurred during equipment downtime. The variance of the total net upstream escapement (var(Total_Net_Up)) was calculated as the sum of the variance of each individual time period estimate $\left(\operatorname{var}\left(T P e r i o d \_N e t \_U p\right)\right)$ as

$$
\operatorname{var}(\text { Total_Net_Up })=\sum_{t}^{n} \operatorname{var}(\text { TPeriod_Net_Up }) .
$$

Where $t$ is the individual time period and $n$ is the number of time periods. The variance of net upstream passages within each individual time period (var(TPeriod_Net_Up)) was calculated as the sum of the variance of the estimated net upstream passages that may have occurred during equipment downtime (var(DN_Time_Net_Up) and the variance of the total adjusted net upstream passages (var(Adj_Net_Up) as

$$
\operatorname{var}\left(T P e r i o d \_N e t \_U p_{t}\right)=v a r\left(D N \_T i m e \_N e t \_U p_{t}\right)+\operatorname{var}\left(A d j \_N e t \_U p_{t}\right) .
$$

Variance for equipment downtime (var(DN_Time_Net_Up)) was estimated by multiplying the variance of mean daily total adjusted net upstream passages $\left(\operatorname{var}\left(\overline{A d j \_N e t \_U p_{t}}\right)\right.$ by the square of the sum of days not sampled (Days_Not_Sampled) during that time period as per the equation below. For periods of extended downtime, greater than 24 hours, we generated a weighted mean of the adjusted net upstream passages for the seven days before and after the period of downtime to generate variance around the interpolation estimate (Chris Beasley and Rishi Sharma, Quantitative Consultants - personal communication).

$$
\operatorname{var}\left(D N_{-} T i m e \_N e t \_U p_{t}\right)=\operatorname{var}\left(\overline{A d j \_N e t \_U p_{t}}\right) \cdot\left(\sum(\text { Days_Not_Sampled })_{t}\right)^{2} .
$$

Days that had downtime adjustments were excluded when calculating the variance of the mean. The number of days not sampled could be a whole number or a fraction of a day. The variance of the total adjusted net upstream passages (var(Adj_Net_Up) was calculated using the total adjusted reviewer observations (Adj_Reviewer_Obs) and the associated variance (var(Adj_Reviewer_Obs), and the estimated CSOT error (CSOT_Error) and that associated variance (var(CSOT_Error) by passage direction $(d)$ within each time period $(t)$. The variance of the total adjusted net upstream passages (var(Adj_Net_Up) was calculated as the product of the variance of total adjusted reviewer observations (var(A_dj_Reviewer_Obs)) and the variance of CSOT error (var(CSOT_Error)) plus the product of the square of total adjusted reviewer observations (Adj_Reviewer_Obs) and variance of CSOT error (var(CSOT_Error) plus the product of the square of CSOT error (CSOT_Error) and the variance of total adjusted reviewer observations (var(Adj_Reviewer_Obs)) as 


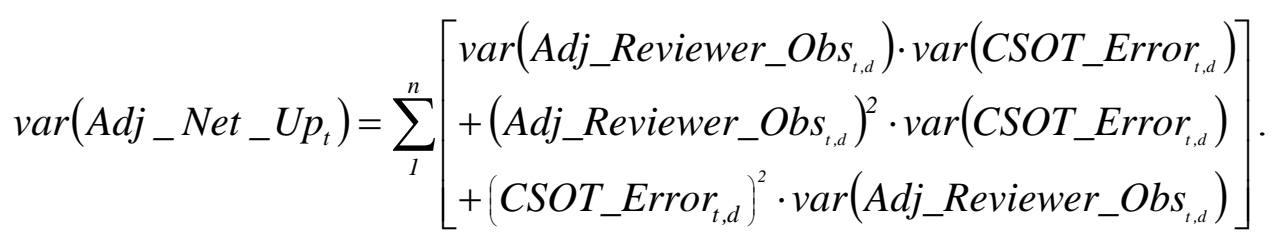

The variance of the total adjusted reviewer observations (var(Adj_Reviewer_Obs)) was calculated as the square of the sum of each individuals (i) observations (Reviewer_Obs) by direction $(\mathrm{d})$ within each time period $(\mathrm{t})$ multiplied by the variance of the individuals reviewer error (var(Reviewer_Error)) as

$$
\operatorname{var}\left(\text { Adj_Reviewer_Obs }_{t, d, r}\right)=\sum\left(\text { Reviewer_Observation }{ }_{t, d, r}\right)^{2} \cdot \operatorname{var}\left(\text { Reviewer_Error }{ }_{t, d, r}\right) \text {. }
$$

The variance of each individuals (i) observation error (var(Reviewer_Error)) within each time period ( $\mathrm{t}$ ), by direction of passage (d) was estimated as the product of the observation error (Reviewer_Error) and 1 minus the observation error (Reviewer_Error) divided by the sample size (Reviewer_Obs_Possible) as

$$
\operatorname{var}\left(\text { Reviewer_Error }_{t, d, r}\right)=\frac{\left(\text { Reviewer_Error }_{t, d, r}\right) \cdot\left(1-\text { Reviewer_Error }_{t, d, r}\right)}{\text { Reviewer_Obs_Possible } \text { E }_{t, d, r}} .
$$

Similarly, the variance of the CSOT error (var(CSOT_Error) within each time period $(\mathrm{t})$, by direction of passage ( $p$ ) was estimated as the product of the CSOT error (CSOT_Error) and 1 minus the CSOT error (CSOT_Error) divided by the sample size (CSOT_Obs_Possible) as

$$
\operatorname{var}\left(C S O T_{-} \text {Error }_{t, d}\right)=\left[\left(\text { CSOT_Error }_{t, d}\right) \cdot\left(1-C S O T \_ \text {Error }_{t, d}\right) / \text { CSOT_Obs_Possible }_{t, d}\right] .
$$

Calculations of the running daily sum of observation, escapement estimates, and confidence intervals were completed to enable the determination of the maximum net upstream passages.

\section{Productivity}

One of the goals of this project is to provide long term salmon productivity information on the natural origin salmon population in the Secesh River for supplementation program reference stream comparison and threatened species recovery monitoring. Progeny-per-parent ratios (adult:adult ratios) will be determined on a brood year basis. This is a derived performance measure that relies on quantification of adult abundance, an index of spawner abundance (redds), spawner abundance, fish per redd, hatchery fraction, age group structure including age at return, spawner sex ratios, prespawning mortality, and tributary harvest (if any). Calculation of adultto-adult ratios relies on annual run reconstructions and will use two variants of parents; estimated escapement and spawner abundance (Hesse et al. 2006). Age at juvenile emigration and age at 
adult return, to assign individuals to specific brood years, will be determined through dorsal fin ray aging (primary method) and from scales (if needed). Age determination from all salmon carcasses are used to partition the total escapement estimate. The year class (brood year) that each returning spawner originated from can then be determined. Aging methods and calculation of adult-to-adult ratios is a coordinated effort for consistency in application because the Secesh River acts as a reference stream for supplementation program comparison (Vogel et al. 2005, Hesse et al. 2006).

\section{Seasonal Migration and Diel Movement Patterns}

Previous work in Lake Creek and in the Secesh River (Kucera et al. 2005, Kucera and Orme 2007) indicated significant seasonal salmon migration patterns. Seasonal migration and diel patterns were assessed using observed salmon passages (not adjusted passages). Differences in observed daily net upstream passage, the total number of daily passages, and diel patterns were assessed through time. Distinct and clear changes in seasonal migration patterns were used to stratify the season for escapement estimates, observation error, and downtime adjustments. Differences were assessed by using t-tests where appropriate. Linear regressions were performed between net upstream migration and julian day, daily staff gage level, average daily water temperature, minimum daily water temperature, and maximum daily water temperature to evaluate relationships between these variables. Early season and late season diel salmon passage distribution, of total observed fish passages, was compated by a Kolmogorov-Smirnov test. Tests for statistical significance were conducted at the $p=0.05$ level.

\section{Validation}

Validation monitoring employed use of three underwater optical cameras to provide the independent methodology to validate species identification of DIDSON target counts at the monitoring site. Optical cameras were located near the far standoff structure in a five foot validation zone (Figure 9 and Figure 3). The optical cameras were mounted on a well point and aimed toward the vertical white background located next to the bank standoff structure (Figure 3 ). The camera coverage overlapped each other to ensure complete coverage of the water column within the validation zone so that no salmon passages went undetected. Validation optical cameras and the DIDSON signal were multiplexed and recorded on a videotape to ensure synchronization in time of both sources. Near simultaneous viewing of DIDSON and the optical camera recordings was then possible. Optical camera data was stored along with the DIDSON data on a VHS T-160 tape on extended play at eight frames per second. Data collected included species, date, time, and direction of movement. The standard validation approach in the Secesh River used optical cameras during daytime and nighttime periods starting from approximately 3:00 p.m to 9:00 a.m. the following morning (Kucera and Orme 2007). In 2008 validation monitoring began on July 30 due to higher stream discharge prior to this date. Optical cameras validated the DIDSON size-based salmon enumeration approach of counting fish targets $\geq 55 \mathrm{~cm}$ in total length, with date and time stamped optical camera identified species and counts. 


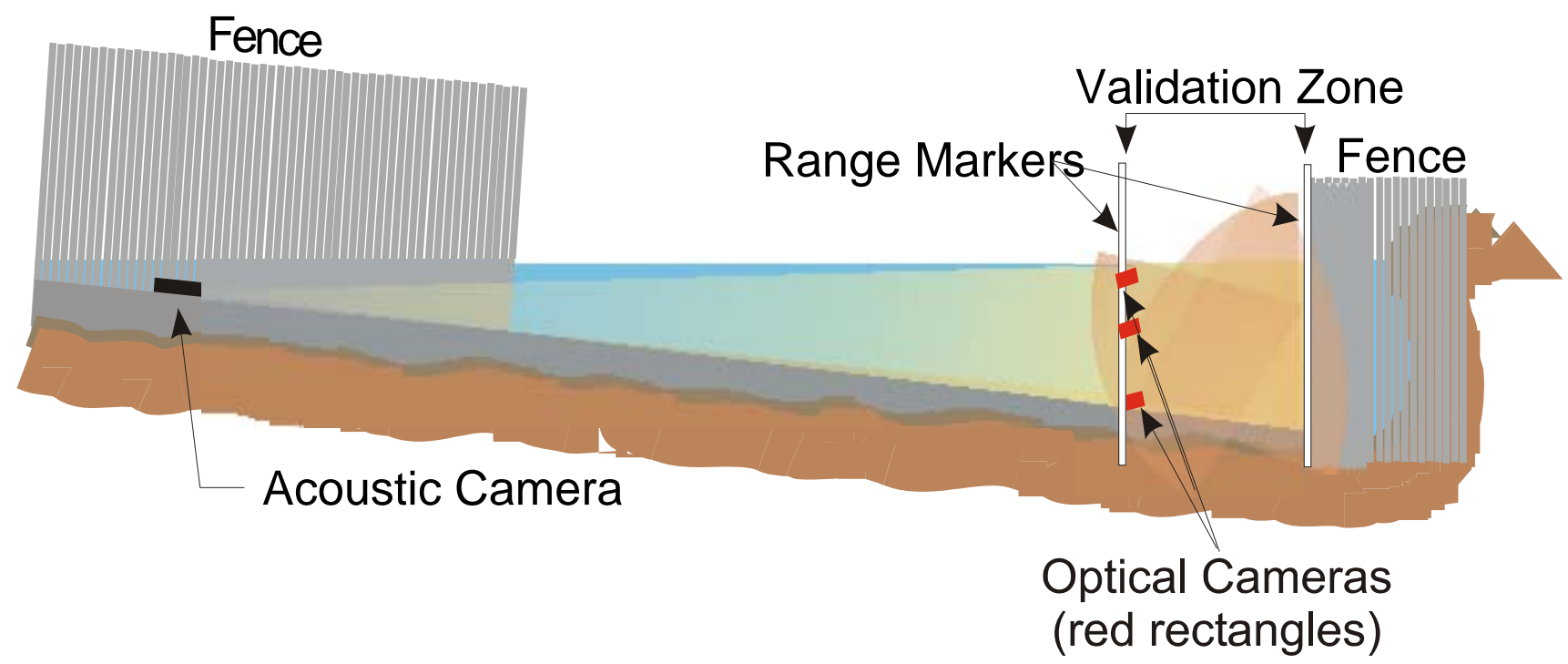

Figure 9. Cross-section view of the validation zone indicating where optical cameras were used as the independent method to validate DIDSON target counts in the Secesh River in 2008.

A stratified random sample of videotapes $(n=13$ days) were viewed to determine the total number of salmon passages, upstream and downstream, within the validation zone. Due to late installation of optical cameras validation occurred during the month of August only. Correct species identification was verified from videotaped salmon passages compared to passages observed and counted as salmon during DIDSON file review. A single fish was defined as the sampling unit with the total number of passages defined as the number of unique fish observed.

\section{Precision}

The precision of the DIDSON sonar to record salmon targets and the subsequent methodology to estimate salmon escapement was evaluated by operating two DIDSON sonar units in the Secesh River in 2008. The two DIDSON monitoring sites, termed DIDSON 1 and DIDSON 2, were located $12 \mathrm{~m}$ apart so that sonar signals would not interfere with one another. Both units were operated identically, sampled the entire water column, and were operated 24 hours a day.

DIDSON sonar was operated over a block of five days from July 5 (00:00:00 hour) to July 9 (23:59:59 hour). Blocks of days were selected because the monitoring sites were located in adult salmon holding areas, and fish would sometimes hold in between the two sonar unit locations thus biasing the net upstream count comparison (i.e. - fish would pass one sonar site but not the other site). This fish behavior also invalidated a random day sampling design for the precision comparison. The time period selected represented the early part of the salmon migration and contained an uninterrupted time series of sonar data (minimal downtime). Original DIDSON files were viewed by a single observer, and date, time, number of salmon targets, direction of travel, and total length was recorded. A subsample of days was viewed independently by two viewers ( 3 of the 5 days). Reader specific error and salmon escapement estimates were 
determined using methods described in the Escapement and Variance Estimation methods section in this report. The true number of net upstream salmon passages during the time period was also determined. Differences in observed net upstream passage between the two sonar units were resolved by reviewing files until all missed passages were found. Precision was then evaluated within the time period relative to the estimated net upstream passage between sonar units and was comparable to precision estimation methods used in 2005, 2006, and 2007 (Kucera and Orme 2007).

\section{Known Length Carcass Trials}

Known length carcass trials were conducted with sonar unit 111 in 2008 to examine the accuracy of observers to manually measure target lengths. High frequency DIDSON files were collected at a $5 \mathrm{~m}$ window length, and targets measured with the DIDSON software. A total of 21 Chinook salmon carcasses ranging in length from $55.3 \mathrm{~cm}$ to $103.2 \mathrm{~cm}$ were used in the known

length carcass trials. These lengths were representative of the expected lengths of returning adult salmon to the Secesh River. Nylon rope was attached to each carcass through the upper and lower tip of the snout, and each carcass was pulled upstream through the DIDSON ensonified zone. The best length from an individual carcass trial was independently selected by each observer, manually measured, and the total length recorded. This was repeated for all of the remaining carcasses. A linear regression was used to compare the relationship between known length and manually measured lengths for each of the two observers.

\section{Listed Chinook Salmon Population Status}

Adult natural origin salmon escapement and spawner abundance (wild fish) in the entire Secesh River drainage was estimated for application to management goals and listed species recovery monitoring. Escapement, as used here refers to a population measure of numbers of adults (including jacks) that have escaped to a certain point, usually the mouth of a stream, and differs from the term spawner abundance. Spawner abundance is defined as a population measure of the estimated number of total spawners on the spawning grounds. Redd count and carcass data used was collected by the Tribe's ISS project (Lockhart et al. 2008, BPA Project No. 198909802). DIDSON technology was used to estimate adult salmon escapement from 2004 through 2008. Adult escapement estimation methods for 1998 to 2003 are described in Faurot and Kucera (2004). The DIDSON adult salmon escapement estimate was used to estimate natural and hatchery salmon escapement upstream of the DIDSON monitoring site. The number of redds located downstream of the DIDSON monitoring site in 2008 was identified from extensive area redd count surveys. The number of redds located downstream of the DIDSON site was expanded by a DIDSON generated fish per redd number. This number was determined by dividing the DIDSON escapement estimate (fish) by the extensive area redd count upstream of the DIDSON site (redds). The DIDSON salmon escapement estimate was summed with the redd count expansion abundance estimate, for redds located downstream of the DIDSON site, to estimate total adult salmon escapement in the Secesh River system (natural and hatchery fish combined). An average hatchery fraction was calculated using values calculated from the Lake Creek underwater video fish counting station and from carcass recoveries in the Secesh River excluding Lake Creek (Faurot and Kucera 2004). It was believed these provided the most accurate estimate of hatchery composition for the entire Secesh River. The hatchery fraction 
observed at the video count station was utilized as no pelvic fin clipped carcass recoveries were obtained on Lake Creek in 2008; which the video may have missed. The estimated natural origin salmon escapement for the entire Secesh River was derived as follows. The DIDSON escapement estimate was added to, the number of salmon redds located below the DIDSON site multiplied by the DIDSON fish per redd number, and then multiplied by the proportion of natural origin salmon in the spawning population. Natural origin spawner abundance relied on use of carcass recovery data to calculate the proportion of females in the spawning population, a wild female prespawning mortality percentage, and the number of wild female prespawning mortalities. The number of wild female prespawning mortalities was then subtracted from the natural origin escapement estimate and provided the estimate of spawner abundance. There was no salmon harvest to account for in the escapement estimates in 2008. In addition, the Johnson Creek/East Fork South Fork Salmon River (EFSF) salmon population spawner abundance data was used to compare with the Secesh River population. The Johnson Creek/EFSF population is recognized by the ICTRT (2005) as a population for recovery planning. Salmon spawner abundance is quantified in Johnson Creek as part of the supplementation program monitoring and evaluation (Rabe and Nelson 2008, BPA Project No. 199604300) and represents the vast majority of the salmon production that occurs in the Johnson Creek/EFSF population. Salmon in the East Fork South Fork Salmon River were extirpated (ICTRT 2007) and only remnant natural spawning remains. Therefore, the Johnson Creek spawner abundance estimate was expanded by the number of redds located in the East Fork South Fork Salmon River similar to the Secesh River calculation outlined above. The regression fish per redd value and prespawning mortality value from Lake Creek was used as a surrogate, from the same year, and applied to calculate the East Fork South Fork Salmon River spawner abundance. This value was then added to the Johnson Creek spawner abundance to obtain the total Johnson Creek/EFSF population spawner abundance.

Johnson Creek is a tributary to the East Fork South Fork Salmon River, and is located in the South Fork Salmon River drainage in Idaho. The Johnson Creek population represents a hatchery supplemented salmon population with weirs for trapping adults, whereas the Secesh River represents a natural origin salmon population. Spawner abundance estimates for Johnson Creek includes adjustment for natural origin salmon broodstock take, mortalities at weirs, hatchery composition, and includes jacks. Both streams in this comparison collect adult salmon spawner abundance information and do not rely on annual redd counts for indices of abundance.

\section{RESULTS AND DISCUSSION}

\section{DIDSON Site Salmon Escapement}

The DIDSON monitoring site (rkm 30) was installed and operational on June 10, 2008. The first upstream salmon passage was observed on July 3, seven days after DIDSON file reading began (see Methods). Estimated salmon escapement, of wild and hatchery fish combined, was $888 \pm$ 65 fish (95\% confidence interval) (Table 2, Figure 10). The DIDSON monitoring site was operational for $98.1 \%$ of the salmon migration season in 2008 . 
The maximum number of net upstream migrating salmon (888) was upstream of the monitoring site by August 27. This number represents the largest number of spawning adults that was available to contribute to salmon reproductive success. After August 27 there was a total net downstream passage of 16 salmon past the monitoring site (Appendix Table 7). When operations ceased a total of 872 salmon remained upstream of the DIDSON site (Table 2). The net loss of 16 salmon represents $1.8 \%$ of the estimated escapement. If all downstream moving fish were males, the estimated sex ratio from carcass recoveries may be slightly skewed toward females.

DIDSON technology has been used to estimate adult salmon ecapement in the Secesh River since 2004 (Figure 10). Salmon escapement in 2008 increased by 587 fish, as compared to the 2007 escapement estimate of 301 fish (Kucera 2008). Escapement levels have varied by over four fold during the 2004 to 2008 status monitoring period. A high percentage of the total number of Secesh River Chinook salmon redds are located upstream of the DIDSON monitoring site (Table 2). Salmon escapement estimates and variance estimators at the monitoring site account for $97.4 \%$ to $99 \%$ of all salmon redds in the entire Secesh River drainage.

DIDSON salmon escapement estimates were expanded by plus 20.4 fish for equipment downtime and minus 109 salmon for reader specific error and CSOT error in 2008 (Table 2, Appendix Table 7). If reader specifc error and CSOT error had not been accounted for, salmon escapement would have been positively biased by $12.3 \%$ in 2008 (Figure 11). Similarly, salmon escapement would have been overestimated by $10.3 \%$ to $53.3 \%$ from 2007 to 2005 if reader specific error and CSOT error had not been used to adjust daily salmon passage (Figure 11, Table 2). The $95 \%$ confidence intervals around the adjusted escapement estimates did not overlap unadjusted escapement estimates from 2005 to 2008, suggesting that the estimates may be significantly different.

Table 2. Secesh River adult salmon escapement estimate at the DIDSON monitoring site $( \pm 95 \%$ confidence intervals), coefficient of variation, adjustments to the estimated escapement due to equipment down time and DIDSON file reader and CSOT processing error, estimated number of salmon remaining upstream of the monitoring site at the end of the migration season, and percent of total Secesh River redds located upstream of the monitoring site from 2004 to 2008.

\begin{tabular}{|c|c|c|c|c|c|c|}
\hline Year & $\begin{array}{l}\text { Escapement } \\
\text { Estimate }\end{array}$ & $\begin{array}{c}\text { Coefficient } \\
\text { of } \\
\text { Variation }\end{array}$ & $\begin{array}{c}\text { Down } \\
\text { Time } \\
\text { Adjustments }\end{array}$ & $\begin{array}{l}\text { File reader/ } \\
\text { CSOT Error } \\
\text { Adjustments }{ }^{1}\end{array}$ & $\begin{array}{c}\text { End of } \\
\text { Season } \\
\text { Estimate }\end{array}$ & $\begin{array}{c}\text { Percent } \\
\text { of Redds } \\
\text { Upstream } \\
\text { of } \\
\text { DIDSON }\end{array}$ \\
\hline 2004 & $914( \pm 194)$ & 10.8 & +86 & -105 & $901( \pm 194)$ & 99.0 \\
\hline 2005 & $336( \pm 59)$ & 8.9 & +5 & -179 & $335( \pm 59)$ & 98.0 \\
\hline 2006 & $209( \pm 24)$ & 5.8 & +6 & -43 & $180( \pm 24)$ & 98.7 \\
\hline 2007 & $301( \pm 23)$ & 5.6 & +48 & -31 & $291( \pm 33)$ & 98.8 \\
\hline 2008 & $888( \pm 65)$ & 3.7 & +20 & -109 & $872( \pm 64)$ & 97.4 \\
\hline
\end{tabular}


An estimated fish per redd value was calculated in 2008 by using the DIDSON escapement estimate divided by extensive area redd count totals located upstream of the DIDSON monitoring site (Appendix Table 6). Extensive area redd counts conducted by the Tribe's ISS project identified 374 salmon redds upstream of the DIDSON monitoring site, with 10 redds located downstream of the site. The estimated 2008 fish per redd value was 2.37 . This fish per redd value was intermediate between the values observed from 2004 (2.34), 2005 (1.68), 2006 (2.82), and 2007 (3.67). In 2008, 2.6\% of the salmon redds were located downstream of the DIDSON monitoring site.

Extensive area redd counts located upstream of the DIDSON site was compared to DIDSON escapement estimates to evaluate the relationship between the two variables. Using years as samples, five data points were available for regression analysis (Appendix Figure 1). Two data points anchor the low values and two data points anchor the higher values. The index of relative abundance (redds) was significantly related to escapement $(F=46.72, p<0.006)$ at lower levels of salmon escapement. It was not possible to evaluate the relationship of peak index redd counts, conducted by the Idaho Department of Fish and Game, and escapement because of difference in redd count boundaries and small usable sample size $(n=3)$. The authors urge caution with use of this data based on the small sample size. 


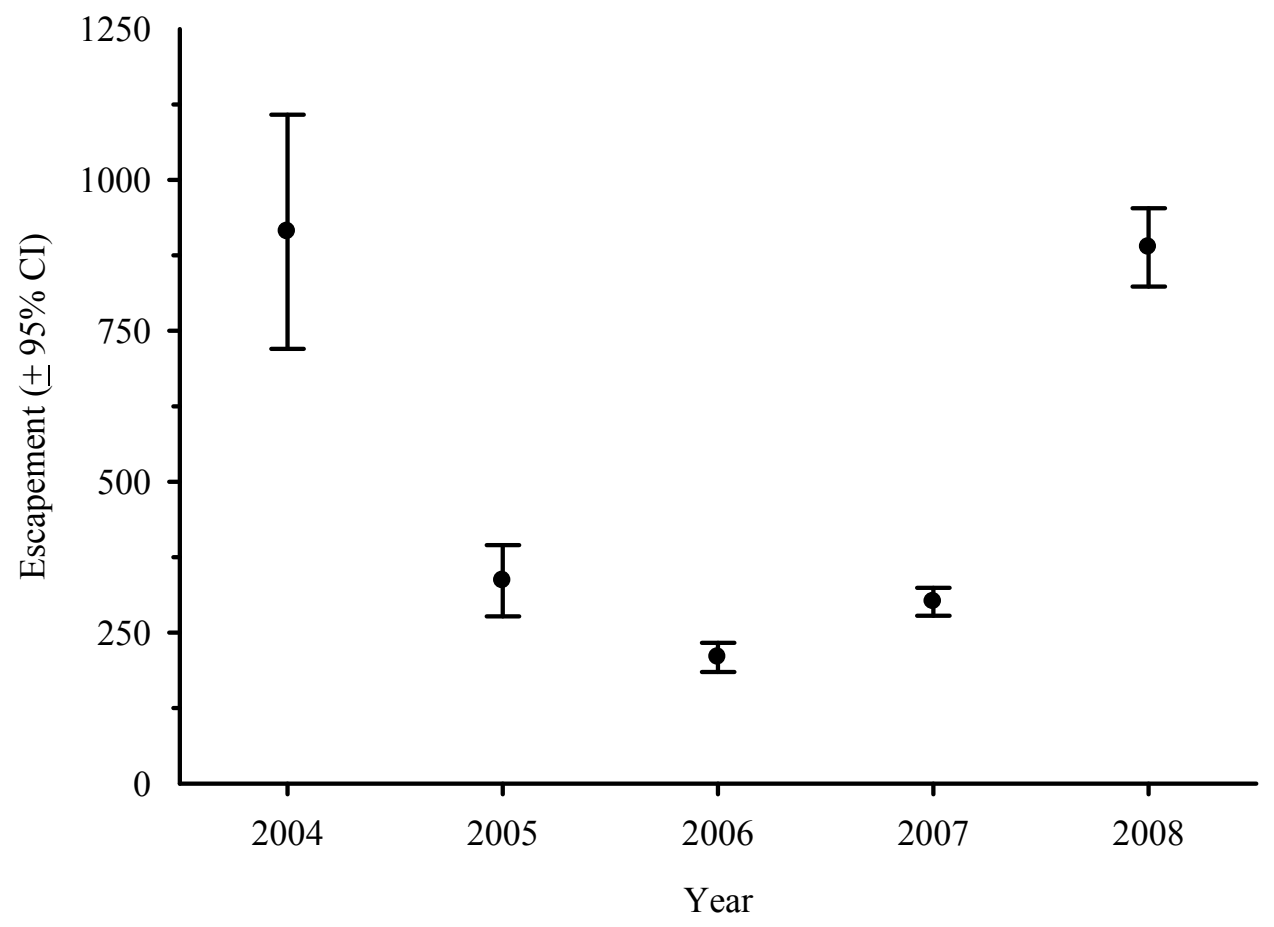

Figure 10. Estimated adult salmon escapement ( $\pm 95 \%$ confidence intervals) at the DIDSON monitoring site in the Secesh River from 2004 to 2008.

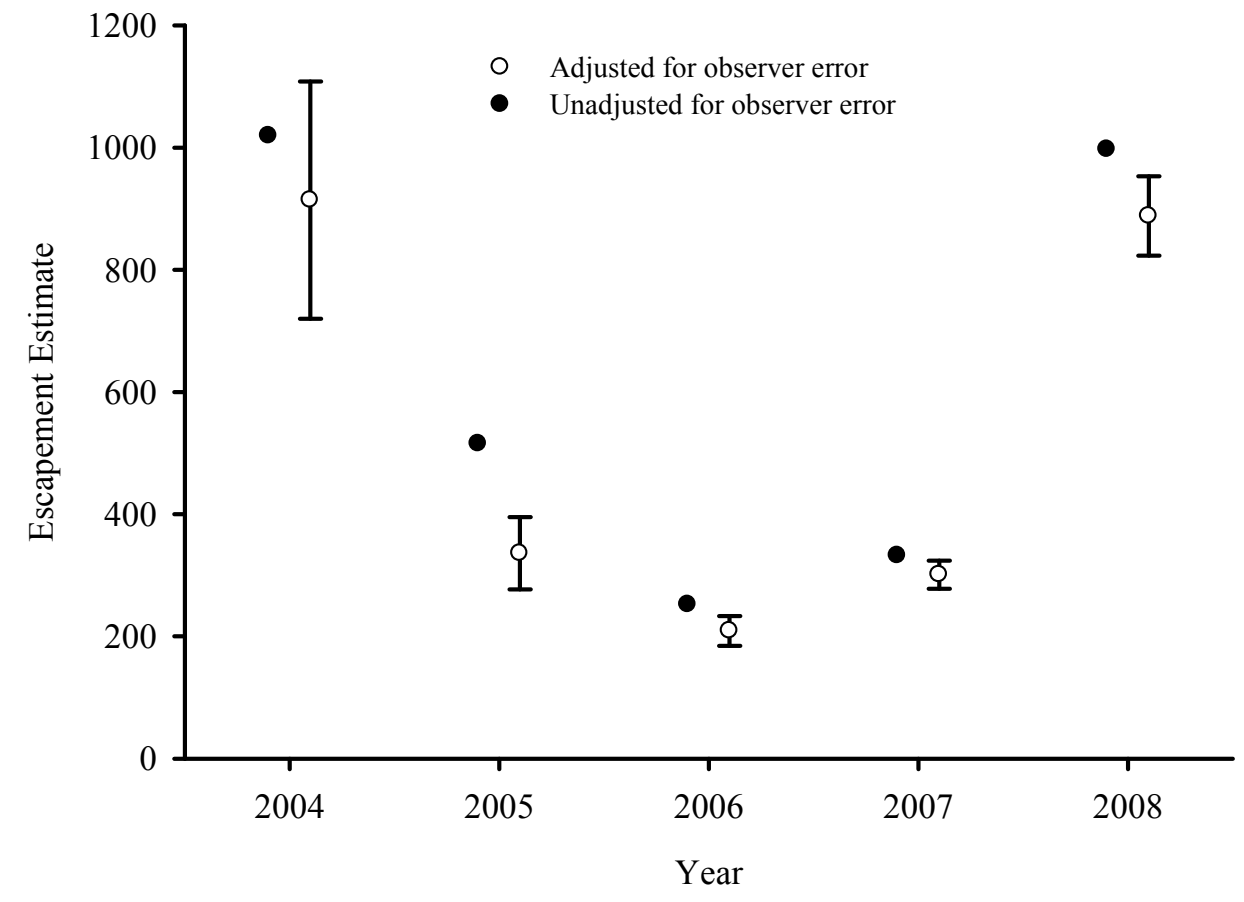

Figure 11. Comparison of DIDSON adult salmon escapement estimates adjusted for observer error ( $\pm 95 \%$ confidence intervals) and unadjusted for observor error, in the Secesh River from 2004 to 2008 . 


\section{Potential Sources of Error in DIDSON Escapement Estimates}

All measurable sources of error in DIDSON escapement estimation were identified and corrected for in 2008 (Table 3). It was unlikely that adult salmon passed upstream before DIDSON site installation. The first upstream salmon passage was observed on July 3. Given the general high quality of high frequency DIDSON images, and the validation results, we believe it unlikely that migrating salmon went undetected.

This was the fourth year that original DIDSON files were CSOT processed to motion-only periods of salmon movement to reduce the size of files that had to be manually read. The comparison of salmon passages on original files to passages on CSOT processed files showed that the motion detection feature captured most but not all salmon passages (Appendix Table 1). Of the 15 systematic sample days compared, a total of 681 upstream and 493 downstream passages were present on original files. CSOT processed files captured $100 \%$ of the upstream passages during period one (early season) and period two (late season) (Appendix Table 1). The percentage of downstream moving passages detected by CSOT processed files during period one and two was $94 \%$ and $96.9 \%$. This was the second year that no upstream salmon passages were missed by CSOT processed files during either early season or late season file review. Motion detection efficencies were applied by early season and late season and direction of passage to correct the daily number of observed salmon passages.

Observer error from original DIDSON files was determined for each observer, statistically evaluated between observers, and was applied by direction of salmon movement to adjust daily salmon counts per observer (Appendix Tables 1 and 7). Observer 2 and observer 3 were used for all CSOT processed DIDSON file reading in 2008. The percentage of correctly identified upstream moving salmon targets for these two observers ranged from $99.2 \%$ to $100 \%$ during period one and period two of the migration. The percentage of correctly identified downstream moving salmon targets for observer 2 and observer 3 was $96.5 \%$ to $98.6 \%$ over the two periods of salmon migration. Modeling of the sample size used to calculate observation error (Kucera and Orme 2007) indicated that a reduction in confidence intervals occurred rapidly as sample size increased from $5 \%$ to $15 \%$ of the total observations. The proportional reduction in confidence intervals was minimal as sample size increased from $20 \%$ to $50 \%$ of the total observations. In $2008,22.8 \%$ of the total observations were reviewed to determine observer error. Values used in the modeling suggest that the $22.8 \%$ of total observations used to calculate observer error was sufficiently large. Adjustments for observer error and CSOT processing error amounted to a minus 109 fish correction.

It was necessary to adjust daily salmon passage in 2008 for minor periods of equipment downtime. Fifteen hours of equipment downtime occurred that necessitated adjustment to daily salmon passages. Adjustment for equipment downtime resulted in a plus 20 fish correction.

The potential error from not counting jack salmon that were less than $55 \mathrm{~cm}$ in total length was considered to be small. In 2008, six jack salmon out of 346 total carcass recoveries $(1.7 \%)$ in the Secesh River were less than $55 \mathrm{~cm}$ in total length $(53.5 \mathrm{~cm}$ fork length) (Ryan Kinzer - personal communication). The undercounting error associated with not recording jack salmon less than $55 \mathrm{~cm}$ would represent a small affect on the 2008 salmon escapement estimate. 
The potential for counting bull trout greater than $55 \mathrm{~cm}$ in length as salmon was also considered a small effect. One net upstream bull trout passage of a fish greater than $55 \mathrm{~cm}$ in length was observed at the Lake Creek fish counting station in 2008. Lengths obtained at the underwater video site are considered accurate to $\pm 5 \mathrm{~cm}$.

Table 3. Potential sources of error in DIDSON salmon escapement estimation in the Secesh River in 2008.

Concern

Potential Effect

Fish passages before installation

None

Undetected fish

None

DIDSON CSOT processed file motion error

Corrected

DIDSON file reader specific error

Corrected

Fish passages during equipment downtime

Corrected

Not counting jack salmon less than $55 \mathrm{~cm}$ in length

Small

Counting bull trout greater than $55 \mathrm{~cm}$ in length as salmon

Small

\section{Secesh River Salmon Escapement}

Population scale salmon escapement in the Secesh River (natural origin and hatchery) has ranged from 117 fish in 1998 to 1,438 salmon in 2001 (Figure 12), a difference of over ten fold. The highly variable data set shows no clear overall trend over the 11 year period. However, two small trends appear evident in the data. First, salmon escapement increased from the 1998 to 2001 time frame mentioned above. The highest salmon escapement observed in 2001 occurred during a drought year. Secondly, escapement declined from 2001 (1,438 fish) through 2006 when 212 salmon were estimated in the population. A substantial increase in escapement has occurred from 2007 to 2008, from 307 fish to 912 salmon, respectively. Whether this mini-trend continues, only future years' information will determine.

Natural origin salmon escapement and spawner abundance (wild fish only) were evaluated via linear regression to examine the relationship between these performance measures (Figure 13). Using years as samples, escapement and spawner abundance were significantly related $(\mathrm{F}=$ $80,882, \mathrm{p}<0.0001)$, although only five data points were available in the analysis. This result was not unexpected as only hatchery fraction and prespawning mortality are the main difference between the two variables (i.e. - no appreciable harvest, hatchery composition, brood removal). Estimates of prespawning mortality in the Secesh River are considered to be minimum values. 


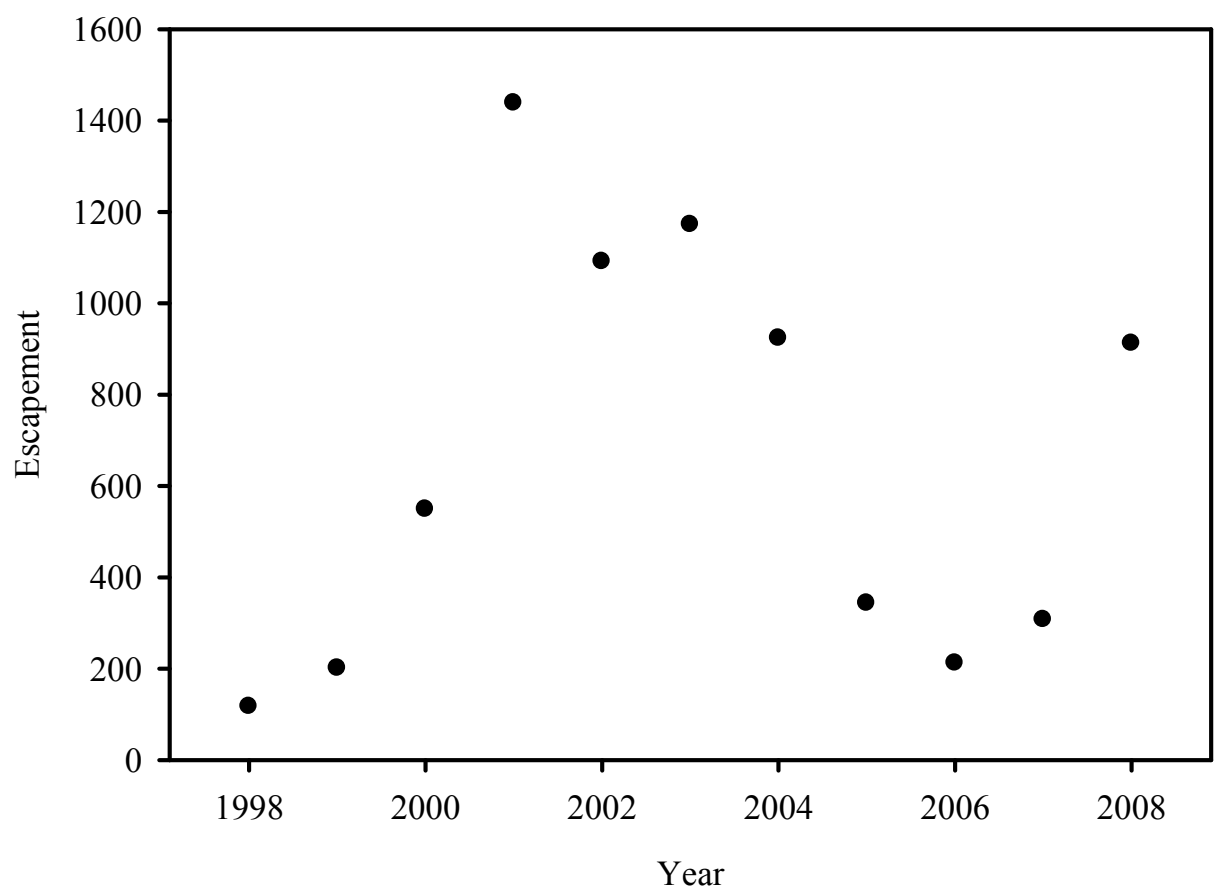

Figure 12. Population scale salmon escapement in the Secesh River (natural origin and hatchery) from 1998 to 2008.

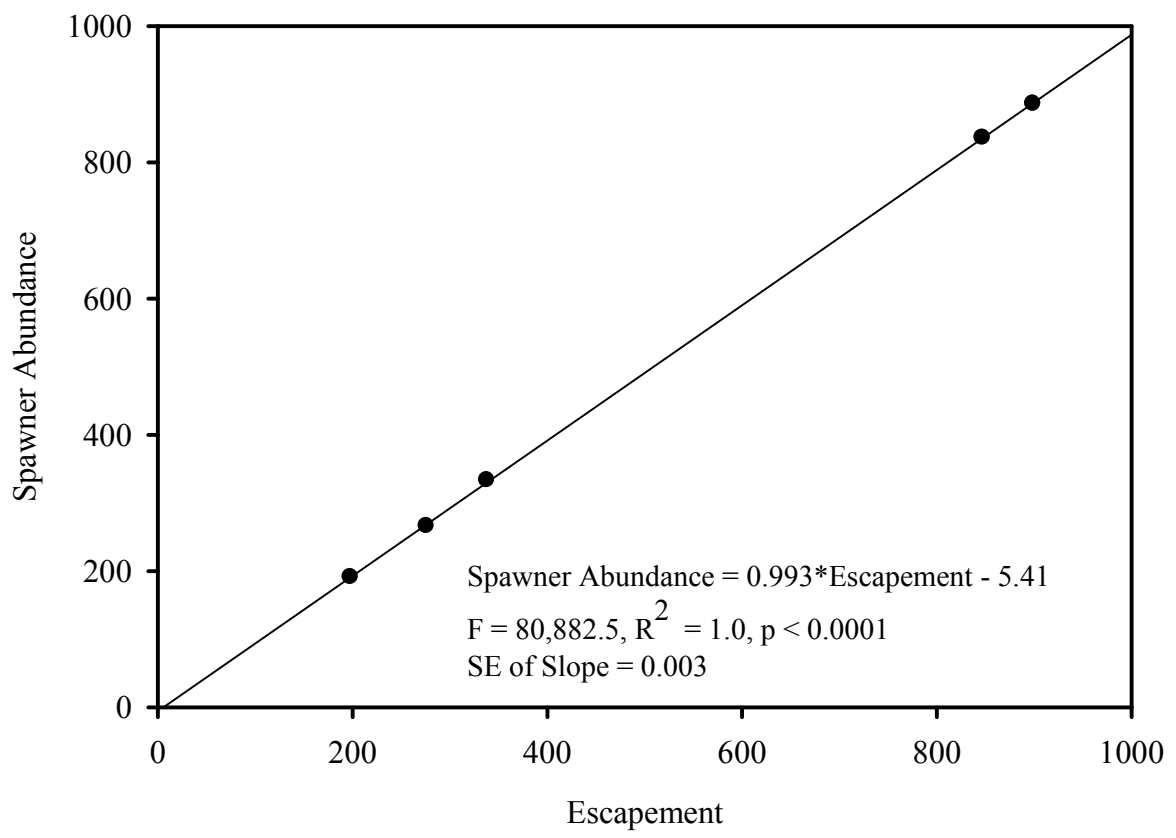

Figure 13. Linear regression between natural origin salmon escapement and spawner abundance in the Secesh River from 2004 to 2008. 
Productivity Analysis

Calculation of progeny-per-parent ratios (adult:adult ratios) relies on annual run reconstructions and will use two variants of parents; estimated escapement and spawner abundance (Hesse et al. 2006). DIDSON salmon escapement monitoring in the Secesh River began in 2004. Estimated salmon escapement (wild and hatchery fish) in 2004 was 923 fish. The estimated spawner abundance in 2004 was 886 salmon. The 2004 parent brood year would return adult progeny in 2007 (jacks), 2008 (four year olds), 2009 (five year olds), and 2010 (six year olds if any). Age assignment of adult returns from carcass recoveries in 2007 and 2008 is currently pending laboratory analysis (Jerry Lockhart - personal communication).

\section{Migration Timing and Diel Movement Patterns}

Adult salmon migration timing in the Secesh River occurred over a 74 day period from July 3 to September 14 in 2008 (Figure 14, Appendix Table 7). A total of 5,262 salmon passages were observed at the DIDSON monitoring site (unadjusted data). Adult salmon migrated on the descending limb of the spring hydrograph and moved past the monitoring site 11 days after the observed peak spring runoff date which occurred on June 22 (Figure 14). Linear regressions indicated daily net upstream salmon passage was significantly related to day of the year $(\mathrm{n}=74$, F statistic $=34.07, p$-value $\left.=<0.0001, \mathrm{r}^{2}=0.32\right)$ and daily staff gage level $(\mathrm{n}=74, \mathrm{~F}$ statistic $=$ $18.98, \mathrm{p}<0.0001, \mathrm{r}^{2}=0.21$ ) (Figure 14). Staff gage data was not available prior to June 6 , and it was believed that higher staff gage levels may have occurred before this date; staff gage was used as a surrogate for stream discharge. Salmon arrival timing occurred at an average daily water temperature of $11.2^{\circ} \mathrm{C}$, as water temperatures were increasing. Daily net upstream salmon passage was significantly related to average daily water temperature (linear regression, $\mathrm{n}=74, \mathrm{~F}$ statistic $=8.58, \mathrm{p}<0.004, \mathrm{r}^{2}=0.11$ ) and minimum daily water temperature (linear regression, $\mathrm{n}$ $=74$, F statistic $\left.=12.35, \mathrm{p}<0.0008, \mathrm{r}^{2}=0.15\right)$ (Figure 15). Salmon spawning in the Secesh River was estimated to have begun before August 13 as a number of redds were observed on that date (Jerry Lockhart - personal communication). Mean daily water temperatures ranged from $7.8^{\circ} \mathrm{C}$ to $14.8^{\circ} \mathrm{C}$ during spawning; maximum daily water temperatures ranged from $9.7^{\circ} \mathrm{C}$ to $18.4^{\circ} \mathrm{C}$. Numerous authors have reported on the preferred spawning temperatures of Chinook salmon (Bell 1986, Reiser and Bjornn 1979, Bjornn and Reiser 1991, Raleigh et al. 1986, McCullough 1999, Chambers 1956 as cited by Raleigh et al. 1986). Spring Chinook salmon normally spawn as water temperatures decline from $12.8^{\circ} \mathrm{C}$ to $4.5^{\circ} \mathrm{C}$. McCullough (1999) reported that it appears that temperatures greater than $12.8^{\circ} \mathrm{C}$ can be assumed to begin inhibiting spawning. Water temperatures are important because females exposed to temperatures above $13.3^{\circ} \mathrm{C}$ to $15.6^{\circ} \mathrm{C}$ may experience elevated prespawning mortality and the survival of eggs to the eyed stage decreases (McCullough 1999). This in turn has the potential to affect population productivity which is an objective of this study.

At the population level, Secesh River salmon arrival timing was summarized by the percent of the spawning run observed by date (Appendix Table 5). The salmon spawning migration had $10 \%$, median, and $90 \%$ net upstream passage dates in 2008 of July 8, July 16, and August 12, respectively. An estimated $90 \%$ of the population had migrated into the Secesh River by the estimated date of first spawning (August 13). 


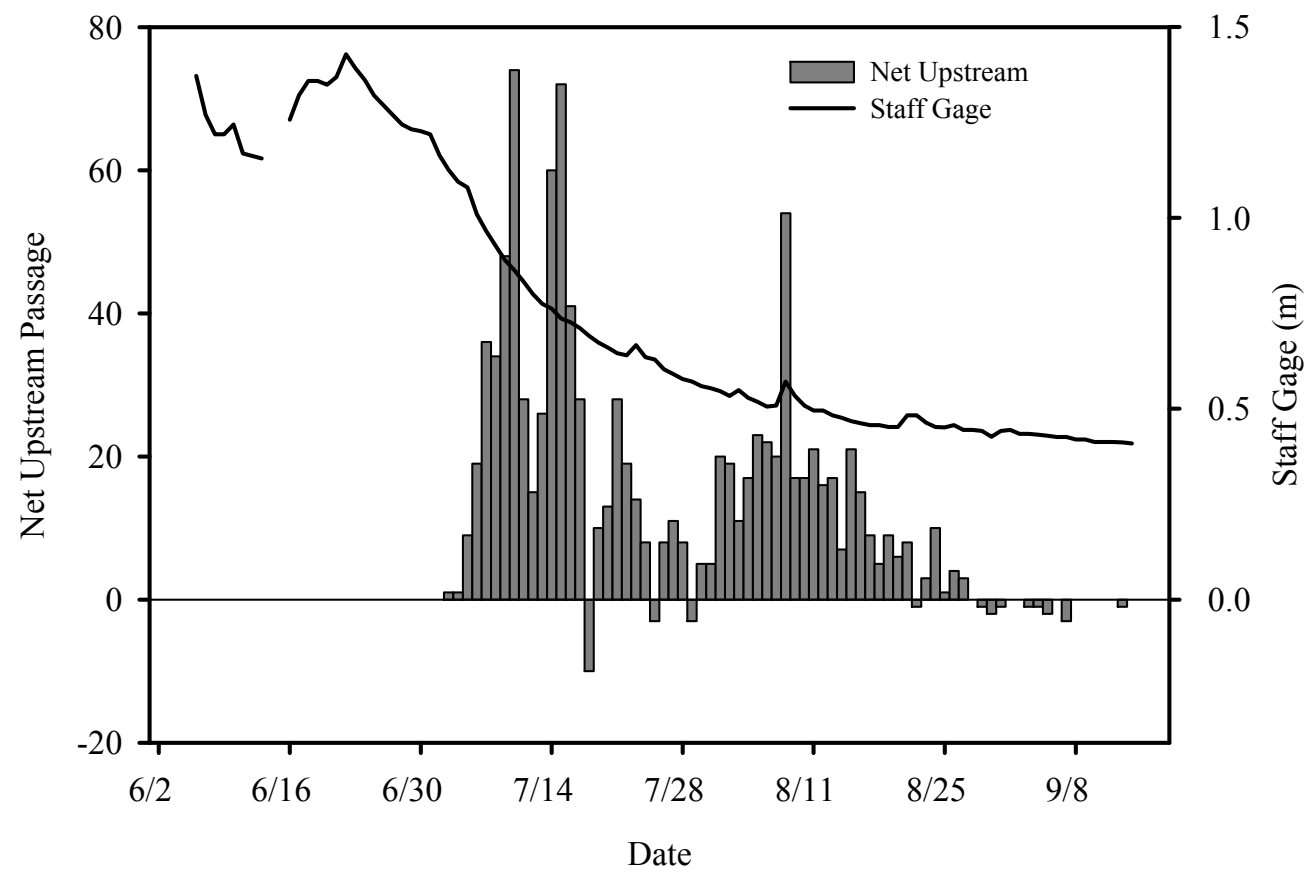

Figure 14. Staff gage versus net upstream salmon migration in the Secesh River in 2008 (unadjusted data).

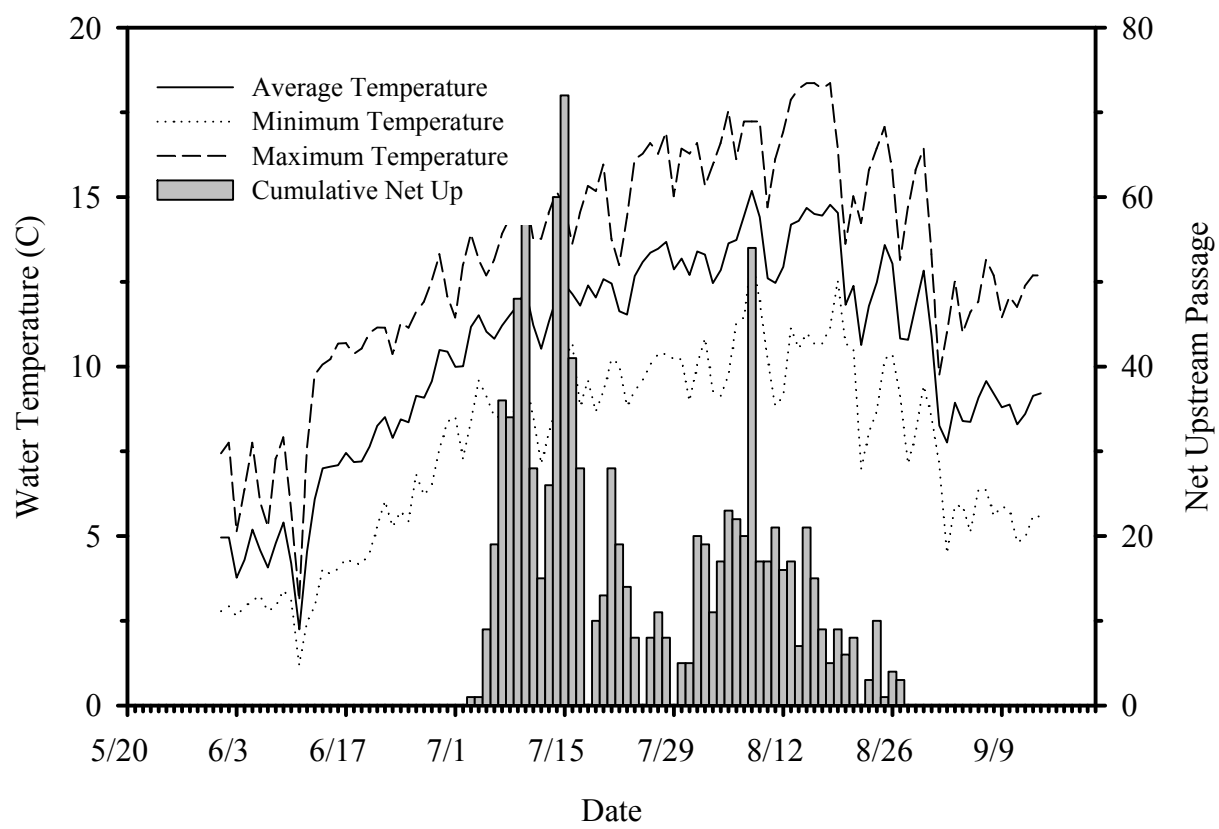

Figure 15. Average, minimum, and maximum daily water temperature versus daily net upstream salmon passage in the Secesh River in 2008 (unadjusted data). 
The DIDSON 1 monitoring site was located within adult salmon holding/staging habitat. Salmon passage was very different during the early season (first segment of the run) versus late season or second segment of the run (Figure 16). During the early season salmon actively migrated upstream and there were 1.7 total passages, upstream and downstream movements, for every one net upstream passage. The late season salmon migration exhibited much more total movement with 10.4 total passages for every one net upstream passage. For example, on July 27 295 total salmon passages were observed, with a net upstream passage of 11 fish. The 295 salmon was the largest total number of fish passages observed during any 24 hour period in 2008. The date of largest net upstream salmon passage occurred on July 10 when 74 fish migrated upstream past the monitoring site. At the end of the spawning season an estimated 16 salmon moved downstream past the DIDSON monitoring site. If these fish images were actually male salmon, and not bull trout, the estimated age structure from carcass recoveries would underestimate the number and proportion of males in the spawning population.

The salmon migration period was stratified into two distinct time segments based on the number of net upstream passages relative to the number of total passages observed. The early season salmon migration (July 3 through July 22) consisted of 956 total observed passages (754 upstream and 202 downstream) with an observed net upstream passage of 552 salmon, or 27.6 salmon per day (20 days) (unadjusted data). Early season migrating salmon comprised 57.1\% (552) of the total observed net upstream passages for the entire season. During the late season salmon migration (July 23 through September 14), 4,306 passages were observed (2,360 upstream and 1,946 downstream) with an observed net upstream passage of 414 salmon, or 7.7

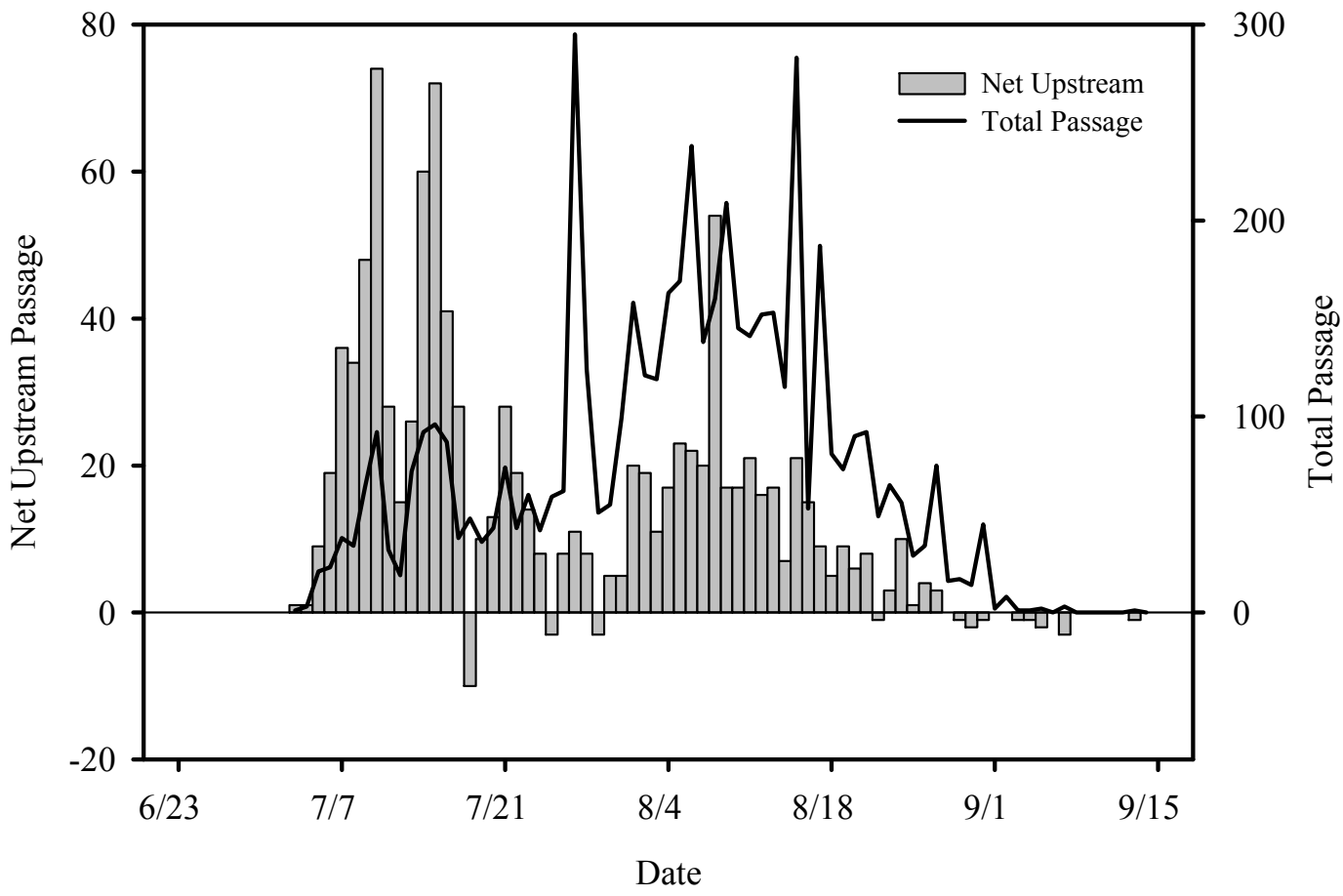

Figure 16. Net upstream and total passages of adult salmon migrating past the DIDSON monitoring site in the Secesh River in 2008 (unadjusted data). 
salmon per day (54 days) (unadjusted data). The late season migration contained $42.9 \%$ (414) of the total observed net upstream passages for the season. The mean net upstream passage per day observed for the first segment (27.6 salmon/day) was significantly different (two tailed $\mathrm{t}$ test, $\mathrm{t}=$ 3.7646, $\mathrm{P}<0.001)$ than the second segment $(7.7$ salmon/day).

Diel migration patterns were evaluated between the early season and late season total observed salmon passages (Figure 17). No significant difference in diel passage distribution was observed between early season versus late season migrating salmon (Kolmogorov-Smirnov test, $\mathrm{p}=$ 0.085). However, a larger percentage of early season migrating salmon moved between the hours of 1900 to $0000(39.5 \%)$ than did late season fish (20\%). In general, more late season migrating salmon moved during the daytime hours of 0600 to $1800(61.4 \%)$ than did their early season counterparts $(43 \%)$ (Figure 17$)$.

The significant difference between the mean net upstream salmon passage rate, and a substantial difference in diel passage rates, seemed to indicate distinct behavioral differences between early season and late season migrating fish. During the early season migration, salmon move upstream with little downstream movement (Figure 16). These salmon may consist of fish heading to headwater spawning areas. The monitoring site was located within a long, deep run (approximately 100 meters long and 1 meter deep) with relatively slow water velocity bracketed by much higher velocity areas at each end. The long run and relative deep depth appeared to provide a salmon holding/staging area where fish could hold with little expenditure of energy. During the late season salmon run, fish appear to stage at the monitoring site and engage in prespawning behavior requiring more upstream and downstream movement such as mate selection, posturing, and chasing between males. In addition, the high number of passages observed is likely due to the proximity of the monitoring site to spawning locations. Although the vast majority of spawning is several kilometers upstream, some spawning is observed as close as 50 meters upstream of the monitoring site. 


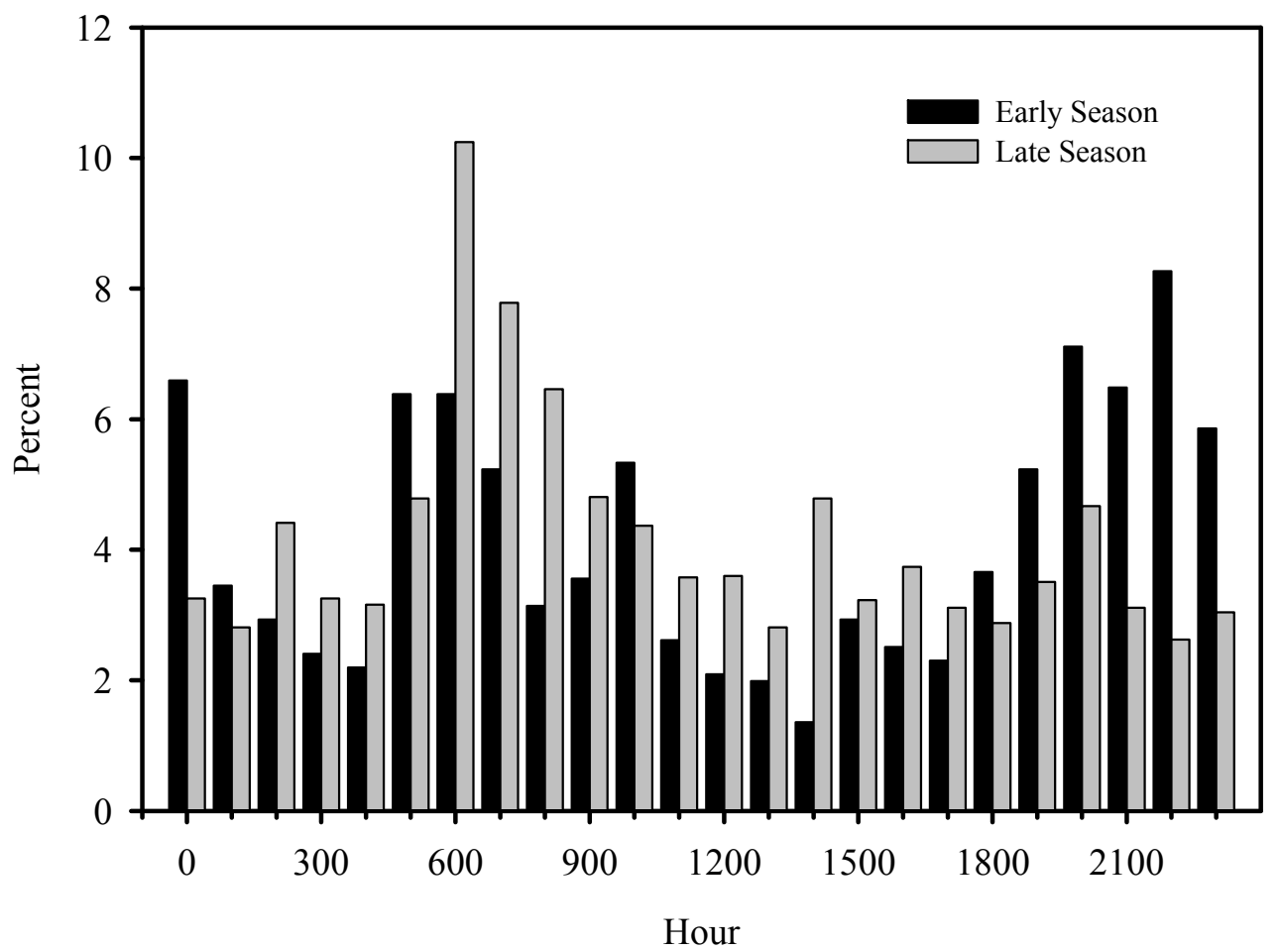

Figure 17. Percent of total observed salmon passages by hour for the early season (July 3 to July 22) and late season (July 23 to September 14) salmon migration in the Secesh River in 2008.

\section{Validation Monitoring}

DIDSON files allowed collection of high quality two dimensional fish images that could be measured by computer software to allow counts of fish greater than $55 \mathrm{~cm}$ in length as salmon. There was a concern that mixed species composition with bull trout could result in erroneous counts of larger bull trout $\geq 55 \mathrm{~cm}$ as salmon. To address this question, three underwater optical cameras were used as the independent method for validation (species identification) of DIDSON target counts in 2008. Optical cameras are the standard validation approach used for hydroacoustics (Gregory et al. 2001, Gough and Gregory 1997), resistivity counters (Smith et al.1996, McCubbing et al. 2000), and electronic counters (Shardlow 1998). Validation occurred in a five foot validation zone in the main stream channel during daytime and nightime periods.

The 2008 salmon migration timing (Figure 18) is portrayed by all of the vertical bars combined. The dark black vertical bars represent the period validated by optical cameras. The first adult salmon passage was observed on July 3, and validation began on July 30. High stream flow precluded installation of optical cameras prior to July 30, and validation results are available for the month of August only. A stratified random sample of 13 days was selected to compare DIDSON target counts that were $\geq 55 \mathrm{~cm}$ in length with optical camera identified salmon (Table 4). According to the DIDSON target length criteria, a total of 860 optical camera recorded salmon passages (478 upstream, 382 downstream) were observed in the validation zone. Optical camera recorded salmon passages represented $15.3 \%$ (478) of the total observed DIDSON 
upstream passages, and 17.8\% (382) of the total observed DIDSON downstream passages. Validation was examined by direction of passage to determine whether consistent bias was apparent in the data. Validation monitoring of upstream passages, between DIDSON and optical cameras, was identical during the 13 days evaluated (Table 4). DIDSON counted 478 out of a possible 478 optical camera identified upstream salmon passages for a $0 \%$ error. DIDSON recorded 382 out of a possible 382 optical camera identified downstream salmon passages, again resulting in a $0 \%$ error (Table 4 ). Because the data was identical (i.e. - no variation) a paired ttest was not performed. Daily salmon passage data was not adjusted for species identification concerns. In addition, optical cameras identified eight salmon passages ( 3 upstream, 5 downstream) that were $\leq 55 \mathrm{~cm}$ in length that DIDSON observed but did not record as salmon due to the $55 \mathrm{~cm}$ length criteria. The three missed upstream optical camera salmon passages represented $0.096 \%$ of the total observed DIDSON upstream passages. The five missed downstream optical camera salmon passages represented $0.23 \%$ of the toal observed DIDSON downstream passages. Technically, according to the criteria employed of counting only targets $\geq$ $55 \mathrm{~cm}$ as salmon, DIDSON did not misidentify any targets. However, DIDSON did not correctly count these eight targets as salmon because the lengths were smaller than the $55 \mathrm{~cm}$ criteria.

Validation monitoring results in 2007 provided the first evidence of a species identification concern relative to DIDSON target counts (Kucera 2008). Six large migratory bull trout $\geq 55 \mathrm{~cm}$ were recorded as salmon passages in 2007. Optical camera validation in 2005 and 2006 indicated no misidentified bull trout (Kucera and Orme 2006, Kucera and Orme 2007) recorded as salmon passages. In 2004, during daytime validation only, no large migratory bull trout were recorded as salmon passages. The potential for bias in salmon escapement estimates, due to mixed species composition, indicated the need to continue optical camera validation monitoring in the Secesh River. Validation monitoring should be considered a standard requirement for DIDSON monitoring in other locations. 


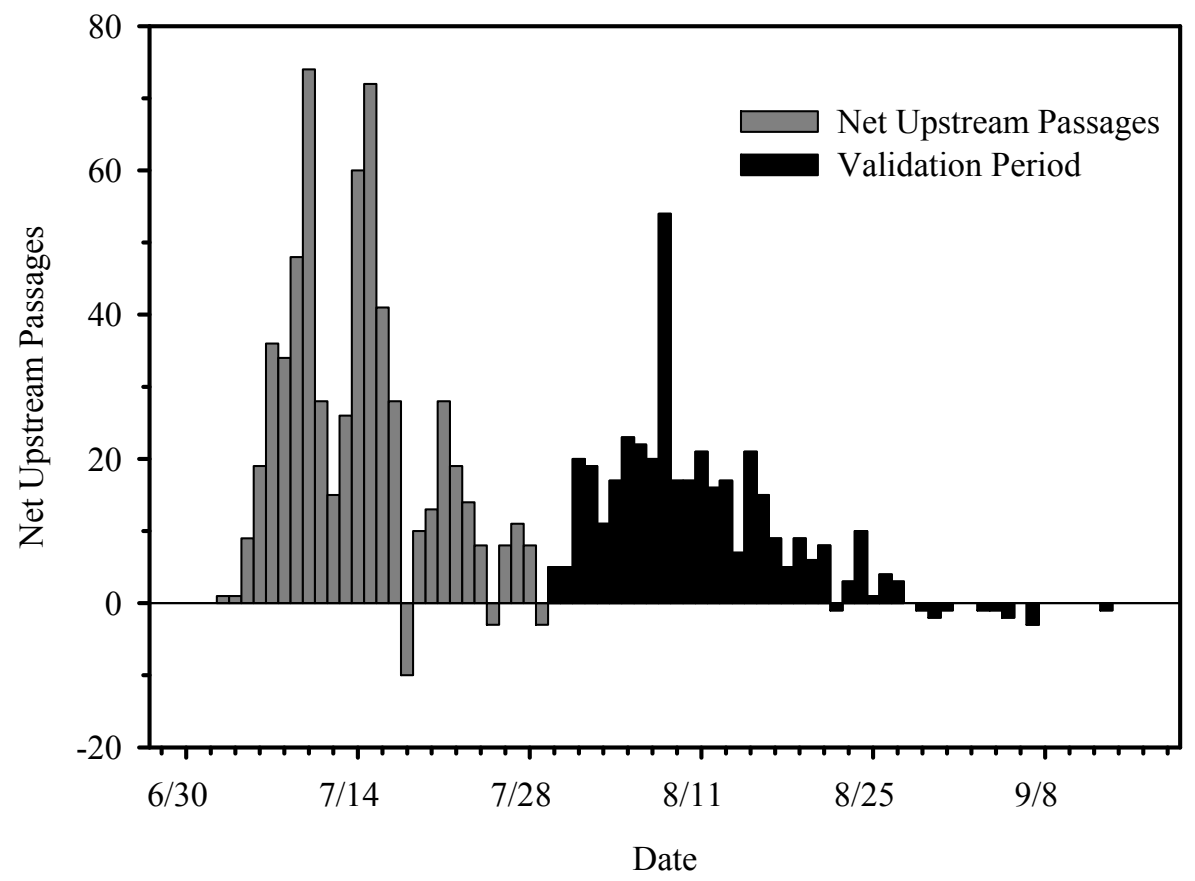

Figure 18. Daily net upstream salmon passages (all vertical bars) and underwater optical camera validation period for species identification (dark black vertical bars) at the DIDSON monitoring site in the Secesh River in 2008.

\section{Validation Monitoring Limitations}

The validation challenge experienced in the Secesh River has been that high stream discharge has precluded installation of underwater optical cameras early enough to validate species identification during the entire salmon spawning migration (Figure 18). Validation has not been able to directly measure the potential magnitude of bias of counting bull trout that are $\geq 55 \mathrm{~cm}$ in length as salmon. In no year has the project been able to validate DIDSON target counts over the entire salmon spawning migration. Concern existed over the potential magnitude of bias of counting larger migratory bull trout $\geq 55 \mathrm{~cm}$ as Chinook salmon.

Watry and Scarnecchia (2005) reported on a radio tagging study of migratory bull trout in the Secesh River. This study identified migratory bull trout spawning in two tributaries in the Lake Creek system; Pete Creek and Threemile Creek. Migratory bull trout would have to move upstream past the DIDSON monitoring site to move into Lake Creek (Figure 1). Downstream post-spawning migrations occurred in late August and mid September with primary overwintering areas, downstream of the DIDSON site, located in Loon Lake, the lower Secesh River, and the lower South Fork Salmon River. Furthermore, Watry and Scarnecchia (2005) reported radio tagging few large migratory bull trout. Only 4 of 45 tagged fish in 2003, and 3 of 26 tagged bull trout in 2004 were $\geq 55 \mathrm{~cm}$ in size. This study reported fork lengths of radio 
Table 4. Validation zone comparison, by direction of fish passage, between DIDSON target counts and optical camera identified salmon passages from 13 stratified random sample days in August in the Secesh River in 2008.

\begin{tabular}{|c|c|c|c|c|c|c|}
\hline \multirow[t]{3}{*}{ Date } & \multicolumn{3}{|c|}{ Upstream Passages } & \multicolumn{3}{|c|}{ Downstream Passages } \\
\hline & \multirow{2}{*}{$\begin{array}{l}\text { DIDSON } \\
\text { Targets }\end{array}$} & \multicolumn{2}{|c|}{ Video } & \multirow{2}{*}{$\begin{array}{l}\text { DIDSON } \\
\text { Targets }\end{array}$} & \multicolumn{2}{|c|}{ Video } \\
\hline & & Chinook & $\begin{array}{l}\text { Bull } \\
\text { Trout }\end{array}$ & & Chinook & $\begin{array}{l}\text { Bull } \\
\text { Trout }\end{array}$ \\
\hline August 3 & 35 & 35 & 0 & 33 & 33 & 0 \\
\hline August 5 & 94 & 94 & 0 & 78 & 78 & 0 \\
\hline August 7 & 55 & 55 & 0 & 29 & 29 & 0 \\
\hline August 10 & 66 & 66 & 0 & 50 & 50 & 0 \\
\hline August 12 & 74 & 74 & 0 & 63 & 63 & 0 \\
\hline August 16 & 29 & 29 & 0 & 17 & 17 & 0 \\
\hline August 18 & 33 & 33 & 0 & 26 & 26 & 0 \\
\hline August 20 & 30 & 30 & 0 & 27 & 27 & 0 \\
\hline August 22 & 20 & 20 & 0 & 17 & 17 & 0 \\
\hline August 26 & 23 & 23 & 0 & 21 & 21 & 0 \\
\hline August 28 & 5 & 5 & 0 & 6 & 6 & 0 \\
\hline August 29 & 7 & 7 & 0 & 7 & 7 & 0 \\
\hline August 31 & 7 & 7 & 0 & 8 & 8 & 0 \\
\hline Total & 478 & 478 & 0 & 382 & 382 & 0 \\
\hline
\end{tabular}

tagged bull trout, which we used to estimate total lengths for comparison to measured DIDSON target lengths.

Relative numbers and size of bull trout $(\geq 35-40 \mathrm{~cm}$ ) migrating into Lake Creek were recorded during underwater video monitoring of adult salmon escapement investigations from 2004 to 2008 (Kucera and Faurot 2005, Kucera and Orme 2006, Kucera and Orme 2007; Jerry Lockhart - personal communication) (Table 5). Since enumeration of bull trout was a secondary study objective, data collected did not encompass the entire migration, and is considered an index of the bull trout run into Lake Creek. Given the results of the Watry and Scarnecchia (2005) radio tagging study it was assumed that migratory bull trout would move upstream past the DIDSON monitoring site and into Lake Creek. The observed bull trout migration into Lake Creek occurred from June 12 to September 11 from 2004 to 2008, and overlapped in time with the salmon migration observed at the DIDSON site. Numbers of bull trout observed in Lake Creek have ranged from 47 fish in 2008 to 141 fish in 2006 (Table 5). The Lake Creek underwater video count station was installed later than normal in 2008 on July 9 and some bull trout probably went undetected. Numbers of larger migratory bull trout $\geq 55 \mathrm{~cm}$ observed in Lake 
Creek have been small, ranging from one fish in 2008 to 13 fish in 2007. The number of larger bull trout appeared to increase from 2005 to 2007 (Table 5).

Given the available information it appears that there is a relatively small migratory run of bull trout in Lake Creek with few large individuals $\geq 55 \mathrm{~cm}$ in the run. The potential magnitude of bias of counting bull trout that are $\geq 55 \mathrm{~cm}$ in length as salmon is considered small. This assumption will be further evaluated in 2009 through installation of optical cameras after ice-out to validate early season salmon migration at the DIDSON site. No discernible pulses in downstream passage were observed early in the salmon migration period (Figure 14) that may have been downstream moving adult steelhead.

Table 5. DIDSON salmon escapement estimate compared to the relative number of bull trout and bull trout $\geq 55 \mathrm{~cm}$ in length observed at the Lake Creek underwater video count station from 2004 to 2008.

\begin{tabular}{cccc}
\hline Year & $\begin{array}{l}\text { DIDSON } \\
\text { Escapement } \\
\text { Estimate }\end{array}$ & $\begin{array}{l}\text { Number of } \\
\text { Bull Trout } \\
\text { (Lake Creek) }\end{array}$ & $\begin{array}{l}\text { Number of } \\
\text { Bull Trout } \\
\geq 55 \mathrm{~cm} \\
\text { (Lake Creek) }\end{array}$ \\
\hline 2004 & 914 & 126 & 5 \\
2005 & 336 & 112 & 3 \\
2006 & 209 & 141 & 7 \\
2007 & 301 & 108 & 13 \\
2008 & 888 & 47 & 1 \\
& & & \\
\hline
\end{tabular}

Precision Analysis

Precision of the DIDSON technology to record salmon targets was evaluated in two ways: 1) by operating two sonar units in the Secesh River and comparing escapement estimates and associated confidence intervals, and 2) by comparing total stream escapement estimates between the DIDSON sonar unit and an underwater video fish counting station in 2004.

Salmon escapement and 95\% confidence intervals for the five continuous days of DIDSON operation in 2008 was 145.7 fish $( \pm 2.3)$ for DIDSON 1, and 150.5 fish $( \pm 5.0)$ for DIDSON 2 (Table 6). The 95\% confidence intervals around the escapement estimates overlapped one another, suggesting that the escapement estimates were not significantly different. Review of DIDSON 1 upstream and downstream passages revealed a $6.7 \%$ downstream observation error occurred during original file review. Sample size for determination of DIDSON 1 downstream observer error was small $(n=15)$, with the sample size for upstream error was considered to be 
adequate $(n=109)$. A review of DIDSON 2 passages indicated a $2.6 \%$ observer error rate in upstream passages during original file review. Sample sizes for quantification of DIDSON 2 downstream error was small $(\mathrm{n}=20)$, with 115 upstream passages available during file review. Observed error rates were used to adjust both DIDSON 1 and DIDSON 2 escapement estimates. The precision analysis in 2008 occurred during the early portion of the salmon migration when predominantly upstream-only moving salmon were observed (i.e. - very few downstream movements).

Precision comparisons between DIDSON 1 and DIDSON 2 sonar units conducted from 2005 through 2008 have been very consistent. Escapement estimates and associated $95 \%$ confidence intervals have overlapped each other in 2005, 2007, and 2008 indicating the escapement estimates are not significantly different between the two sonar units. In 2006, the lack of overlap in the $95 \%$ confidence intervals suggested a significant difference between the escapement estimates. However, the difference observed in escapement estimates between DIDSON 1 and DIDSON 2 monitoring sites in 2006 (14.3\%) was due to observer error (Kucera and Orme 2007). The actual number of net upstream passages after reviewing discrepancies in reader counts was 21 salmon for DIDSON 1 and DIDSON 2 (Table 6).

Although the estimated escapement between DIDSON units was slightly different during the 2005 to 2007 evaluation, the actual number of passages between sites was identical (Table 6). Reading all original DIDSON files in 2008 to record actual passages was not repeated. The ability to record the same number of net upstream passages indicates that the methods used to deploy, aim, and record passages are sound.

In 2004, the DIDSON salmon escapement estimate was compared to an underwater video fish counting station escapement estimate over a 51 day period. The underwater video fish counting station was located approximately $100 \mathrm{~m}$ upstream of the DIDSON monitoring site and was identical to the description of the Lake Creek fish counting station (Kucera and Orme 2007). A linear regression indicated that the net upstream escapement at the fish counting station and at the DIDSON monitoring site were nearly identical (slope $=1.01$ ), after correcting DIDSON daily salmon passages for directional observer error, and were highly correlated $\left(\mathrm{R}^{2}=0.998\right)$ (Kucera and Faurot 2005). There was one caveat to this escapement comparison. DIDSON estimated daily salmon passages were adjusted for observer error and underwater video salmon passages were not adjusted for observer error. However, in nine years of operating the Lake Creek underwater video weir for salmon escapement monitoring (Kucera and Orme 2007), video observer error rates are typically low averaging 1-2\%. We do not believe that adjusting for the video observer error would have dramatically changed the results of the linear regression described above. Two chinook salmon redds were observed between the two sampling sites.

The results suggest that the DIDSON technology can be used to generate accurate and precise estimates of salmon escapement if appropriate methodologies are used. 
Table 6. Comparison of total viewer salmon passage observations, estimated net upstream salmon passages ( $\pm 95 \%$ confidence interval), and actual net upstream salmon passages used in DIDSON precision analysis in 2005, 2006, 2007, and 2008.

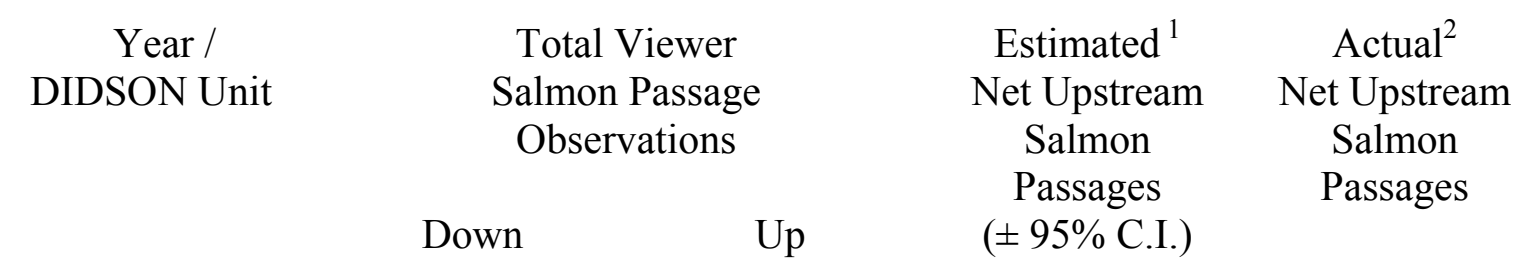

\section{8}

DIDSON 1

DIDSON 2

18

23

7

5

78

24

102

45

165
169

52

49

$145.7( \pm 2.3)$

$150.5( \pm 5)$

NA

NA

2006

DIDSON 1

DIDSON 2

2005

DIDSON 1

DIDSON 2

121

76
132

87
$45( \pm 0)$

$45( \pm 1.9)$

$24( \pm 0)$

$21( \pm 0)$

21

21

45

45

$9.6( \pm 4.8)$

10

$9.5( \pm 2.9)$

10

\footnotetext{
1 - Passages estimated by applying estimated reader specific error.

2 - Actual number of net upstream passages from original DIDSON file counts.
}

\section{DIDSON Operations}

This section reports standard DIDSON operations from 2004 to 2008 that demonstrate consistency and comparability in the data collected in the Secesh River. The following discussion presents information on DIDSON unit transect location, frames per second DIDSON data was collected at, percent of the salmon migration DIDSON was operational, whether validation and precision analysis occurred, and what sonar unit was deployed for salmon escapement data collection over the five year period. Specific data related to these topics can be found in subsections within this report and in previous year's annual reports (Kucera and Faurot 2005, Kucera and Orme 2006, Kucera and Orme 2007, and Kucera 2008). In addition, 2008 results related to data management and processing, observer error, CSOT error and downtime error related to escapement estimation, DIDSON target re-review, and validation monitoring are presented, as are known length carcass trials. 
The DIDSON transect location (monitoring site) was sited at the same location over the five year period with one minor exception in 2006 (Table 7, Figure 3 - bottom photo). In 2006 the DIDSON unit was installed and operated on the stream bottom one meter from the upstream edge of the artificial substrate shown in Figure 3 (Kucera and Orme 2007). This occurred because the artificial substrate was damaged during spring runoff in 2006. DIDSON transect location was the same in 2004, 2005, 2007, and 2008, with the sonar unit attached to the artificial substrate (Figure 3) for data collection. Standardized location of the DIDSON monitoring site is important because different sites may affect salmon behavior, passage rates, and error rates associated with escapement estimation.

High frequency DIDSON files were recorded at seven frames per second from 2004 through 2006, and six frames per second in 2007 and 2008 (Table 7). These frame rates were adequate to identify, count, and measure fish targets moving through the ensonified zone during the study period. Frame rates were reduced to six frames per second in 2007 because that was sufficient to identify salmon targets while reducing overall daily sonar file size.

A measure of the reliability of DIDSON technology is the percent of time the sonar unit was operational during the salmon migration period. The DIDSON unit was operational from $84 \%$ of the salmon migration period in 2007 to $98.1 \%$ of the time in 2008 (Table 7). Sonar was generally very reliable with the topside box and DC power supply used, other than forest fire related downtime at the monitoring site in 2007. Small periods of random downtime were experienced every year and appeared to be related to either fluctuation in power supply, laptop software interaction, or temperature inside the topside box.

Table 7. DIDSON transect location, frame rate data was recorded at, percent of time unit was operational, whether validation and precision occurred, and sonar unit used in the Secesh River from 2004 to 2008.

\begin{tabular}{|c|c|c|c|c|c|c|}
\hline Year & $\begin{array}{l}\text { DIDSON } \\
\text { Transect } \\
\text { Location }\end{array}$ & $\begin{array}{l}\text { DIDSON } \\
\text { Recording } \\
\text { (frames/sec) }\end{array}$ & $\begin{array}{l}\text { DIDSON } \\
\text { Operational } \\
\quad(\%)\end{array}$ & Validation & Precision & $\begin{array}{c}\text { DIDSON } \\
\text { Unit } \\
(\#)\end{array}$ \\
\hline 2004 & Same & 7 & 92.7 & $\mathrm{Yes}^{3}$ & $\mathrm{Yes}^{4}$ & 111 \\
\hline 2005 & Same & 7 & 96.5 & Yes & Yes & 111 \\
\hline 2006 & Same $^{1}$ & 7 & 97.5 & Yes & Yes & 111 \\
\hline 2007 & Same & 6 & $84.0^{2}$ & Yes & Yes & 25 \\
\hline 2008 & Same & 6 & 98.1 & Yes & Yes & 111 \\
\hline \multicolumn{7}{|c|}{$\begin{array}{l}\text { - Artificial substrate was damaged and DIDSON was operated one meter upstream of } \\
\text { the substrate. } \\
2 \text { - Forest fire caused downtime. } \\
3 \text { - Validation occurred during daytime only in August. } \\
\text { - Precision evaluated with underwater video daily salmon passages and DIDSON daily } \\
\text { target counts. }\end{array}$} \\
\hline
\end{tabular}


Validation of DIDSON target counts with underwater video optical cameras for species identification occurred annually (Table 7). Use of optical cameras served two purposes. First, optical cameras provided certainty that DIDSON targets were actually salmon. Secondly, optical cameras provided species identification of the DIDSON target counts that ensured evaluation of a potential mixed species composition with migratory bull trout. During the project start-up year (2004) underwater video was operated during daytime periods only, during the month of August, with multiplexed video recorded at 4.5 frames per second. Validation monitoring from 2005 through 2008 occurred with a stratified random sampling design in place, with daytime and nighttime sampling, and multiplexed video recorded at eight frames per second. High stream discharge early in the season precluded optical camera installation, and data was recorded from 3:00 p.m. in the afternoon to approximately 9:00 a.m. the following morning. In 2007, forest fires constrained access to the monitoring site and validation monitoring occurred from about 10:30 a.m. to 5:30 a.m. the following day. In no year was validation able to cover the entire salmon spawning migration because of early season high stream discharge. Optical cameras would have to be installed after ice-out, prior to early season elevated flows, and withstand debris and turbidity to attempt validation of the entire salmon migration. This validation approach will be tested in 2009.

The precision of the DIDSON sonar to record salmon targets and the subsequent methodology to estimate salmon escapement was evaluated in two ways (Table 7). In 2004, daily net upstream salmon passages were compared (linear regression) between an underwater video count station and DIDSON target counts over a 51 day period (Kucera and Faurot 2005). The underwater video count station was located approximately $100 \mathrm{~m}$ upstream of the DIDSON monitoring site. From 2005 through 2008 two DIDSON sonar units, located $12 \mathrm{~m}$ apart, were operated over a block of days and escapement with $95 \%$ confidence intervals was compared. The precision analysis included a mix of late season migrating samon (2005 and 2006) and early season moving fish in 2007 and 2008. Blocks of days were used because the monitoring sites were located in adult salmon holding areas and fish would hold in between the sonar unit locations thus biasing the net upstream count comparison. This fish behavior at the monitoring site also invalidated a random day sampling design for precision comparisons.

High frequency DIDSON files were collected with two sonar units over the study period (Table 7). DIDSON sonar unit 111 was used in 2004 through 2006 and in 2008. DIDSON sonar unit 25 was used for data collection in 2007. Sonar unit 111 was selected for data collection because it was the newer of the two units and had been tested with known length salmon carcasses with reasonable accuracy. Sonar unit 25 was inadvertently installed in 2007 for data collection. Sonar unit 25 was an older version DIDSON unit which contained outdated internal equipment (backplane assembly, analog to digital board, wiring) which caused an $11 \%$ positive bias in DIDSON target lengths (Bill Hanot, Sound Metrics - personal communication). Subsequently, the 2007 daily salmon passage data required adjustment to all measured lengths for the $11 \%$ positive length bias, and recalculation of the escapement estimate. In addition, sonar unit \#25 was found to contain a degraded front sonar lens in the fall of 2008 that had to be replaced. The effect of the degraded sonar lens in 2007 DIDSON operations was not quantifiable and would be range dependent depending on the focus (Bill Hanot, Sound Metrics - personal communication). 
Data management and data processing continues to be a manageable challenge for the project. High frequency DIDSON files collected approximately $25 \mathrm{gb}$ of data each day at six frames per second. Data were stored on external $400 \mathrm{gb}$ Iomega hard drives. Electronic files were backed up in case external hard drives were damaged, failed, or were stolen. The use of the CSOT file processing software feature reduced early season file size (July 3 to July 22) on average down to of $35.3 \%$ of the original DIDSON file size (64.9\% reduction in size). Early season stream flows were higher in 2008 and created more entrained air bubbles and background noise for file processing. Files processed by the CSOT feature reduced late season file size, July 23 to September 14 , on average down to $21.8 \%$ of the original DIDSON file size $(78.2 \%$ reduction in size). CSOT processing of one day's original DIDSON files usually required two to three hours and was processed overnight. If the CSOT processing parameters remain constant for all files, the "batch" file mode can be used to process files without interruption. If processing parameters remain constant, one week of files could be moved into a single directory and be processed in "batch" mode overnight. The time savings associated with CSOT processing files was partially negated by the fact that a random sample of original DIDSON files had to be read to compare with CSOT processed fish motion-only files. This was conducted to ensure that the computer software correctly identified salmon passages. Lack of automated fish counting software continued to necessitate manual reading of the CSOT processed files. It was necessary for three independent observers to read subsampled fish motion-only files to determine reader specific error. The reader specific error was then applied to the days each individual had read.

Continued improvement in automated salmon counting of DIDSON files will be a high priority, in collaboration with Sound Metrics Corporation.

An evaluation of CSOT processing error in 2008 demonstrated no upstream error during the first or second segment of the salmon migration (Appendix Table 1). Downstream error was larger but not significantly different $(6 \%$ verses $3.1 \%$, $\mathrm{z}$ value $=1.217, \mathrm{P}=0.112)$ during the first segment of the run. The CSOT error was sufficiently different over time which caused us to apply CSOT error to daily salmon observed passages stratified by migration segment and by direction of movement for escapement estimate calculations.

Reader specific error (observation error) occurred during review of original DIDSON files. For original DIDSON files, two of the three observers had similar observation error, with error generally higher for downstream observations (Appendix Table 1). The third observer (observer 1) had more variable upstream and downstream error and the data was used in error comparisons only, not in salmon escapement calculations. Upstream observation error was $0 \%$ to $16.7 \%$ for both the first and second segment of the run. Downstream errors were more variable ranging from $1.4 \%$ to $26.5 \%$ for the first and second segment of the run. The relatively large downstream error (26.5\%) also had a relatively small sample size associated with it $(n=36$ out of a possible $n=49$ observations). Results from observer 1 were significantly different between the first and second segment for upstream passages $(\mathrm{z}$ value $=6.04, \mathrm{p}<0.0000)$ and downstream passages $(\mathrm{z}$ value $=2.56, \mathrm{p}<0.005)$ (Appendix Table 1). No significant difference between the first and second segment of the run, by observer, was found for observer 2 and observer 3 in the upstream or downstream direction. The sample size of upstream passages from which to estimate observer error was reasonable during the first segment of the run and ranged from 156 to 489 passages possible. Sample size for downstream movements during the first segment of 
the run was smaller with 49 to 74 passages possible, with reasonable samples sizes of 323 to 430 possible passages during the second segment of the run.

Observation error for the reviewed CSOT files indicated a significant difference for both of the observers for downstream passages between the first and second segments of the run (Appendix Table 2). Comparisons within observer, by downstream direction, were limited by sample size (Appendix Table 2) during the first segment of the run. A significant difference in upstream passages was also observed for observer 3, between the first and second segment of the run. However, observer 3 missed few passages; only four out of 107 possible in segment 1 and one out of 221 possible during segment two. Sample sizes used to estimate CSOT observer error for the first segment of the run ranged from 83-107 for upstream observation and 31-32 for downstream observations. During the second segment of the run samples sizes were generally higher and ranged from 221-266 for upstream observation and 195-219 for downstream observations (Appendix Table 2).

Comparisons between original and CSOT files were made using all data, not stratified by migration segment. Significant differences were found in two of the four comparisons between CSOT and original files by observer and by direction (Appendix Table 3). Observer 2 accounted for both of the significant differences found in the upstream and downstream direction. Errors for observer 2 ranged from $0.4 \%$ to $3.1 \%$ in the upstream direction and $1.6 \%$ to $3.6 \%$ in the downstream direction, with original file reader error being consistently lower. Of the four comparisons, observation error was greater for CSOT files in three of the four comparisons while observation error was greater for original DIDSON files in one of the four comparisons. Observation error was small for both original file and CSOT file reading, and error ranged from $0.4 \%$ to $3.6 \%$.

Although significant differences were not found in every case, errors were sufficiently different to stratify reader specific error by observer, by direction, and by migration segment. The observation error calculated for the original files reviewed (Appendix Table 1) provided a sufficient sample size from which to calculate error and was used to correct daily salmon passages in escapement estimate calculations. Adjustments to daily salmon passages due to observer error and CSOT file processing error combined amounted to a correction of minus 109 salmon (Table 2).

The DIDSON monitoring site was operational for $98.1 \%$ of the salmon migration (Appendix Table 4). Corrections and adjustments to escapement estimates were made for days that had more than 30 minutes of continuous downtime. Adjustment to daily salmon passages due to equipment downtime amounted to a plus 20 fish in 2008 (Table 2).

A total of 236 DIDSON targets were flagged for end-of-the-season review in 2008. Two observers reviewed all potential fish targets. Fish targets between $52 \mathrm{~cm}$ to $60 \mathrm{~cm}$ were automatically flagged for review to accurately determine length. Length measurement of 169 targets between $52 \mathrm{~cm}$ to $60 \mathrm{~cm}$ was observed in 2008. Of the 169 targets, 30 were originally measured as $\leq 55 \mathrm{~cm}$ and 22 of the 30 targets were confirmed to fall in this non-salmon size category by the observers. A total of 139 targets were originally measured by one or more observers to be greater than $55 \mathrm{~cm}$ up to $60 \mathrm{~cm}$ in length. Upon review, 14 of these targets were 
determined to be less than $55 \mathrm{~cm}$ in length and were not recorded as salmon passages. The remaining 125 fish targets were recorded as salmon passages. The remaining 67 DIDSON targets were reviewed because they were either too close to the sonar unit, contained few acceptable frames to measure, or were questioned as fish targets by the reviewers. Of these 67 targets, 20 were determined not to be salmon and 47 were recorded as salmon passages. Of the original 236 DIDSON targets flagged for re-review, 56 targets (23.7\%) were not recorded as salmon passages.

Underwater optical cameras were used as the independent method to validate DIDSON salmon counts. In 2008, optical cameras were installed on July 30 in a five foot validation zone and images were recorded and used to validate DIDSON target species identification. The installed white vertical background was necessary to backlight and identify fish passages given the dark stream environment (Figure 3 - bottom photo).

Known length salmon carcass trials were conducted in 2008 to examine the accuracy of observers to manually measure target length, collected by high frequency DIDSON files at a $5 \mathrm{~m}$ window length. Sonar unit 111 was used for the comparison. The best length from an individual carcass trial was independently selected and measured by each observer and compared to known length carcasses. A linear regression indicated that manually measured lengths were significantly related to known lengths for both observer 1 and observer 2 at the $p<0.0001$ level (Figure 19). Both observers demonstrated a negative bias in their best length manual carcass measurement. Taking the observer 1 regression equation (Figure 19), observer 1 would measure a $55 \mathrm{~cm}$ true length fish to be $52.08 \mathrm{~cm}$. Results from the observer 2 regression equation indicated observer 2 would measure a $55 \mathrm{~cm}$ true length fish target as a $50.3 \mathrm{~cm}$ fish. Currently, all manually measured sonar lengths $\geq 55 \mathrm{~cm}$ in length are recorded as salmon passages. The negative bias that existed in manual length measurement in these trials, indicate that targets measured in the 50 to $52 \mathrm{~cm}$ range in length need to be recorded as salmon. 

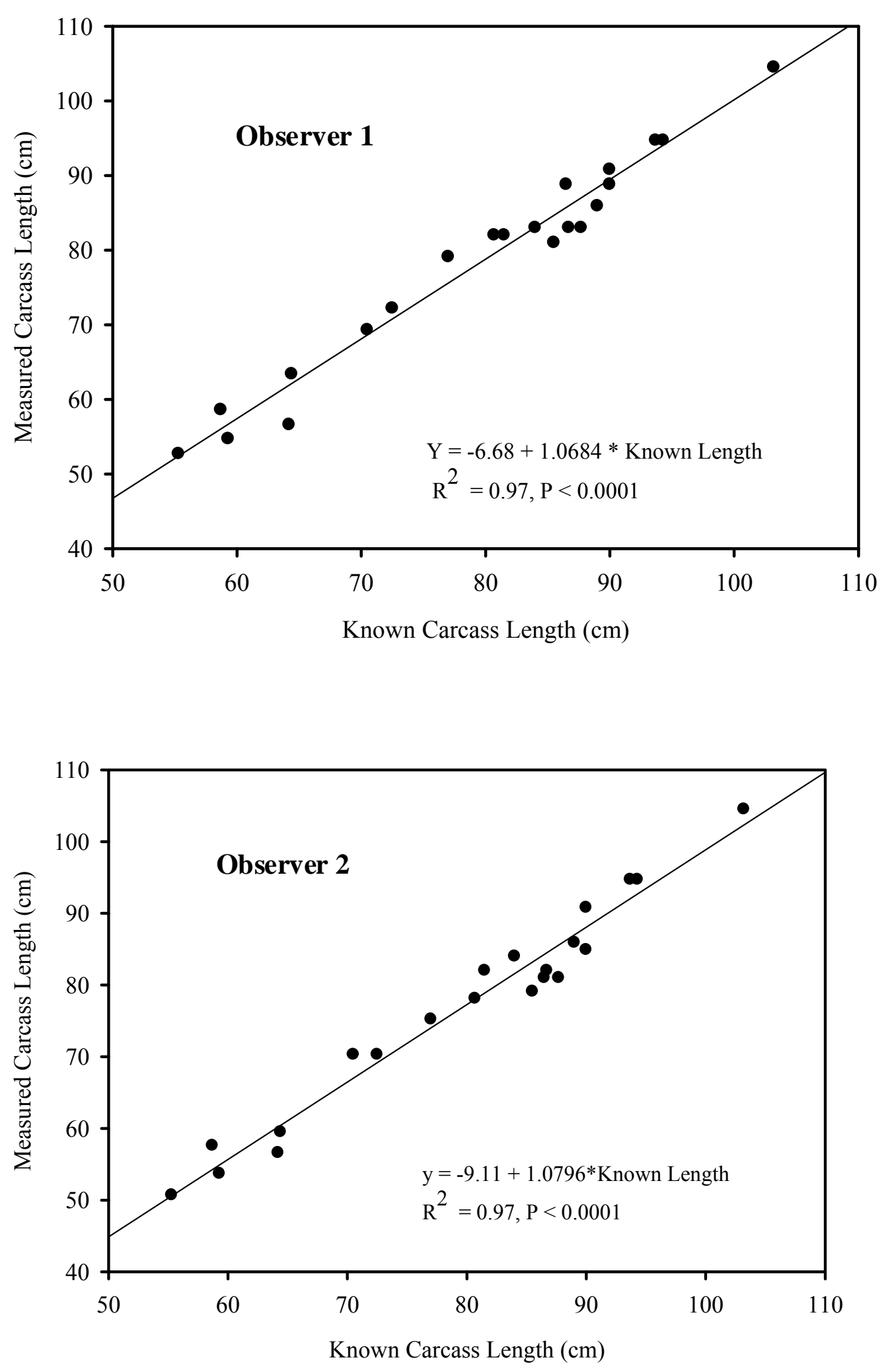

Figure 19. Linear regression between known carcass length and measured carcass length of observer 1 (upper graph) and observer 2 (lower graph) of 21 salmon carcasses in the Secesh River in 2008. 


\section{LISTED CHINOOK SALMON POPULATION STATUS}

The Biological Opinion for operation of the federal Columbia River power system (NMFS 2000) recommended that accurate assessment of spawner escapement of listed ESU's were required for determining the characteristics, viability, recovery status, and delisting of ESU's under the Endangered Species Act. NMFS (2002) further identified interim abundance and productivity targets necessary for delisting. The recovery metric for listed ESU's was the likelihood that the eight year geometric mean abundance of natural spawners would equal or exceed 9,200 spring and summer Chinook salmon in the South Fork Salmon River. Viability criteria for application to interior Columbia Basin salmonid ESU's have been updated and recommended by the Interior Columbia Basin Technical Recovery Team (ICTRT 2007). A minimum adult salmon spawner abundance (viability) threshold of 3,500 fish was recommended by the ICTRT for the South Fork Salmon River major population group (MPG). This included designation of the Secesh River as an intermediate population size category, with a viability level of 750 fish. The ICTRT recommended MPG viability guidelines require that two of the populations in the South Fork Salmon River should exceed viable salmonid population (VSP) guidelines. Specific application to ICTRT proposed criteria also involves productivity and spatial distribution criteria, and geometric mean calculations. The Secesh River is the only remaining natural origin (wild) salmon population in the South Fork Salmon River, and is a logical candidate for measurement of delisting criteria under the ESA to roll up to the larger ESU level. Information from this project may be used by NOAA Fisheries to assess effectiveness of conservation actions and delisting decisions for spring and summer Chinook salmon in the Snake River basin.

This section provides information on natural origin adult salmon escapement and spawner abundance in the Secesh River from 1998 to 2008. Adult salmon escapement estimates in this report have been standardized and supercede that presented in previous years' reports. Natural origin salmon spawner abundance in the Secesh River in 2008 was estimated to be 836 fish (Table 8). This spawner abundance estimate was adjusted for 10 salmon redds located downstream of the DIDSON monitoring site, for known harvest, and for the estimated adult hatchery fraction on the spawning grounds.

Natural origin salmon spawner abundance levels in the Secesh River have fluctuated dramatically since 1998 (Figure 20). Spawner abundance data is presented for direct comparison to the ICTRT (2005) recommended viability threshold which is a 10 year geometric mean value of 750 spawners. In 1998 and 1999 the population was at very low levels, and contained only 103 and 196 spawning adults, respectively. The spawning population increased in size from 2001 to 2004 and experienced four years (one generation) above the viable population threshold. Spawner abundance during this four year period ranged from 886 salmon (2004) to 1,326 fish in 2001. However, spawner abundance declined from the 886 fish observed in 2004 to lower abundance levels ranging from 191 to 333 fish, from 2005 through 2007 (Figure 20). Spawner abundance has increased from 266 fish in 2007 to 836 salmon in 2008; a three fold increase. The 10 year geometric mean spawner abundance in the Secesh River is 538 salmon. The Secesh River salmon population is not viable according to the ICTRT (2007) abundance criteria. In fact, the ICTRT suggested that any population with fewer than 500 individuals was not viable, regardless of its intrinsic productivity (ICTRT 2006). Furthermore, the viable population threshold is a minimum goal to avoid high demographic risk and to promote population 
persistence. The focus for salmon management in the Secesh River is the 5,400 fish escapement goal that the Department has set. Salmon numbers are far below the 5,400 fish management goal set by the Nez Perce Tribe.

Table 8. Total estimated adult salmon escapement (wild and hatchery), natural origin escapement, natural origin spawner abundance, and average hatchery fraction in the Secesh River from 1998 to 2008.

\begin{tabular}{|c|c|c|c|c|}
\hline Year & $\begin{array}{l}\text { Average } \\
\text { Hatchery } \\
\text { Fraction } \\
\quad(\%)\end{array}$ & $\begin{array}{c}\text { Total Salmon } \\
\text { Escapement } \\
\text { (Wild and Hatchery) }\end{array}$ & $\begin{array}{l}\text { Natural Origin } \\
\text { Escapement } \\
\text { (Wild) }\end{array}$ & $\begin{array}{c}\text { Natural Origin } \\
\text { Spawner Abundance } \\
\text { (Wild) }\end{array}$ \\
\hline 1998 & $* 1$ & 117 & 105 & 103 \\
\hline 1999 & $* 1$ & 201 & 196 & 196 \\
\hline 2000 & $* 1$ & 549 & 543 & 541 \\
\hline 2001 & $* 1$ & 1,438 & 1,336 & 1,326 \\
\hline 2002 & $*^{1}$ & 1,091 & 1,006 & 1,001 \\
\hline 2003 & $* 1$ & 1,172 & 1,159 & 1,154 \\
\hline $2004^{2}$ & $2.62^{3}$ & 923 & 899 & 886 \\
\hline $2005^{2}$ & $1.38^{3}$ & 343 & 338 & 333 \\
\hline $2006^{2}$ & $6.50^{3}$ & 212 & 198 & 191 \\
\hline $2007^{2}$ & $9.86^{3}$ & 307 & 276 & 266 \\
\hline $2008^{2}$ & $7.1^{3}$ & 912 & 847 & 836 \\
\hline
\end{tabular}

Given the recent Secesh River natural origin salmon spawner abundance population status, one other Snake River basin salmon spawning aggregate was assessed for purpose of comparison where active salmon escapement monitoring exists. Salmon spawner abundance information from the Johnson Creek/EFSF population was evaluated for this purpose (Figure 21) (Craig Rabe - personal communication, BPA Project No. 199604300). The Johnson Creek/EFSF population was identified as a large population size category with a 10 year geometric mean spawner abundance viability threshold of 1,000 spawners (ICTRT 2007).

Natural origin salmon spawner abundance information was examined for the two streams from 1998 to 2008 for a recent status assessment (Figure 21). Both streams are located within the South Fork Salmon River major population group (MPG). Annual spawner abundance data and 10 year geometric mean abundance (ICTRT 2007) was compared between the two populations. The Secesh River population annual spawner abundance increased substantially from 2000 to 


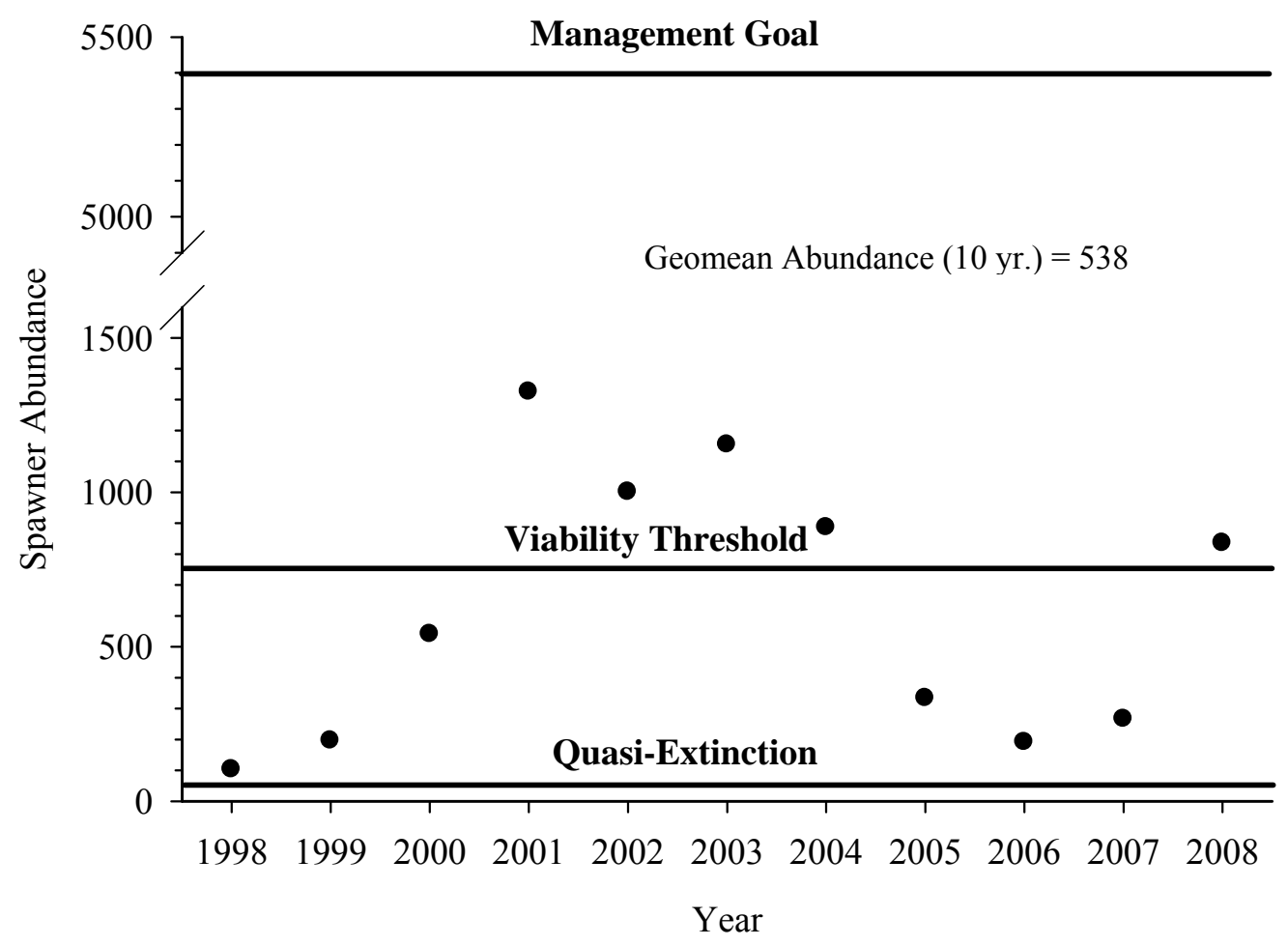

Figure 20. Estimated natural origin salmon spawner abundance (wild fish) in the Secesh River from 1998 to 2008 compared to quasi-extinction threshold, population viability threshold (ICTRT 2007), and management goals.

2001, remained above the viable population threshold from 2001 to 2004, and declined from 2005 through 2007. Spawner abundance in the Secesh River increased again from 266 salmon in 2007 to 836 fish in 2008. The Johnson Creek/EFSF population annual spawner abundance increased from 2000 to 2001, remained above a viable threshold for only one year (2001), and then declined through 2006. Unlike the Secesh River, only a small increase in spawner abundance was observed in the Johnson Creek/EFSF population from 163 fish in 2007 to an estimated 273 salmon in 2008. Natural origin salmon broodstock removal and weir mortalities for the Johnson Creek supplementation program has averaged approximately 78 fish per year (Craig Rabe - personal communication). The 10 year geometric mean natural origin salmon spawner abundance was 538 salmon in the Secesh River, and was 254 salmon in the Johnson Creek/EFSF. Spawner abundance for both salmon populations was below the ICTRT (2007) recommended viable population threshold criteria (Figure 21).

The current status of the two salmon populations is of grave concern, because spawner abundance remains below recommended viable population size thresholds. The major concern at low population size is increased demographic risk of localized extirpation. The value of the spawner abundance data sets is that they provide a direct measure of viability thresholds (Figure 21). The uncertainty that is inherent in utilizing redd count expansion spawner abundance estimate methods is avoided. 

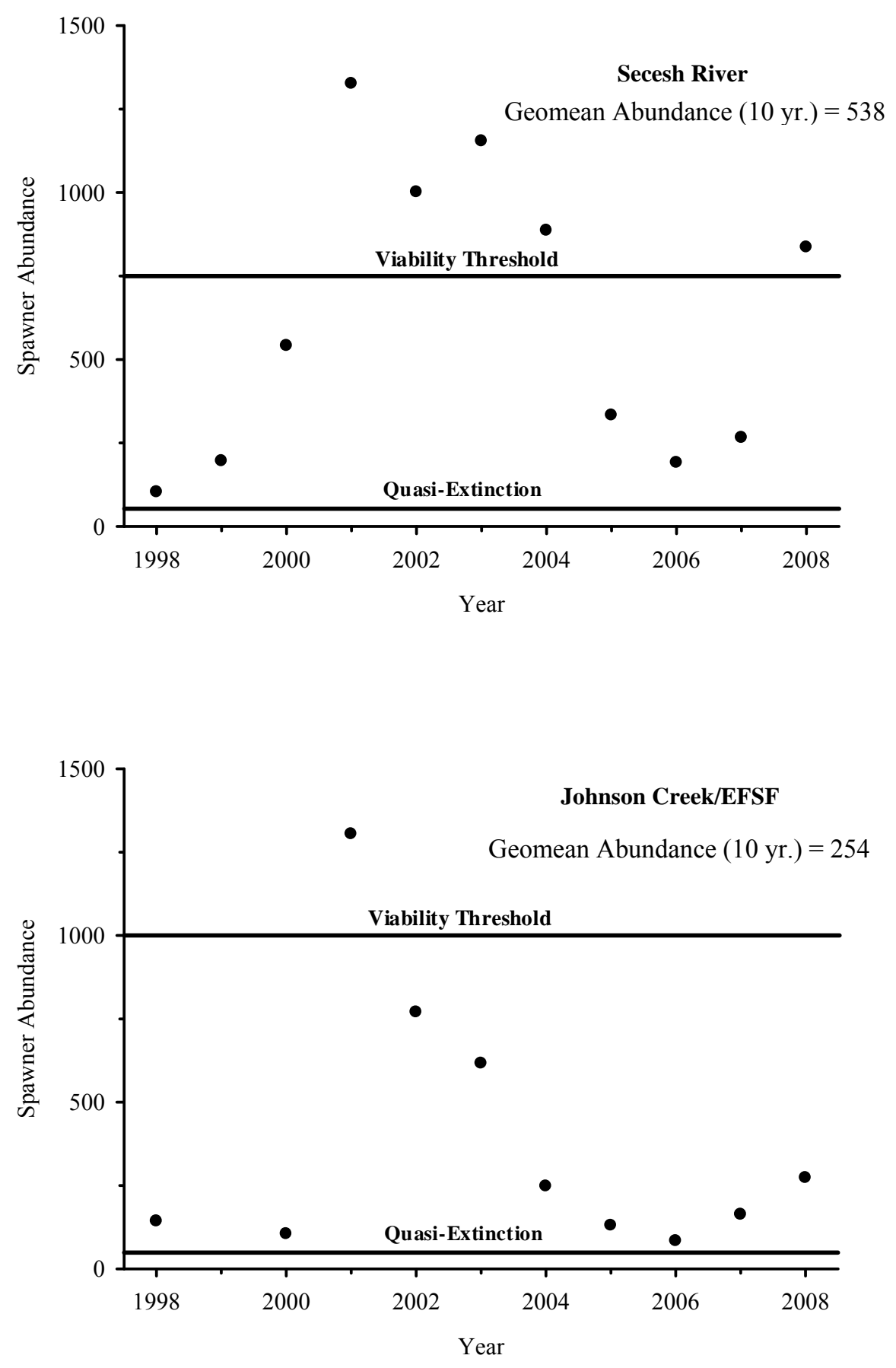

Figure 21. Estimated natural origin salmon spawner abundance and 10 year geometric mean spawner abundance in the Secesh River (upper graph) and Johnson Creek/EFSF Salmon River (lower graph) populations from 1998 to 2008. Spawner abundance is compared to ICTRT (2007) recommended viability and quasi-extinction thresholds. 


\section{RECOMMENDATIONS}

- Install the DIDSON sonar unit in the Secesh River in 2009 to provide tributary specific adult salmon escapement, spawner abundance, and productivity information for use in effective management and listed species recovery metrics monitoring.

- Conduct DIDSON based escapement monitoring along side the Integrated Status and Effectiveness Monitoring Program (BPA Project No. 200301700) project PIT tag arrays, for a minimum of five years, to assess the effectiveness of PIT tag array escapement estimates.

- Discontinue operation of two DIDSON units to estimate precision. Four years of precision data are now available.

- Transition to computer automated salmon counting of DIDSON files as soon as software improvements allow.

- Install underwater optical cameras after ice out to validate early season sonar targets at the DIDSON monitoring site. Use validation approach to attempt to measure potential magnitude of bias of counting large migratory bull trout as salmon.

- Operate optical cameras continuously at the end of the season to quantify downstream movement of male salmon out of spawning areas.

- Provide extensive training to personnel. This should reduce down time due to operator error and, with the additional experience, operators would be able to quickly identify and correct equipment malfunctions.

- Continue to look for improvement in DIDSON CSOT file processing to fish motion-only periods of movement.

- We recommend use of the Secesh River natural origin salmon population as a candidate for measurement of delisting criteria under the ESA to roll up to the larger ESU level. It is the only remaining unsupplemented natural origin salmon population within the South Fork Salmon River major population group.

- We also recommend use of Secesh River natural origin salmon population spawner abundance and productivity information to assess effectiveness of conservation actions and delisting decisions for spring and summer Chinook salmon in the Snake River basin. 


\section{LITERATURE CITED}

Belcher, E., B. Matsuyama, and G. Trimble. 2001. Object identification with acvoustic lenses. Available at Http://www.apl.wahington.edu/programs/DIDSON/Media/object_ident.pdf (December 10, 2003).

Bell, M.C. 1986. Fisheries handbook of engineering requirements and biological criteria. U.S. Army Corps of Engineers. Fish Passage Development and Evaluation Program, North Pacific Division, Portland, OR.

Bjornn, T.C. and D.W. Reiser. 1991. Habitat requirements of anadromous salmonids. Influences of forest and rangeland management on salmonid fishes and their habitats. Amer. Fish. Soc. Special Publ. 19:83-138.

Botkin, D. B., D. L. Peterson, and J. M. Calhoun (technical editors). 2000. The scientific basis for validation monitoring of salmon conservation and restoration plans. Olympic Natural Resources Technical Report. University of Washington, Olympic Natural Resources Center. Forks, Washington, USA

Carmichael, R.W., and numerous co-authors. In press. Grande Ronde/Imnaha spring-summer Chinook major population grouping viability assessment.

Cleary, P.J. in review. Evaluation of spring chinok salmon (Oncorhynchus tshawytscha) supplementation in the Lostine River, Oregon, 2006 annual report. Annual report submitted to the Bonneville Power Administration. Project 199800702, Contract 00025587. Bonneville Power Administration, Portland, OR.

Dunning, D.J., Q.E. Ross, P. Geoghegan, J.J. Reichle, J.K. Menezes, and J.K. Watson. 1992. Alewives avoid high-frequency sound. N. Amer. Jrnl. Fish. Manage.. Vol 12:3 - 407416.

Ecovista. 2004. Salmon subbasin management plan. Contracted by Nez Perce Tribe and Shoshone-Bannock Tribes. Ecovista. Pullman, WA.

Enger, P.S., H.E. Karlsen, F.R. Knudsen, and O. Sand. 1992. Detection and reaction of fish to ultrasound. Fish behavior in relation to fishing operations, 1993, p. 108-112, ICES marine science symposia. Copenhagen. Vol. 196.

Faurot, D., P. A. Kucera and J. Hesse. 2000. Escapement monitoring of adult chinook salmon in the Secesh River and Lake Creek, Idaho, 1998. Annual report submitted to the Bonneville Power Administration. Portland, Oregon.

Faurot, D. and P. A. Kucera. 2001a. Adult chinook salmon abundance monitoring in the Secesh River and Lake Creek, Idaho, 1999. Annual report submitted to the Bonneville Power Administration. Portland, Oregon. 
Faurot, D. and P. A. Kucera. 2001b. Adult chinook salmon abundance monitoring in the Secesh River and Lake Creek, Idaho, 2000. Annual report submitted to the Bonneville Power Administration. Portland, Oregon.

Faurot, D. and P. A. Kucera. 2002. Adult chinook salmon abundance monitoring in Lake Creek, Idaho, 2001. Annual report submitted to the Bonneville Power Administration. Portland, Oregon.

Faurot, D. and P. A. Kucera. 2003. Chinook salmon adult abundance monitoring in Lake Creek, Idaho, 2002. Annual report submitted to the Bonneville Power Administration. Portland, Oregon.

Faurot, D. and P. A. Kucera. 2004. Chinook salmon adult abundance monitoring in Lake Creek, Idaho, 2003. Annual report submitted to the Bonneville Power Administration. Portland, Oregon.

Foose, T. J. ,L. deBour, U. S. Seal and R. Lande. 1995. Conservation Management Strategies based on viable populations. Pages 273-294 in J. D. Ballou, M. Gilpin and T. J. Foose eds. Population Management for Survival and Recovery. Columbia University Press. New York, Chichester, West Sussex.

Gough, P. and J. Gregory. 1997. The development of applications and validation methods for hydroacoustic salmonid counters. A position statement on the R \& D collaboration between the Environment Agency, MAFF, SOAEFD and the Spey Research Trust. Cardiff, United Kingdom.

Gregory, J., J Bray, and P. Gough. 2001. The Development of Applications and Validation Methods for Hydroacoustic Salmonid Counters. R\&D Technical Report W2/037/TR/1, Environment Agency, Bristol, United Kingdom.

Hawkins, A.D. and A.D.F. Johnstone. 1978. The hearing of the Atlantic salmon, Salmon salar. J. Fish. Biol. 13:655-673.

Hesse, J.A., J.R. Harbeck, R.W. Carmichael and 17 contributors. 2006. Monitoring and evaluation plan for Northeast Oregon Hatchery Imnaha and Grande Ronde subbasin spring Chinook salmon. Report submitted to the Bonneville Power Administration. Nez Perce Tribe Department of Fisheries Resources Management. Lapwai, ID.

Interior Columbia River Technical Recovery Team (ICTRT). Draft 2003. Independent populations of chinook, steelhead and sockeye for listed Evolutionary Significant Units within the Interior Columbia River Domain. July 2003.

Interior Columbia River Technical Recovery Team (ICTRT). 2004. Preliminary guidelines for population-level abundance, productivity, spatial structure, and diversity supporting viable salmonid populations: An update. Interior Columbia River Technical Recovery Team. December 13, 2004. 
Interior Columbia Basin Technical Recovery Team (ICTRT). 2005. Interior ColumbiaBasin TRT: Viability criteria for application to interior Columbia basin salmonid ESUs. Interior Columbia Basin Technical Recovery Team. July, 2005.

Interior Columbia Basin Technical Recovery Team (ICTRT). 2006. Interior Columbia Basin TRT: Viability criteria for application to interior Columbia basin salmonid ESUs. Interior Columbia Basin Technical Recovery Team. January, 2006.

Interior Columbia Basin Technical Recovery Team (ICTRT). 2007. Interior Columbia Basin TRT: Viability criteria for application to interior Columbia basin salmonid ESUs. Interior Columbia Basin Technical Recovery Team. March, 2007.

Isaak, D.J., R.F. Thurow, B.E. Rieman, and J.B. Dunham. 2003. Temporal variation in synchrony among chinook salmon (Oncorhynchus tshawytscha) redd counts from a wilderness area in central Idaho. Can. Jrnl. Fish. Aquatic Sciences 60:840-848.

Johnson, R.L., C.A. McKinstry, D.A. Faurot, and P.A. Kucera. 2004. Validation plan for acoustic imaging camera counting of adult chinook salmon in the Secesh River, Idaho. In D. Faurot and P.A. Kucera - Chinook salmon adult abundance monitoring in Lake Creek, Idaho, 2003. Annual report submitted to the Bonneville Power Administration. Portland, Oregon.

Knudsen, F.R., P.S. Enger, and O. Sand. 1992. Awareness reactions and avoidance resoponses to sound in juvenile Atlantic Salmon, Salmon salar, L.J. Fish. Biol. 40 No. 4, 523-534.

Knudsen, F.R., P.S. Enger, and O. Sand. 1994. Avoidance responses to low frequency sound in downstream migrating Atlantic Salmon smolt. J. Fish. Biol. 45, No 2, 227-233.

Knudsen, F.R., C.B. Schreck, S. M. Knapp, P.S. Enger, and O. Sand. 1997. Infrasound produces flight and avoidance responses in Pacific juvenile salmonids. J. Fish. Biol., 51, No. 4, 824-829.

Kucera, P.A., D. Faurot, and R.W. Orme. 2005. Chinook salmon (Oncorhynchus tshawytscha) adult abundance monitoring in Lake Creek and Secesh River, Idaho, 2004. Annual report DOE/BP-00004600-5. Bonneville Power Administration. Portland, Oregon.

Kucera, P.A. and R.W. Orme. 2006. Chinook salmon (Oncorhynchus tshawytscha) adult abundance monitoring in the Secesh River and Lake Creek, Idaho. 2005 Annual report DOE/BP-00020615-1. Bonneville Power Administration. Portland, Oregon.

Kucera, P.A. and R.W. Orme. 2007. Chinook salmon (Oncorhynchus tshawytscha) adult escapement monitoring in Lake Creek and Secesh River, Idaho in 2006. Annual report Document ID \# P102843. Bonneville Power Administration. Portland, Oregon.

Kucera, P.A. . 2008. Use of dual frequency identification sonar to determine adult Chinook salmon (Oncorhynchus tshawytscha) escapement in the Secesh River, Idaho. Annual report Document ID \# P107127. Bonneville Power Administration. Portland, Oregon. 
Kynard, B. and J. O’Leary. 1990. Behavioral guidance of American Shad using underwater AC electrical and acoustic fields. Proceedings of the International Symposium on Fishways '90 in Gifu, Japan, October 8-10, 1990.

Lockhart, J., W. Kellar, R. Kinzer, T. Covel, and J. Helmich. 2008. Salmon supplementation studies in Idaho rivers. 2006-2007 Annual report (Brood Year 2005) Document ID \# P0105590. Bonneville Power Administration. Portland, Oregon.

Maxwell, S.L. and N.E. Gove. 2004. The feasibility of estimating migrating salmon passage rates in turbid rivers using a dual frequency identification sonar (DIDSON) -20002. Regional information report No. 2A04-05. Alaska Department of Fish and Game. Anchorage, Alaska.

McCubbing, D. J., B. Ward and L. Burroughs. 2000. Salmonid escapement enumeration on the Keogh River: a demonstration of a resistivity counter in British Columbia. Province of British Columbia Fisheries Technical Circular 104. Vancouver, B. C.

McCullough, D. A. 1999. A review and synthesis of effects of alterations to the water temperature regime on freshwater life stages of salmonids, with special reference to Chinook salmon. Report prepared for the Environmental Protection Agency, Report No. EPA 910-R-99-010. U.S. Environmental Protection Agency, Seattle, WA.

McElhany, P., M. H. Ruckelshaus, M. J. Ford, T. C. Wainwright, and E. P. Bjorkstedt. 2000. Viable salmonid populations and the recovery of evolutionary significant units. U. S. Department of Commerce. NOAA Technical Memorandum. NMFS-NWFSC-42,156 p.

Moore, D.S. and G.P. McCabe. 1993. Introduction to the Practice of Statistics. W.H. Freeman and Company. New York.

Moursund, R.A., K.D. Ham, P.S. Titzler, R.P. Mueller, G.E. Johnson, J. Hedgepeth, and J.R. Skalski. 2002. Hydroacoustic evaluations of fish passage at the Dalles dam in 2001. U.S. Army Corps of Engineers, Portland, Oregon.

Mueller, R.P., R.A. Moursund, T.M. Degerman, and G.A. McMichael. 2003. Feasability of monitoring fall chinook salmon fallback at Priest Rapids Dam using an acoustic camera 2001. In Chinook salmon in the Priest Rapids project, G.A. McMichael, D.R. Geist, T.P. Hanrahan, E.V. Arntzen, R.P. Mueller, R.A. Moursund, J.A. Carter, J.M. Becker, C.A. McKinstry, W.A. Perkins, D.D. Dauble, T.M. Degerman, J.R. Skalski, R.L. Townsend, B.B. James, and D.R. Thornhill. P. 4.41-1 to 4.4-18. Technical Appendix E-4.B in Public Utility District No. 2 of Grant County, Final License Application Priest Rapids Project FERC No. 2114. Public Utility District No. 2 of Grant County, Ephrata, Washington.

Nestler, J.M. et al. 1992. Responses of blue back herring to high frequency sound and implications for reducing entrainment at hydropower dams. North Amer. Jrnl. Fish. Manag. 12:667-683. 
NMFS (National Marine Fisheries Service). 1992. Threatened status for Snake River spring/summer chinook salmon, threatened status for Snake River fall chinook salmon, final rule. Federal Register 57:78 (22 April 1992) 7:14, 653,663.

NMFS (National Marine Fisheries Service). 2000. Final Biological Opinion: Operation of the federal Columbia River power system including the juvenile fish transportation program and the Bureau of Reclamation's 31 projects, including the entire Columbia Basin Project. December 21, 2000

NMFS (National Marine Fisheries Service). 2002. Interim abundance and productivity targets for Interior Columbia River Basin salmon and steelhead listed under the Endangered Species Act (ESA). April 4, 2002 letter from Bob Lohn, National Marine Fisheries Service to Frank L. Cassidy, Jr. Chairman, Northwest Power Planning Council. Seattle, WA.

NOAA Fisheries. 2004. Endangered Species Act Section 7 consultation biological opinion. Consultation on remand for operation of the Columbia River power system and 19 Bureau of Reclamation projects in the Columbia basin (revised and reissued pursuant to court order, NWF v. NMFS, Civ. No. CV 01-640-RE (D. Oregon)). NOAA Fisheries, Northwest Region.

Northwest Power Planning Council. 2000. 2000 Columbia River basin fish and wildlife program. Council Document 2000-19. Northwest Power Planning Council, Portland, OR.

Northwest Power and Conservation Council. 2005. [draft]. Columbia River basin research plan. Northwest Power and Conservation Council, Portland, OR.

Rabe, C. and D. Nelson 2008. Status and monitoring of natural and supplemented chinook in Johnson Creek Idaho. Annual progress report to the Bonneville Power Administration, BPA Project Number 199604300. Portland, Oregon.

Raleigh, R.F., W.F. Miller, and P.C. Nelson. 1986. Habitat suitability index models and instream flow suitability curves: Chinook salmon. U.S. Fish and Wildlife Service Biol. Report 82(10.122). 64 pp.

Reiser, D.W. and T.C. Bjornn. 1979. Habitat requirements of anadromous salmonids. Gen. Tech. Rep. PNW-96. USDA Forest Service. Pacific Northwest Forest and Range Experiment Station. Portland, OR. 54 pp.

Ross, Q.E., D.J. Dunning, R. Thorne, J.K. Menezes, G.W. Tiller, and J.K. Watson. 1993. Response of alewives to high-frequency sound at a power plant intake on Lake Ontario. N. Amer. Jrnl. Fish. Man. 13 No. 2, 291-303.

Shardlow, T. 1998. Field assessments of the Vaki infrared counter at Cheewhat Lake and the Big Qualicum River. Report to file. Pacific Biological Station. Department of Fisheries and Oceans, Canada. 
Smith I. P., A. D. F. Johnstone and D. A. Dunkley. 1996. Evaluation of a portable electrode array for a resistivity fish counter. Fisheries management and ecology, 1996 3:129-141.

Tiffan, K.F., D.W. Rondorf, and J.J. Skalicky. 2004. Imaging fall chinook salmon redds in the Columbia River with a dual-frequency identification sonar. North American Journal of Fisheries Management 24:1421-1426.

U.S. Army Corps of Engineers, Bureau of Reclamation, and Bonneville Power Administration. 2004. Final updated proposed action for the FCRPS Biological Opinion remand. U.S. Army Corps of Engineers, Bureau of Reclamation, and Bonneville Power Administration. November 24, 2004.

U.S. Army Corps of Engineers, Bureau of Reclamation, and Bonneville Power Administration. 2005. 2005-2007 implementation plan for ther federal Columbia River power system Endangered Species Act updated proposed action. U.S. Army Corps of Engineers, Bureau of Reclamation, and Bonneville Power Administration. May 2005.

Vogel, J.L., J.A. Hesse, J.R. Harbeck, D.D. Nelson, and C.D. Rabe. 2005. Johnson Creek summer Chinook salmon monitoring and evaluation plan. Northwest Power and Conservation Council Step 2/3 document. Prepared for BPA, DOE/BP-16450. Bonneville Power Administration, Portland, OR. 
APPENDIX 
Appendix Table 1. Two sample $\mathrm{Z}$ test comparing within observer file reader error of fish original DIDSON 1 file manual counts, and comparison of original DIDSON file to fish motion-only file counts on subsampled days, by direction of fish movement, of adult salmon in the Secesh River in 2008. Ho: $\mathrm{P} 1=\mathrm{P} 2$, Ha: $\mathrm{P} 1 \neq \mathrm{P} 2$. Proportions were used to adjust daily upstream and downstream salmon counts for individual readers. Migration period 1 (early season) was from July 3 to July 22, and period 2 (late season) was from July 23 to September 14. Significant difference at $p<0.05$ level is highlighted in bold.

\begin{tabular}{|c|c|c|c|c|c|c|}
\hline Reader & Period & Observed & Possible & Proportion & Z Value & $\mathrm{P}$ value \\
\hline \multicolumn{7}{|c|}{ Up Stream Movements } \\
\hline \multirow[t]{2}{*}{1} & 1 & 130 & 156 & 0.8333 & & \\
\hline & 2 & 367 & 376 & 0.9761 & 6.0453 & 0.0000 \\
\hline \multirow[t]{2}{*}{2} & 1 & 207 & 209 & 0.9904 & & \\
\hline & 2 & 488 & 489 & 0.9980 & 1.3918 & 0.0820 \\
\hline \multirow[t]{2}{*}{3} & 1 & 209 & 209 & 1.0 & & \\
\hline & 2 & 485 & 489 & 0.9918 & 1.3113 & 0.0949 \\
\hline \multirow[t]{2}{*}{ Motion } & 1 & 195 & 195 & 1.0 & & \\
\hline & 2 & 486 & 486 & 1.0 & $N / A$ & N/A \\
\hline \multicolumn{7}{|c|}{ Downstream Movements } \\
\hline \multirow[t]{2}{*}{1} & 1 & 36 & 49 & 0.7347 & & \\
\hline & 2 & 282 & 323 & 0.8731 & 2.5622 & 0.0052 \\
\hline \multirow[t]{2}{*}{2} & 1 & 73 & 74 & 0.9865 & & \\
\hline & 2 & 423 & 430 & 0.9837 & 0.1758 & 0.4302 \\
\hline \multirow[t]{2}{*}{3} & 1 & 72 & 74 & 0.9730 & & \\
\hline & 2 & 415 & 430 & 0.9651 & 0.3458 & 0.3647 \\
\hline \multirow[t]{2}{*}{ Motion } & 1 & 63 & 67 & 0.9403 & & \\
\hline & 2 & 413 & 426 & 0.9695 & 1.2170 & 0.1118 \\
\hline
\end{tabular}


Appendix Table 2. Two sample $Z$ test comparing within observer file reader error of CSOT processed files by direction of movement and migration segment in the Secesh River in 2008. Ho: $\mathrm{P} 1=\mathrm{P} 2$, Ha: $\mathrm{P} 1 \neq \mathrm{P} 2$. Significant difference at $\mathrm{p}<0.05$ level highlighted in bold. Migration period 1 (early season) was from July 3 to July 22, and period 2 (late season) was from July 23 to September 14.

\begin{tabular}{|c|c|c|c|c|c|c|}
\hline Observer & Period & $\begin{array}{l}\text { Number } \\
\text { Observed }\end{array}$ & $\begin{array}{l}\text { Number } \\
\text { Possible }\end{array}$ & $\begin{array}{l}\text { Observer } \\
\text { Error }\end{array}$ & Z Value & $\mathrm{P}$ value \\
\hline \multicolumn{7}{|c|}{ Up Stream Movements } \\
\hline \multirow[t]{2}{*}{2} & 1 & 81 & 83 & 0.024 & & \\
\hline & 2 & 257 & 266 & 0.034 & 0.4433 & 0.3288 \\
\hline \multirow[t]{2}{*}{3} & 1 & 103 & 107 & 0.037 & & \\
\hline & 2 & 220 & 221 & 0.004 & 2.2771 & 0.0114 \\
\hline \multicolumn{7}{|c|}{ Downstream Movements } \\
\hline \multirow[t]{2}{*}{2} & 1 & 28 & 31 & 0.097 & & \\
\hline & 2 & 213 & 219 & 0.027 & 1.9407 & 0.0261 \\
\hline \multirow[t]{2}{*}{3} & 1 & 29 & 32 & 0.094 & & \\
\hline & 2 & 195 & 195 & 0.000 & 4.3042 & 0.0000 \\
\hline
\end{tabular}


Appendix Table 3. Estimated observer error of missed salmon passages by direction for the entire season of original DIDSON files and CSOT processed files in the Secesh River in 2008. The number of observed passages and the number of passages possible are also shown. Two sample $\mathrm{Z}$ test compares error by direction between original and CSOT processed DISON files (Ho: $\mathrm{P} 1=\mathrm{P} 2$, Ha: $\mathrm{P} 1 \neq \mathrm{P} 2$ ).

\begin{tabular}{|c|c|c|c|c|c|c|}
\hline Observer & $\begin{array}{l}\text { File } \\
\text { Type }\end{array}$ & $\begin{array}{l}\text { Number } \\
\text { Observed }\end{array}$ & $\begin{array}{l}\text { Number } \\
\text { Possible }\end{array}$ & $\begin{array}{c}\text { Observer } \\
\text { Error }\end{array}$ & Z Value & $\mathrm{P}$ value \\
\hline \multicolumn{7}{|c|}{ Up Stream Movements } \\
\hline \multirow[t]{2}{*}{2} & Original & 695 & 698 & 0.0043 & & \\
\hline & CSOT & 338 & 349 & 0.0315 & 3.6149 & 0.0002 \\
\hline \multirow[t]{2}{*}{3} & Original & 694 & 698 & 0.0057 & & \\
\hline & CSOT & 323 & 328 & 0.0152 & 1.5240 & 0.0638 \\
\hline \multicolumn{7}{|c|}{ Downstream Movements } \\
\hline \multirow[t]{2}{*}{2} & Original & 496 & 504 & 0.0159 & & \\
\hline & CSOT & 241 & 250 & 0.0360 & 1.7526 & 0.0398 \\
\hline \multirow[t]{2}{*}{3} & Original & 487 & 504 & 0.0337 & & \\
\hline & CSOT & 224 & 227 & 0.0132 & 1.5732 & 0.0578 \\
\hline
\end{tabular}


Appendix Table 4. Equipment downtime at the DIDSON monitoring site in 2008.

\begin{tabular}{ccccc}
\hline Date & Time stopped & Time re-started & $\begin{array}{c}\text { Total Outage } \\
\text { (Hours:Minutes) }\end{array}$ & Comments \\
\hline July 3 & $12: 47: 36$ & $13: 02: 37$ & $00: 32$ \\
July 3 & $13: 04: 58$ & $13: 21: 58$ & \\
July 7 & $12: 48: 25$ & $13: 08: 47$ & $00: 20$ \\
July 11 & $22: 34: 05$ & $23: 59: 59$ & $1: 26$ \\
July 12 & $0: 00: 00$ & $12: 57: 36$ & $12: 58$ \\
July 28 & $13: 52: 21$ & $14: 00: 37$ & $0: 17$ \\
July 28 & $14: 09: 31$ & $14: 18: 01$ & \\
September 7 & $23: 01: 21$ & $23: 59: 59$ & $0: 59$ \\
September 8 & $0: 00: 00$ & $14: 20: 29$ & $14: 20$ \\
\hline
\end{tabular}


Appendix Table 5. Percent of the salmon migration observed at the Secesh River DIDSON monitoring site, by date, from 2004 to 2008 (adjusted data).

\begin{tabular}{|c|c|c|c|c|c|}
\hline $\begin{array}{c}\text { Percent of } \\
\text { Run Observed }\end{array}$ & $\begin{array}{l}2004 \\
\text { (Date) }\end{array}$ & $\begin{array}{l}2005 \\
\text { (Date) }\end{array}$ & $\begin{array}{l}2006 \\
\text { (Date) }\end{array}$ & $\begin{array}{l}2007 \\
\text { (Date) }\end{array}$ & $\begin{array}{l}2008 \\
\text { (Date) }\end{array}$ \\
\hline 10 & June 26 & July 3 & July 2 & June 26 & July 8 \\
\hline 20 & July 1 & July 5 & July 4 & June 30 & July 10 \\
\hline 30 & July 3 & July 7 & July 6 & July 1 & July 12 \\
\hline 40 & July 7 & July 8 & July 9 & July 5 & July 14 \\
\hline 50 & July 15 & July 14 & July 11 & July 8 & July 16 \\
\hline 60 & July 18 & July 21 & July 15 & July 14 & July 21 \\
\hline 70 & July 30 & July 26 & July 22 & July 26 & August 2 \\
\hline 80 & August 7 & August 7 & July 29 & August 9 & August 8 \\
\hline 90 & August 13 & August 16 & August 12 & August 14 & August 12 \\
\hline 100 & August 28 & August 28 & August 20 & August 23 & August 27 \\
\hline
\end{tabular}


Appendix Table 6. Extensive area Chinook salmon redd count data from the Secesh River and tributaries from 1998 to 2008 (after Lockhart et al. 2008).

\begin{tabular}{|c|c|c|c|c|c|c|c|}
\hline \multirow[b]{2}{*}{ Year } & \multicolumn{2}{|c|}{ Lake Creek } & \multirow[b]{2}{*}{$\begin{array}{l}\text { Secesh } \\
\text { River } \\
\text { main- } \\
\text { stem }\end{array}$} & \multirow[b]{2}{*}{$\begin{array}{l}\text { Summit } \\
\text { Creek }\end{array}$} & \multirow[b]{2}{*}{$\begin{array}{c}\text { Grouse } \\
\text { Creek }\end{array}$} & \multirow[b]{2}{*}{$\begin{array}{l}\text { Lick } \\
\text { Creek }\end{array}$} & \multirow[b]{2}{*}{$\begin{array}{c}\text { Total } \\
\text { Secesh } \\
\text { Drainage } \\
\text { Redds }\end{array}$} \\
\hline & $\begin{array}{l}\text { Index } \\
\text { Area }\end{array}$ & $\begin{array}{c}\text { Non-index } \\
\text { Area }\end{array}$ & & & & & \\
\hline 1998 & 45 & 5 & 54 & 8 & 5 & 0 & 117 \\
\hline 1999 & 13 & 11 & 34 & 8 & 0 & 0 & 66 \\
\hline 2000 & 157 & 22 & 119 & 7 & 23 & 0 & 328 \\
\hline 2001 & 296 & 41 & 269 & 36 & 60 & 3 & 705 \\
\hline 2002 & 176 & 24 & 242 & 55 & 29 & 0 & 527 \\
\hline 2003 & 200 & 44 & 251 & 61 & 31 & 2 & 589 \\
\hline 2004 & 151 & 32 & $147^{1}$ & 53 & 13 & 0 & 398 \\
\hline 2005 & 68 & 11 & $102^{1}$ & 6 & 18 & 0 & 205 \\
\hline 2006 & 37 & 2 & $25^{1}$ & 9 & 2 & 0 & 75 \\
\hline 2007 & 31 & 0 & $40^{1}$ & 2 & 10 & 0 & 83 \\
\hline 2008 & 121 & 37 & $112^{1}$ & 64 & 49 & 1 & 384 \\
\hline
\end{tabular}




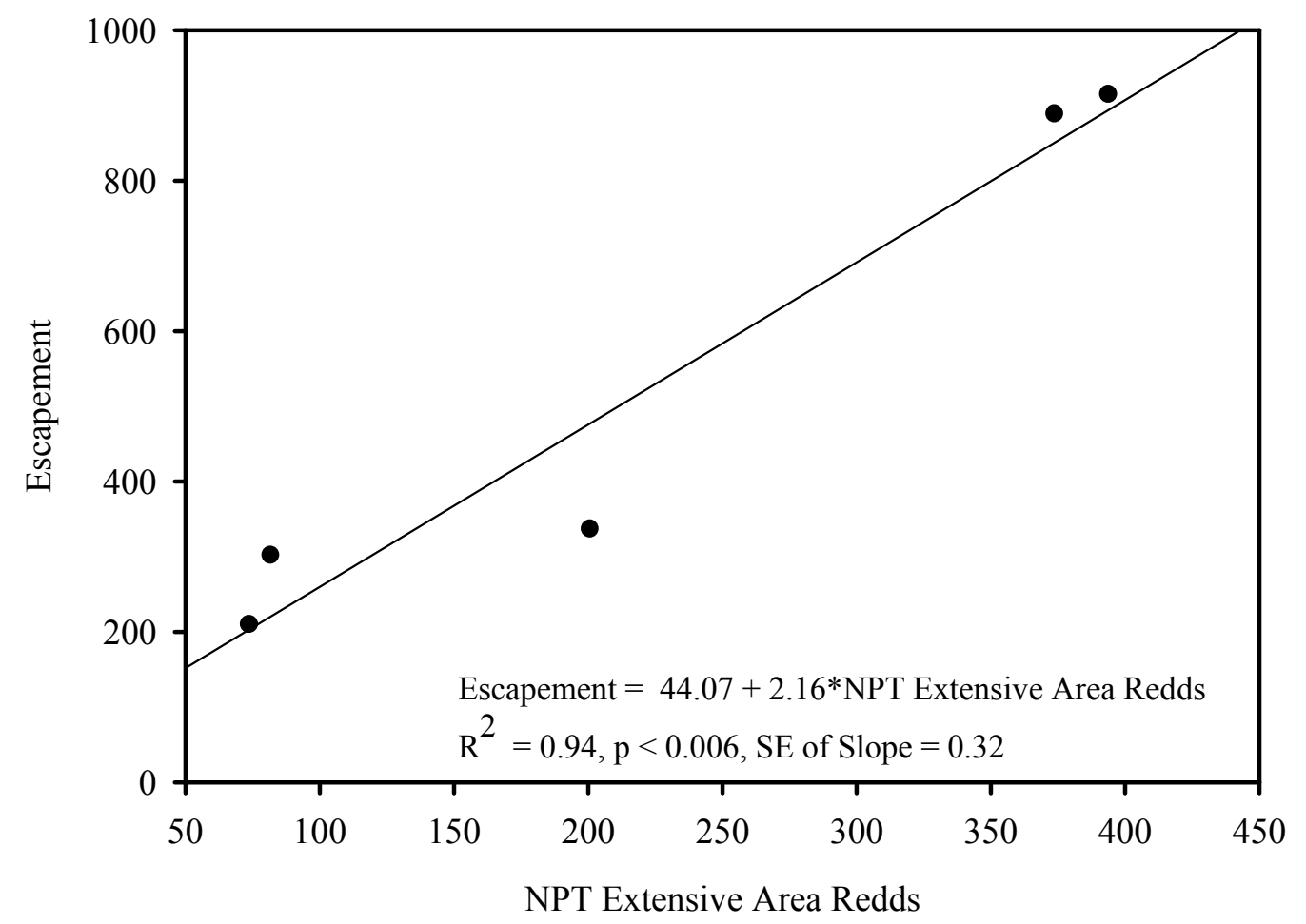

Appendix Figure 1. Linear regression between DIDSON determined salmon escapement and multiple pass extensive area redd counts located upstream of the DIDSON site in the Secesh River from 2004 to 2008. Redd count data courtesy of Jerry Lockhart. 
Appendix Table 7. Dates of observed total and net upstream migration, net adjustments due to reader and motion detection error, net adjustments due to downtime, adjusted daily net upstream passages, and adjusted cumulative net upstream passages of adult spring and summer Chinook salmon at the DIDSON monitoring site in the Secesh River in 2008.

\begin{tabular}{|c|c|c|c|c|c|c|}
\hline Date & $\begin{array}{l}\text { Observed } \\
\text { Total } \\
\text { Movements }\end{array}$ & $\begin{array}{l}\text { Observed } \\
\text { Net } \\
\text { Upstream }\end{array}$ & $\begin{array}{l}\text { Reader-Motion } \\
\text { Detection } \\
\text { Adjustment }\end{array}$ & $\begin{array}{l}\text { Down Time } \\
\text { Adjustment }\end{array}$ & $\begin{array}{l}\text { Adjusted } \\
\text { Net } \\
\text { Upstream } \\
\end{array}$ & $\begin{array}{c}\text { Cumulative } \\
\text { Upstream }\end{array}$ \\
\hline June 26 & 0 & 0 & 0.00 & 0.0 & 0.0 & 0 \\
\hline June 27 & 0 & 0 & 0.00 & 0.0 & 0.0 & 0 \\
\hline June 28 & 0 & 0 & 0.00 & 0.0 & 0.0 & 0 \\
\hline June 29 & 0 & 0 & 0.00 & 0.0 & 0.0 & 0 \\
\hline June 30 & 0 & 0 & 0.00 & 0.0 & 0.0 & 0 \\
\hline July 1 & 0 & 0 & 0.00 & 0.0 & 0.0 & 0 \\
\hline July 2 & 0 & 0 & 0.00 & 0.0 & 0.0 & 0 \\
\hline July 3 & 1 & 1 & 0.00 & 0.02 & 1.0 & 1 \\
\hline July 4 & 3 & 1 & -0.09 & 0.00 & 0.9 & 1.9 \\
\hline July 5 & 21 & 9 & -0.52 & 0.03 & 8.5 & 10.4 \\
\hline July 6 & 23 & 19 & -0.17 & 0.00 & 18.8 & 29.2 \\
\hline July 7 & 38 & 36 & -0.09 & 0.55 & 36.5 & 65.7 \\
\hline July 8 & 34 & 34 & 0.00 & 0.00 & 34.0 & 99.7 \\
\hline July 9 & 64 & 48 & -0.69 & 0.00 & 47.3 & 146.9 \\
\hline July 10 & 92 & 74 & -0.78 & 0.19 & 73.4 & 220.3 \\
\hline July 11 & 32 & 28 & -0.17 & 1.76 & 29.6 & 249.9 \\
\hline July 12 & 19 & 15 & 0.02 & 17.62 & 32.6 & 282.5 \\
\hline July 13 & 72 & 26 & -1.22 & 0.00 & 24.7 & 307.2 \\
\hline July 14 & 92 & 60 & -0.44 & 0.11 & 59.6 & 366.8 \\
\hline July 15 & 96 & 72 & -0.07 & 0.00 & 71.9 & 438.6 \\
\hline July 16 & 87 & 41 & -1.07 & 0.00 & 39.8 & 478.5 \\
\hline July 17 & 38 & 28 & -0.05 & 0.01 & 27.9 & 506.4 \\
\hline July 18 & 48 & -10 & -1.94 & -0.02 & -12.1 & 494.3 \\
\hline July 19 & 36 & 10 & -1.13 & 0.00 & 8.8 & 503.1 \\
\hline July 20 & 43 & 13 & -1.30 & 0.00 & 11.6 & 514.7 \\
\hline July 21 & 74 & 28 & -1.99 & 0.05 & 25.9 & 540.6 \\
\hline July 22 & 43 & 19 & -1.04 & 0.00 & 17.9 & 558.5 \\
\hline July 23 & 60 & 14 & -1.20 & 0.00 & 12.7 & 571.2 \\
\hline July 24 & 42 & 8 & -0.91 & 0.01 & 7.0 & 578.3 \\
\hline July 25 & 59 & -3 & -1.80 & 0.00 & -4.9 & 573.4 \\
\hline July 26 & 62 & 8 & -1.48 & 0.00 & 6.4 & 579.8 \\
\hline July 27 & 295 & 11 & -6.33 & 0.01 & 4.4 & 584.2 \\
\hline July 28 & 124 & 8 & -2.58 & 0.06 & 5.4 & 589.6 \\
\hline
\end{tabular}


Appendix Table 7. Continued.

\begin{tabular}{|c|c|c|c|c|c|c|}
\hline Date & $\begin{array}{c}\text { Observed } \\
\text { Total } \\
\text { Movements }\end{array}$ & $\begin{array}{l}\text { Observed } \\
\text { Net } \\
\text { Upstream } \\
\end{array}$ & $\begin{array}{c}\text { Reader-Motion } \\
\text { Detection } \\
\text { Adjustment } \\
\end{array}$ & $\begin{array}{l}\text { Down Time } \\
\text { Adjustment }\end{array}$ & $\begin{array}{l}\text { Adjusted } \\
\text { Net } \\
\text { Upstream }\end{array}$ & $\begin{array}{c}\text { Cumulative } \\
\text { Upstream }\end{array}$ \\
\hline July 29 & 51 & -3 & -1.21 & 0.00 & -4.3 & 585.3 \\
\hline July 30 & 55 & 5 & -1.11 & 0.00 & 3.8 & 589.2 \\
\hline July 31 & 99 & 5 & -2.09 & 0.00 & 2.8 & 592.0 \\
\hline August 1 & 158 & 20 & -3.05 & 0.00 & 16.8 & 608.8 \\
\hline August 2 & 121 & 19 & -2.24 & 0.00 & 16.7 & 625.5 \\
\hline August 3 & 119 & 11 & -3.00 & 0.00 & 7.8 & 633.3 \\
\hline August 4 & 163 & 17 & -4.04 & 0.01 & 12.7 & 646.1 \\
\hline August 5 & 169 & 23 & -3.99 & 0.00 & 18.8 & 664.8 \\
\hline August 6 & 238 & 22 & -6.00 & 0.06 & 15.7 & 680.5 \\
\hline August 7 & 138 & 20 & -3.21 & 0.01 & 16.6 & 697.1 \\
\hline August 8 & 160 & 54 & -2.59 & 0.00 & 51.2 & 748.4 \\
\hline August 9 & 209 & 17 & -5.35 & 0.00 & 11.3 & 759.7 \\
\hline August 10 & 145 & 17 & -2.83 & 0.00 & 14.1 & 773.8 \\
\hline August 11 & 141 & 21 & -2.64 & 0.00 & 18.3 & 792.0 \\
\hline August 12 & 152 & 16 & -3.01 & 0.01 & 12.9 & 804.9 \\
\hline August 13 & 153 & 17 & -3.01 & 0.00 & 13.9 & 818.8 \\
\hline August 14 & 115 & 7 & -2.40 & 0.00 & 4.5 & 823.3 \\
\hline August 15 & 283 & 21 & -5.82 & 0.00 & 15.0 & 838.2 \\
\hline August 16 & 53 & 15 & -0.82 & 0.03 & 14.2 & 852.4 \\
\hline August 17 & 187 & 9 & -5.02 & 0.00 & 3.7 & 856.1 \\
\hline August 18 & 81 & 5 & -2.13 & 0.00 & 2.7 & 858.8 \\
\hline August 19 & 73 & 9 & -1.76 & 0.00 & 7.1 & 866.0 \\
\hline August 20 & 90 & 6 & -2.35 & 0.00 & 3.5 & 869.5 \\
\hline August 21 & 92 & 8 & -2.34 & 0.02 & 5.5 & 875.0 \\
\hline August 22 & 49 & -1 & -1.44 & 0.00 & -2.5 & 872.5 \\
\hline August 23 & 65 & 3 & -1.75 & 0.00 & 1.1 & 873.7 \\
\hline August 24 & 56 & 10 & -1.01 & 0.00 & 9.0 & 882.6 \\
\hline August 25 & 29 & 1 & -0.62 & 0.00 & 0.4 & 883.0 \\
\hline August 26 & 34 & 4 & -0.66 & 0.00 & 3.3 & 886.3 \\
\hline August 27 & 75 & 3 & -1.60 & 0.00 & 1.3 & 887.6 \\
\hline August 28 & 16 & 0 & -0.36 & 0.00 & -0.4 & 887.2 \\
\hline August 29 & 17 & -1 & -0.40 & 0.00 & -1.4 & 885.8 \\
\hline August 30 & 14 & -2 & -0.36 & 0.00 & -2.4 & 883.4 \\
\hline August 31 & 45 & -1 & -1.03 & 0.00 & -2.1 & 881.4 \\
\hline Sept. 1 & 2 & 0 & -0.04 & 0.00 & 0.0 & 881.3 \\
\hline Sept. 2 & 8 & 0 & -0.18 & 0.00 & -0.2 & 881.1 \\
\hline
\end{tabular}


Appendix Table 7. Continued.

\begin{tabular}{ccccccc}
\hline & $\begin{array}{c}\text { Observed } \\
\text { Total } \\
\text { Movements }\end{array}$ & $\begin{array}{c}\text { Observed } \\
\text { Net } \\
\text { Upstream }\end{array}$ & $\begin{array}{c}\text { Reader-Motion } \\
\text { Detection } \\
\text { Adjustment }\end{array}$ & $\begin{array}{c}\text { Down Time } \\
\text { Adjustment }\end{array}$ & $\begin{array}{c}\text { Adjusted } \\
\text { Net } \\
\text { Upstream }\end{array}$ & $\begin{array}{c}\text { Cumulative } \\
\text { Upstream }\end{array}$ \\
\hline Sept. 3 & 1 & -1 & -0.05 & 0.00 & -1.0 & 880.1 \\
Sept. 4 & 1 & -1 & -0.07 & 0.00 & -1.1 & 879.0 \\
Sept. 5 & 2 & -2 & -0.13 & 0.00 & -2.1 & 876.9 \\
Sept. 6 & 0 & 0 & 0.00 & 0.00 & 0.0 & 876.9 \\
Sept. 7 & 3 & -3 & -0.20 & -0.14 & -3.3 & 873.5 \\
Sept. 8 & 0 & 0 & 0.00 & 0.00 & 0.0 & 873.5 \\
Sept. 9 & 0 & 0 & 0.00 & 0.00 & 0.0 & 873.5 \\
Sept. 10 & 0 & 0 & 0.00 & 0.00 & 0.0 & 873.5 \\
Sept. 11 & 0 & 0 & 0.00 & 0.00 & 0.0 & 873.5 \\
Sept. 12 & 0 & 0 & 0.00 & 0.00 & 0.0 & 873.5 \\
Sept. 13 & 1 & -1 & -0.05 & 0.00 & -1.0 & 872.5 \\
Sept. 14 & 0 & 0 & 0.00 & 0.00 & 0.0 & 872.5 \\
& & & & & & \\
\hline
\end{tabular}

